\title{
Jamaica's National Dance Theatre Company - A Postcolonial Reading of the Repertoire
}

\section{Dancing Cultural Roots: Kinaesthetic Memory and the Discovery of Self}

All we can ask for is that the dancer will transmit to an audience which deserves it, an aesthetically satisfying and emotionally exciting structural relationship between the elements of space, dynamics and rhythm. For those of us who want the movement patterns of Jamaica and Jamaicans to be faithfully reflected in this artform we will expect the dancer to make his art move to the pulse of Jamaica. That's as far as we need to go in nationalistic terms (Nettleford 1968: 131).

As the previous survey on Jamaica's African Creole religious and recreational practices has shown, kinaesthetic memory of these practices is essential for an understanding of the emerging Caribbean dance theatre of the 1930s and 40s. In his essay on the cultural links between Africa and the Caribbean, Harry Hoetink has furthermore described, how the African body in the context of colonization was at the same time perceived as a "vehicle of transportation, and as an aesthetic object" (Hoetink 1979: 30). Bodily practice functioned as a collective cultural marker within a minimum size unit, as, for example, in the relation of mother and child. Gestures, corporeal rhythms and movement patterns have 
thus been culturally encoded as traces of African cultural heritage. ${ }^{1}$ Yet, as has also been shown, Jamaican kinaesthetic memory of African religious and recreational practices reflects such African heritage in historically selective terms, since creolized Jamaican movement patterns draw form the vast repertoire of African, Amerindian as well as European dance forms.

\section{Kinaesthetic Memory}

All conventional memory is erased and yet in this trance of overlapping spheres of reflection a primordial or deeper function of memory begins to exercise itself [...] (Harris 1967:51). ${ }^{2}$

The constant danger of confusing remembering and imagining, resulting from memories becoming images in this way, affects the goal of faithfulness corresponding to the truth claim of memory. And yet ...

And yet, we have nothing better than memory to guarantee that something has taken place before we call to mind a memory of it (Ricoeur 2004: 7).

More recently, Joseph Roach has referred to Circum-Atlantic cultural performances as "rites of memory," performed by the Caribbean diaspora's "anxious survivors, who now feel obliged more or less to reinvent themselves, taking into account the roles played by their predecessors" (1996: 1-2). Analyzing the relationship of memory, performance and substitution, Roach suggests to look at these embodied cultural performances as a reproduction or recreation of kinaesthetic memory, which evolves from a process of "surrogation" to imaginatively fill the "cavities created by loss through death or other forms of departure" (1996: 1-2). Important for Roach's concept is not only that he examines surrogation as it mediates between the participating cultures, as well as it negotiates between identity and difference, but also that surrogation embodies the genealogy of performance as discursive "counter-memory" (1996: 5-6). Kinaesthetic imagination is thus defined as the community's "mnemonic reserve," where "imagination and memory converge" by establishing "a way of thinking through movements - at once remembered and reinvented - the otherwise unthinkable, just as dance is often said to be a way of expressing the unspeakable" (Roach 1996: 27).

1 Similarly, Roger Bastide's ethnography of African survivals in the New World argues for a prevalence of collective "motor sequences" (1971: 194).

2 Wilson Harris commenting on the socio-cultural signifiance of Haitan Vodou trance. 
Particularly, when transferred onto the national dance theatre stage, kinaesthetic memory thus builds on a truth claim, which - as Paul Ricoeur has claimed - may confuse "remembering and imagining" to a certain extent and yet, such imagined kinaesthetic memory publicly displayed will still somewhat "guarantee that something [i.e. in this context the African cultural heritage] has taken place" in order to assure one's historical existence and identity (2004: 7). In fact, Ricoeur has pointed out that the act of remembering presents the conflation of "memory-image" in form of an "incantation," which oscillates between degrees of hallucination and truthfulness (2004: 54). Ricoeur's theoretical assessment of memory in relation to history and forgetting, appears furthermore suggestive of the phenomenological impact of Jamaican dance theatre, which precisely develops its dance vocabulary from the vestiges of African Caribbean kinaesthetic memory, i.e. the Caribbean's cultural genealogy. The question, hence, arises as to what kind of "memory-images" are evoked by dance theatre in terms of their reception as either a faithful recognition of shared bodily expression, or an ideological manipulation of the same. If shared kinaesthetic memory constitutes the African diaspora in the New World, as - in Ricoeur's terms - "a matter of national self-love [...] in terms of its losses [i.e. in the case of the Caribbean, certainly the trauma of the Middle Passage]," then analysis obviously needs to assess the political implications of such performed remembrances. As Ricoeur furthermore explains, recalled "wounds to collective memory" are directly interconnected with the "work for recollection" and tied to the "problematic of identity," which appears after all as fragile an entity to distortion as memory itself (2004: 78-81). Ideological manipulation between the "demand for identity and the public expressions of memory" appears therefore almost inevitable, if not necessarily intended (2004: 82). Ricoeur remarks:

It is in fact in this role that ideology, as a factor of integration, can be established as the guardian of identity, offering a symbolic response to the causes affecting the fragility of identity. At this level of radicality, that of symbolically mediated action, there is as yet no manipulation, hence no abuse of memory. One can speak only of the silent constraint exerted on the mores of a traditional society. This is what makes the notion of ideology practically ineradicable. But it must be added straight away that this constitutive function of ideology can scarcely operate outside of the connection to its second function - the justification of a system of order or power - nor can it operate even potentially apart from the function of distortion that is grafted onto the pre- 
ceding one. [...] Ideology, we may presume, arises precisely in the breach between the request for legitimacy emanating from a system of authority and our response in terms of belief (2004: 82-83).

Hence, a postcolonial analysis of Jamaican dance theatre will have to investigate the ideological underpinnings of choreography, which employs kinaesthetic memory in terms of a formerly silenced tradition and heritage, precisely, to claim its legitimacy and power in the new social order. As Loren Kruger has pointed out for South African postcolonial drama: "What is at stake in these performances is not merely the restoration or even the revision of the past, but the transformation of received material in the inauguration of a new model that might provide the basis for future restoration" (1999: 5). These theoretical premises present therefore the focus of the following analysis of selected examples from the NDTC's dance theatre repertoire in terms of its transformative/revolutionary potential for articulating Jamaica's postcolonial nationalism.

\section{Choreographing Independence}

The immediate past has attempted to destroy the influence of the glory that is Africa, it has attempted to make us condemn and mistrust the vitality, the vigour, the rhythmic emotionalism that we get from our African ancestors. It has flung us into conflict with the English traditions of the public schools and even worse it has imposed on us the Greek ideal of balanced beauty (N.W. Manley 1939). ${ }^{3}$

\section{African Scenario}

African Scenario (1962) was according to choreographer Rex Nettleford the company's first dance work to enunciate Jamaican dance theatre's indebtedness to the African heritage in terms of the NDTC's evolving vocabulary. Performed on occasion of Jamaica's independence celebrations, it formed part of the NDTC's inauguration show "Roots and Rhythms" (Nettleford 1985: 137). Drawing on Nettleford's exposure to traditional West African dance, his choreography explored the African "rituals, dress, music and dances" by "focussing on correspondences in

3 In: Nettleford 1971: 108. 
traditional Jamaican life" (Nettleford 1985: 137). ${ }^{4}$ As he has outlined the choreographic plot in Dance Jamaica:

The story seems almost pure in its simplicity. A young girl enters maturity and is betrothed. Losing her loved one to war, she invokes the gods for his return. Finally he returns in safety and rejoicing. This Caribbean portrayal of ancestral rites was set against traditional African scenes of puberty, fertility, war, fetish, and masquerade (1985: 137).

While the NDTC singers undertook "serious study of the songs of the Ga and Akan peoples of Ghana" and Eddy Thomas "created brilliant costume designs based on the ceremonial dress of West Africa," Nettleford stresses right away that the company did not endeavor to create an authentic portrayal of Africa by any means, but rather attempted to show "a Caribbean vision faithful both to the essence of its ancestral sources and to the realities of the changes that naturally occurred as a result of transplantation to the Americas" (1985: 137).

Recalling the impact of his visits to Ghana and Nigeria, Nettleford expressed his intention as follows:

There was absolutely no doubt, when I went and I saw the retention - the way people moved - it convinced me that there was a definite way in which people like us move. The other thing that convinced me was the elegance, the setting of different rhythms in the body. There was a man called Opoku, the artistic director of the Ghana Company, whom I met in Kumasi and we talked. But you know how we really communicated? We danced. We just put on the music and we danced. It was wonderful (Interview 7 Aug. 2003).

Working on African Scenario Nettleford became primarily interested in the aspect of "African retention in the Caribbean" in order to create "a suite type of dance" supposed to be meaningful to Jamaicans rather than to merely reproduce African source material. Accordingly, the choreography is divided into four larger compositional segments of initiation, war, invocation of the gods, and "rejoicing". 5

4 In 1962 Rex Nettleford had visited West Africa, where he reports to have "renewed acquaintances in classes and repertoire sessions with Beryl Kari-Kari and the Obadjeng Dance Group in Accra, Ghana, and with Opoku in Kumasi, as well as with dancing 'societies' in Nigeria" (Nettleford 1969: 34).

5 The following analysis is based on the video-taped version of African Scenario, NDTC Archive CARIMAC Center, UWI, Mona Campus, Kingston. 


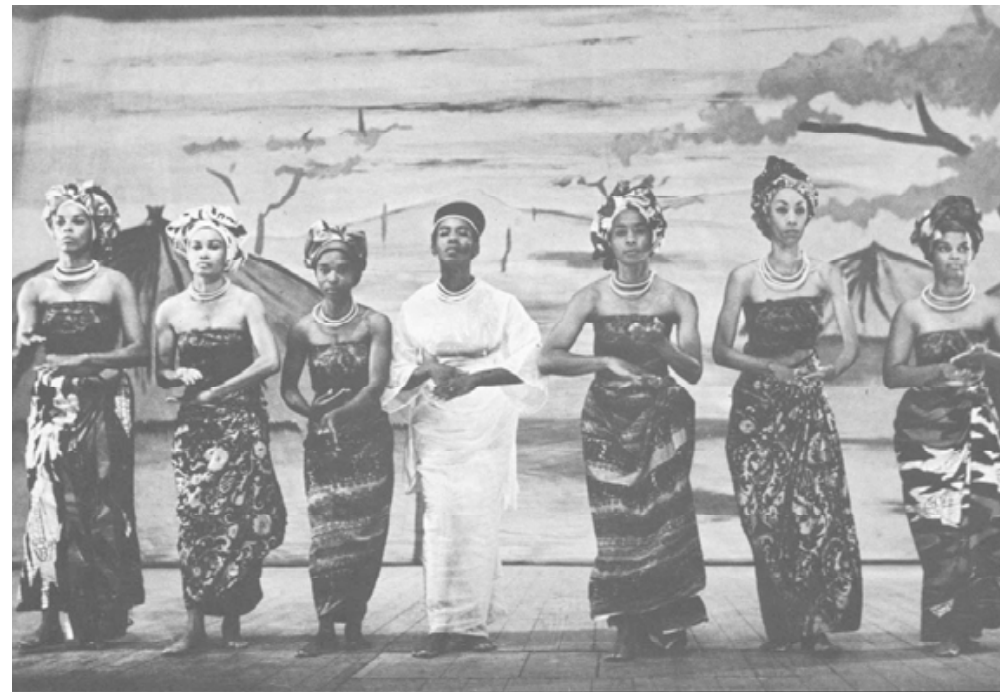

Barbara Requa, Joyce Campbell, Monica McGowan, Rosalie Markes, Sheila Barnett, Yvonne daCosta, and Shirley Campbell in Rex Nettleford's African Scenario, circa 1962. Photograph by Maria La Yacona (rpt. in: Nettleford 1969: 90).

African Scenario opens to an a-cappella chorus by the NDTC singers on a tableau of female dancers in front of the scenic backdrop of an African village. Except for the Initiate, all of the present women dancers have turned their backs to the audience and are dressed in blue flowered skirts, red tops and matching head-ties. Only the Initiate in a white robe is facing front and as soon as the drums set in, she is the one to start the basic movement: a scant shuffle, carefully brushing the footsole over the ground and bending the torso slightly with stretched arms to her left in a swinging motion. From there she switches into a more accentuated contract/release sequence of the upper torso, which is supported by a mirroring movement of the arms as if to invite the other female dancers, who then slowly start to move as well by lifting their arms above their heads. Turning to face the audience, all female dancers shift into progressions with the upper body bent parallel to the ground in a rippling move with arms extending from leg parallel to up facing front and back, introducing a familiar step, which is still prevalent in West African modern dance.

During the next sequence, the women exit and enter from both sides with a kick jump step. Testifying to the West African inspiration, 
the women dancers' accompanying hand and facial expressions of this sequence are reminiscent of what Doris Green has identified as a particular feature of body segmentation in Akan dances, which employ "complex arm, hand and foot movements together with head, facial and eye expressions" (Green 1996: 15). As the drum beat increases, the Initiate moves into an inner circle, which is slowly evolving from the other dancers' progressions. With the rhythm building up to higher intensity, one sees the Witch Doctor enter from stage right in a traversing sequence of leaps. When he and the other dancers exit, the Initiate remains by herself, awaiting her Fiancé, while musically attended by the silent call of a slow beating solo-drum. Then, the Fiancé enters accompanied by a male dancer and soon the couple faces each other as, simultaneously, the assisting man and another woman start to strip off the Initiates' white robes to reveal a natural fabric loin-cloth costume underneath. When the couple's pas de deux unfolds, the drum beats become again more intense. Finally, the women and the Witch Doctor enter again, as a rising intensity takes hold of the scene, which ends with the monotonous acceleration of the initiation ritual.

After another brief call and response patterned chorus interlude by the NDTC singers - this time accompanied by hand clapping percussion, but again no drums - the second choreographic segment opens with the male dancers entering in yellow calf-length skirts, naked torsos - except of a crossed yellow cloth band encircling the back and front shoulder area - and a yellow headband, to which a tall red feather has been attached in front. As the dancers approach upstage, they come to a halt in second position parallel with arms stretched out to both sides, holding a stick in their right hand and suggesting a stance of defiant pugnacity. By the end of the sequence, this image of 'fierce African warriors ready to combat' takes up all the stage space, when last but not least the Witch Doctor steps up front from back of their midst to lead the crowd into a sequence of diagonal attack/retreat progressions from front left to back right and vice versa. 


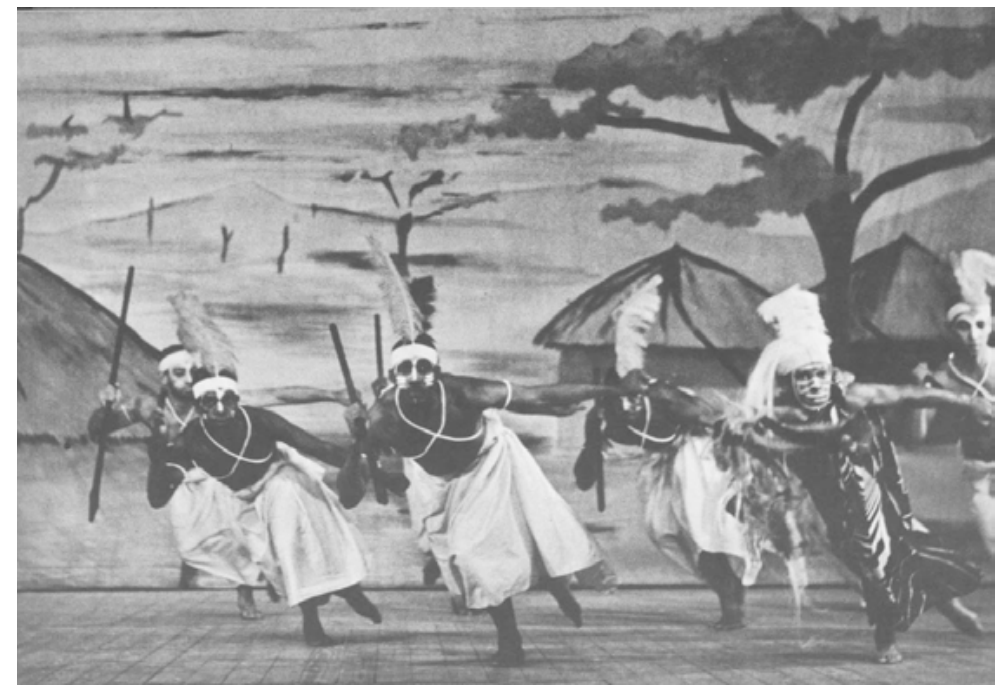

Dennis Scott, Thomas Pinnock, Audley Butler, Milton Dawes, Eddy Thomas, and Bert Rose in Rex Nettleford's African Scenario, circa 1962. Photograph by Maria LaYacona (rpt. in: Nettleford 1969: 91).

Particularly the Witch Doctor's outstanding performance asserts certain awe. His toga-like costume is covered by an eye-dazzling black and white pattern of rhombic lines, matched by his and the warriors' white facial war mask make-up as well as the almost ankle length white hair extension which fiercely flies about his body as he kick-jumps forward on one leg. Then, he suddenly lifts up in the air, turning around to land back down in a body-breaking bounce. Raising their sticks harpoonlike above their heads, the male dancers next join in a circle progression, leaping forward to abruptly rest down before the following movement sequence begins from a brief silence to announce what has come to be known as the NDTC's 'Savannah' step. ${ }^{6}$

When the drums set in again, the step increases in tempo and the parallel line dissolves into singular performances of more and more intense torso and shoulder ripple isolations to evoke movements from possessional dances as well as to prepare for the entrance of the female dancers, who are now dressed in white bast-fibre skirts of an anklelength. During this scene, the female dancers exert quickly alternating exits and entrances with most of the movement centered around the

6 Rex Nettleford introduced this parallel to front progression step during his master class at the EMC summer school workshop 2003. 
pelvis in contract release progression, passing each other several times before falling 'exhausted' to the ground with one leg lifted towards the ceiling. During this scene, each of the dancers is 'armed' with two white bast-fibre pompoms as well as wearing a white knit head-cover to hold an enormous white bast-fibre hair extension to swirl and further bedazzle the beholder's eye in a powerful display of magicoreligious dance moves from a fetish dance of spirit invocation.

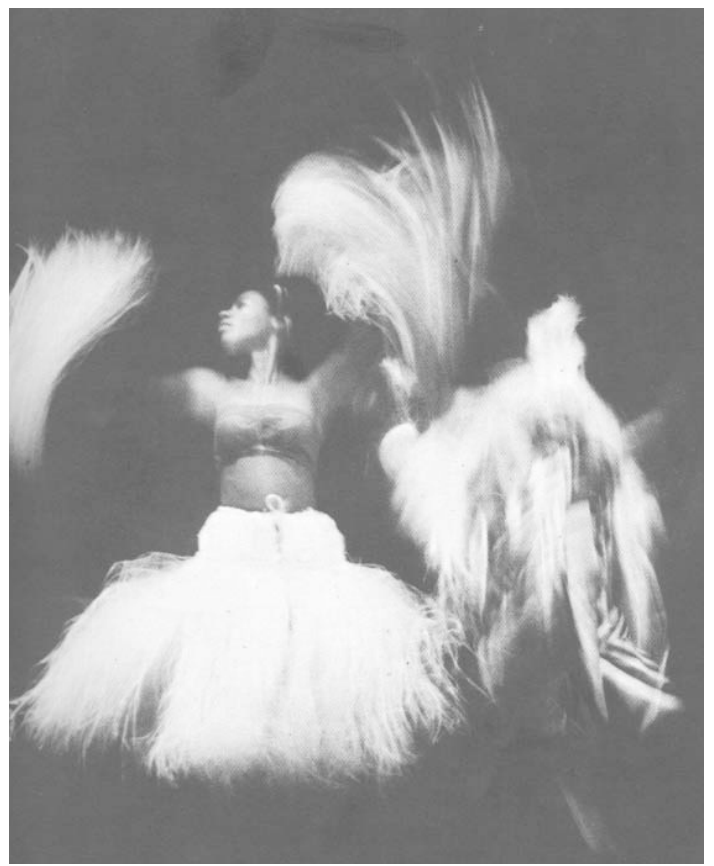

Rosalie Markes in Rex Nettleford's African Scenario, circa 1962.

Photograph by Maria LaYacona (rpt. in: Nettleford 1969: 91).

After another brief interlude by the NDTC singers two male dancers then enter from stage left and right, stripped of their former skirts to bikini pants. Similar to the intimidating awe of the Witch Doctor's appearance, the introduction of the mask dance likewise evokes the symbolically charged, supernatural force of ancestral spirituality at this point. Being a popular form throughout Africa, the full body mask exerts specific power. As Green explains: 
Although the mask is not a living object, it has a psychological significance which might be considered as a psychological disguise. When the person adorns the mask, he is transformed into the spirit or being he is representing. The identity of the mask wearer is not revealed according to secrecy of tradition. It is on record that during ceremonies, women, uninitiated boys, and girls are not permitted near the mask wearers in order to keep the identity of the masked performers secret (1996: 21).

While the mask in African Scenario is of course taken out of its religious background here, it still theatrically conveys much of its former transformative quality. For example, when about half of the group of women dancers enters again, they have undergone quite noticeable transformation, primarily indicated by their costume change. Crafted from bamboo strips, the costume consists of a belt-type construction to attach a magnificent circle-shaped cover, which emphasizes rather than hides the dancers' behinds as they shake their buttocks back and forth. Fertility overtones come to mind as this group is joined by the other group of women, who are still dressed in the flowered Caribbean skirts costume of the opening scene. However, they, too, have changed as their costumes are now further adorned with a broad red shawl surrounding their waists. Finally, therefore, all of the company dancers appear somewhat more 'initiated' than before, as they celebrate the "rejoicing" of bride and groom in African Scenario's progression finale.

Assuming that the shawl around the waist indeed symbolizes birth and fertility, then not only have the dancers been 'initiated,' but also in a way their audiences, who by perceiving African Scenario's birth/initiation ritual have been theatrically introduced to the Caribbean's African heritage. Unsurprisingly therefore, after a little more than twenty minutes of such extravagant exploration of African heritage, Jamaican audience response to African Scenario was quite mixed. While some people were shocked, others felt that the African movement was not yet strong enough. As Nettleford recalls:

When the work was first performed it evoked favourable responses from many Jamaicans, though some people felt that middle-class restraint had imposed itself on the bodies of the dancers, male and female alike. At least one viewer walked out of the Little Theatre in disgust - all that 'belly-rolling and back-to-Africa nonsense'. A few complained that the drumming was too much for them. [...] The approach to African Scenario was ritualistic and frankly theatrical - thanks to the usual collaboration of Eddy Thomas on cos- 
tumes. But the work carried undercurrents of identity with Africa and this disturbed some people among the Jamaican audiences (1969: 34).

Just how disturbing the display of fierce African warrior and initiation dances must have been at the time is certainly hard to tell now, but one should remember that by 1962/63 - only a year after independence the black power movement was still in its infancy and had not yet arrived on everybody's political agenda.

Delineating the postcolonial decolonization process, Fanon has distinguished three phases of cultural liberation: 1 . assimilation of the colonial pattern, 2. remembering of origin and 3. cultural revolution. In many ways African Scenario suggests a reading in terms of that second phase, for it theatrically presents the quest and exploration of the African cultural heritage in Jamaican society. Fanon's argument, however, also addresses the danger of such artistic undertaking as merely articulating an estranged and banal longing for exoticism through its oftentimes superficial celebration of folk customs and traditions (1990: 178179). Admittedly, Nettleford's approach to explore the similarity between the African and Caribbean dance heritage in African Scenario may at first seem to adhere to Fanon's auto-exoticism. And yet, I will argue that despite its auto-exoticism African Scenario does not merely indulge in the rediscovery of African heritage and ancestry per se, but explores that vocabulary in terms of the NDTC's vision of a new Caribbean selfimage.

Evidently, the African heritage had always been prevalent in Caribbean movement patterns as has been shown in the previous section. Movements introduced by African Scenario could thus easily be identified in Jamaican Kumina, Jonkonnu, Maroon and Pocomania dances. ${ }^{7}$ Hence, African Scenario appears as the outspoken re-invention of African Caribbean identity in terms of Roach's surrogation rather than an orientalist fantasy. Thus redressing Fanon's critique, I consequently propose a reading of African Scenario not as the superficial imitation of

7 Compare NDTC Stratford Festival Programme 1963. In the taped version of African Scenario Nettleford introduced the choreography as follows: "African Scenario, the dance that follows, goes back to the source for its inspiration, utilizing the dances of the Ga, Ashanti, Ewe and Fanti people of West Africa to portray aspects of traditional life: puberty, fertility, war, fetish and masquerade. The movement patterns portray elements of dance to be found among the Kumina people who live in the eastern end of the island, among the Jonkonnu mummers, the Maroons and Pocomania $[\ldots . . . "$ (NDTC Archive). 
African initiation ritual at hand, but as the symbolic initiation of the Jamaican audience at large. Metaphorically speaking, the initiation of the girl and her marriage to the African warrior - whom she loses to war yet regains invigorated - may be interpreted as symbolically representing the rebirth of a people - "taken from Africa, brought to America" (Bob Marley) - rising the stronger from that battle ground of robbed and re-appropriated identification. As Green has described the raison d'être of traditional African puberty dances: "It is hoped that when the viewer sees such dances, they will be more informed" (1996: 20). Certainly her quote cannot be taken literally, as ritual has been theatricalized here, yet the transformative impact of the dance's original meaning remains, if not in terms of sexual initiation, but rather cultural maturation and independence.

I am therefore arguing that African Scenario's quite spectacular assertion of African Caribbean identity not only irritated the spectators' eye in the very direct sense by the swirling bast-fibre pompons and skirts all over the stage, but also impacted on the audience's 'I' (i.e. in terms of a new self-awareness), because it re-appropriated the stereotypical notion of 'barbaric' and 'uncivilized' ritual in an imitative display of unfathomed vigor and strength. Far from oppressive then, such (re-)presentation in fact allowed the dancers to perform their very own imaged imagination of an empowered rather than victimized African Caribbean selfhood. Thus - at least for dance critic Michael Reckord African Scenario worked as an eye-opener. When he recalls:

Thirty years ago, I was a student of ballet - had been for about three years. I enjoyed the dance genre, but in a placid, cerebral sort of way. It was mostly a head thing, though I liked the bodily exercise. Then, one night, at the Little Theatre I saw a dance which zapped my heart, kindled passion, made me fall in love with modern dance. (Paradoxically, it also made me appreciate ballet more). The work was African Scenario. You've heard of it, of course. It caused quite a stir at the time (1993: 2).

Apparently, African Scenario appealed to Reckord, because ideally, for him, "dance, like ritual, will have meaning, a vocabulary, and patterns of movement which emerge from a culture, and which strike chords of recognition in the observer" (1993: 2). One might hence suggest that precisely such "recognition" of kinaesthetic memory from Africanderived movement patterns subtly ushered into Jamaica's new cultural consciousness of the time. 
Considering, furthermore, that African culture was actually never that far removed from Jamaicans to begin with, the NDTC's artistic rediscovery - regardless of whether one conceives of it as being 'exotic' or not - would even in its exoticism still fulfill the important task of developing an African Jamaican consciousness in terms of a newly evolving self-articulation. To recall Anthony D. Smith's argument concerning the degree of invention necessary for the national project at this point, African Scenario does by no means belittle the African tradition's Jamaican legitimacy, but is rather important to reinforce it. More significant than the actual truth claim to certain traditions then, proves the question of "how far that modern public culture is a modern version of the pre-modern ethnic culture, or how far it simply 'uses' elements ('materials') from an older cultural repertoire for its own, quite novel, purposes" (1999: 52). Ultimately therefore, the evidence of African survivals throughout Jamaican folklore appears indeed to be a "modern version of the pre-modern," while at the same time using that heritage to the "quite novel purpose" of building Jamaica as an independent nation.

On behalf of African Scenario this strategy would accordingly be based on the sound proclamation of an African ancestry as a legitimate part of Jamaican high culture. Not only did the performance provoke mixed responses, but its re-appropriating mimicry of the Eurocentric stereotype ultimately undermined the stereotype's denunciatory power. By presenting the 'uncivilized' ritual within the frame of the very 'civilized' Western stage, the image's threatening self-deprecation within colonialist discourse was slowly eroded. Conquering the Western stage by breaking some sort of representational taboo, the NDTC's 'barefoot' performance successfully reversed the cultural hegemony. African 'wilderness' proudly presented thus undermined the discriminatory label from within: an image that Jamaican middle class mimic men of the time certainly needed to re-think. ${ }^{8}$ Eventually therefore, Nettleford's choreography appears to engage the stereotypical notion of the 'primitive' precisely to the extent that the portrayed image ceases to be perceived as such. For what this mimicry of Africanness displays - a Caribbean Africanness as Nettleford quite frankly admits - is not an oppressive stance any longer, but a free appropriation of cultural pride

8 Naipaul's renowned novel The Mimic Men (1967) presented the bleak memoirs of a West Indian colonial politician in exile which at the time was largely received as the paradigmatic description of Caribbean colonial identity crisis and lack of self-definition. 
and self-empowerment. Putting on the mask and beautiful costume of an imagined Africa can thus serve as an invigorating statement in a public contest over representative power.

Lastly, one should bear in mind that the assertion of black pride in Jamaica was simply setting the historical record straight, since ninety percent of the island's population are of African ancestry. Certainly, this presents a social reality quite different from that of the U.S. Adhering to white colonial standards in Jamaica appeared particularly absurd, though no less a reality. As Norman Washington Manley has described the significance of the 1960s Black Power Movement for Jamaica:

Black Power means the acceptance with joy and pride, the fact of blackness, of black dignity and black beauty. It means the acceptance by the black man of his own proud place in the brotherhood of man. It is true that although we have achieved the power of self-government and the dignity of nationhood, there still lurks beneath the surface of many minds and consciences a feeling that the white man can do more and can achieve more than we can do. It is true that the white man in order to achieve and maintain white power has taught the black man the world over to believe in white superiority. It is true that in many, many places he still so believes and leaves us with a world in which the seeds of disharmony are deeply planted and threaten us with danger all the way (in: Nettleford 1971: 379-381).

Yet, while this appeared so, Manley has also made clear that the ultimate vision for his country had to overcome such racialism of the reversed kind. And therefore he continued:

It may well be true to say that there is now and for a long time have been Black Power elements that exploit the feelings about colour that lie on the surface in the Jamaican society, where the society is divided between black and white, and brown, and disunited where matters of skin alone are concerned. This is not to be accepted in Jamaica, and it will not be accepted in Jamaica. We do not want, in Jamaica, to establish the very thing we have fought so many years to break down in our country. We do not want to establish in Jamaica the practices of America or even England or Rhodesia or South Africa we loath and despise. We realise the greatest danger that confronts the human race is race itself, and the patterns of thought that set race against race, [...] We should be proud to think that we can set the world an example by carrying through till we have achieved our goal that will come when Jamaica is an integrated community; [...] (in: Nettleford 1971: 379-381). 
What Manley envisions for Jamaican society is thus precisely the utopia of Brathwaite's Creole nation, a place born on the plantation, that contested locale, where black and white first met. And tellingly enough that setting should become the departure point for the NDTC's second exploration of independence choreography in 1963.

\section{Plantation Revelry}

Plantation Revelry (1963) was the first choreography, which Nettleford in Dance Jamaica has referred to as one of the "social commentary" dances in the NDTC repertoire (1985: 106). Building on the LTM Pantomime tradition, the choreography evolved from typical 19th-century plantation dances. As Nettleford has summarized the plot:

The dance, which takes place in the nineteenth century, opens at the pier, where friends and workers from the family plantation gather to greet Miss Amelia, returning from England. Her arrival is awaited with excitement, and her old Nanny sings a folk melody recalling the pleasurable moments they spent together before her charge was sent to England to be educated. The second scene opens on the front lawn of the great plantation mansion. The old butler brings Amelia something to eat, while Amelia's friends greet her in a dance reminiscent of the country jigs of the period. Two working women try to attract her attention, while young men amuse her with a dance in which they imitate European gentlemen of the period. One of them acts out a mock courtship with her, much to the annoyance of her Nanny. Some of her old friends, dressed up in the costumes of Haitian set-girls, show off their attire. The men return disguised in jonkonnu (John Canoe) costumes, and the revels, heralding her return, end in frolic (1985: 107-108). ${ }^{9}$

Very similar to the Jamaica Pantomime model, Nettleford's Plantation Revelry integrates mime, music, song and dance in an entertaining, tongue in cheek mock-epic of the well known plantation stock characters: two "ladies of quality," high colored of course, accompanied by their black servant boy and the 'guarding angel' black Nanny. ${ }^{10} \mathrm{How}-$

9 Barnett comments on the emergence of Haitian set-girls in Jamaican Jonkonnu: "In 1794, many Haitian families fled from the rebellion in Santo Domingo, bringing with them to Jamaica slaves whose influence would carry-over into the Set-Girls' Groups of the Jonkonnu by the addition of elegance and rivalry among competitors and also the creole domination of sets" (1989: 64).

10 Compare video-taped performance at NDTC archive, CARIMAC Centre, U.W.I. Nettleford reworked the choreography by introducing another 
ever, Nettleford has argued that the lightly treated minstrelsy appears "deceptive" in its "simplicity" (1985: 108-109). Keeping in mind that Christmas in particular was the time of comparative free-license on the plantation - a welcome occasion of part-time role reversal, and, to repeat Patterson, "temporary metamorphosis" of the slaves' status - the class/race division between the characters on stage becomes increasingly blurred. Therefore, the ladies' encounter with the servant during the sequence after the very opening song appears actually less condescending than playful. Since the song tellingly invites the audience to "join in the fun," the spectator is asked not to take things too seriously in this dance performance of reversed role play.

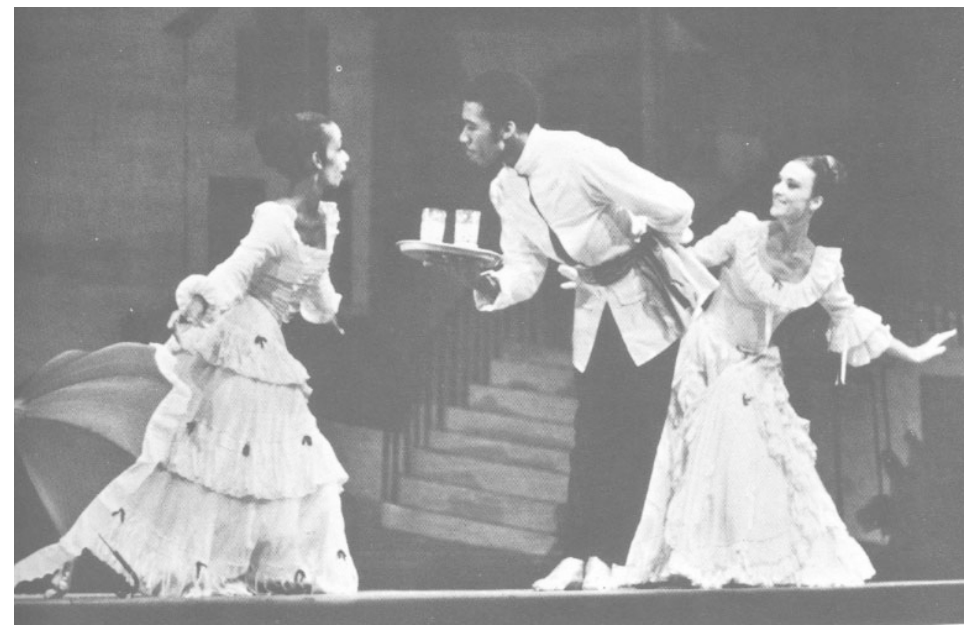

Patsy Ricketts, Jackie Guy, and Beverly Kitson in Rex Nettleford's Plantation Revelry, circa 1963. Photograph by Maria LaYacona (rpt. in: Nettleford 1969: 37).

Historically, many of the slave dances were arranged according to dynamics highly reminiscent of a total theatre aesthetics. Not only was dancing accompanied by singing and drumming, but pantomimic action was also oftentimes an integral part of the game (Hill 1992: 223). A blend of African and European performance traditions, the so-called

female character in this later version. For an account of the pervasiveness of African American stock characters in American motion pictures, for example, compare Donald Bogle, Toms, Coons, Mulattoes, Mammies and Bucks. An Interpretive History of Blacks in American Films (New York: Continuum, 1997). 
'plantation revelries' developed a syncretic form, which is also the basis of Nettleford's choreography. Plantation Revelry thus starts from the European country jig pattern and switches to the African rhythms of the Jonkonnu drums. After the brief interlude with the servant boy, two servant girls enter and make fun of the stilted moves of their mistresses by thoroughly introducing a couple of their own down-to-earth moves. "Bucking" as this section has been called, presents, in fact, a Jamaican oral tradition of song dispute, which dates back to the same period.11 Excelling each other in performance, the women start a mock-quarrel and would probably take right after each other's throats, if the mercy of Miss Amelia and Miss Joan did not thankfully prevent them from doing so. The scene feeds on laughter and poking fun at no matter whom and for what. Consequently, the choreographer's intention appears to be less focused on portraying the racial division than actually the social interaction, which simply demonstrates very common behavior among teenage girls. While there is difference in comportment and behavior between the ladies' and their servants' body posture and dance performances, there is, however, no competitive malice to be noticed. Rather, by exchanging a couple of steps, each couple appropriates part of the other's heritage in a sharing exchange.

Likely, such harmony was historically inaccurate for most of these encounters between mistresses and servants on the plantations. However, what appears more important than historical accuracy is, indeed, the NDTC's coherently pursued Creole vision. Hardships and suffering are not the theme, when Nettleford sets Plantation Revelry at Christmas time soon after Emancipation. At that time, Creole society could ideally have emerged from a happy rejoicing of European and African lifestyle. And speaking in terms of performance it did: for even though it took Jamaican society much longer than Emancipation to achieve social and political integration, the cultural practices had already been aesthetically blended. As Nettleford points out:

The storehouse of Jamaican dance-lore is partly in the $19^{\text {th }}$ century, when the society consolidated and found itself. Plantation revelries produced among

11 Compare NDTC Stratford Festival Programme 1963: "'Bucking' is an old and favourite way of fighting, particularly among women in Jamaica. A 19th century song goes 'Wha' dat you do, Mek Sarah buck you?' (What have you done to cause Sarah to butt (use her head on) you? The two women in the short mime sequence use this old technique to air a grievance." 
the otherwise miserable slaves dances which they had obviously copied from their English masters, with the important difference that they underscored the music with a more complex and, to them, satisfying rhythm. So there is the Quadrille, which has its counterparts in the Spanish and French speaking Caribbean, and which could be called the national dance of Jamaica, more robust than the $18^{\text {th }}$ century court dances of which it is a creolised variant, and less "square" than the wheeling, yipeeing American square dance which seems to share a common heritage. This European influence persisted among the Jon Canoe masqueraders who according to travel writers of the earlier period, were complete with powdered wigs and Georgian dress, but cut capers and went through antics which betrayed African origins of dancing (1968: 132).

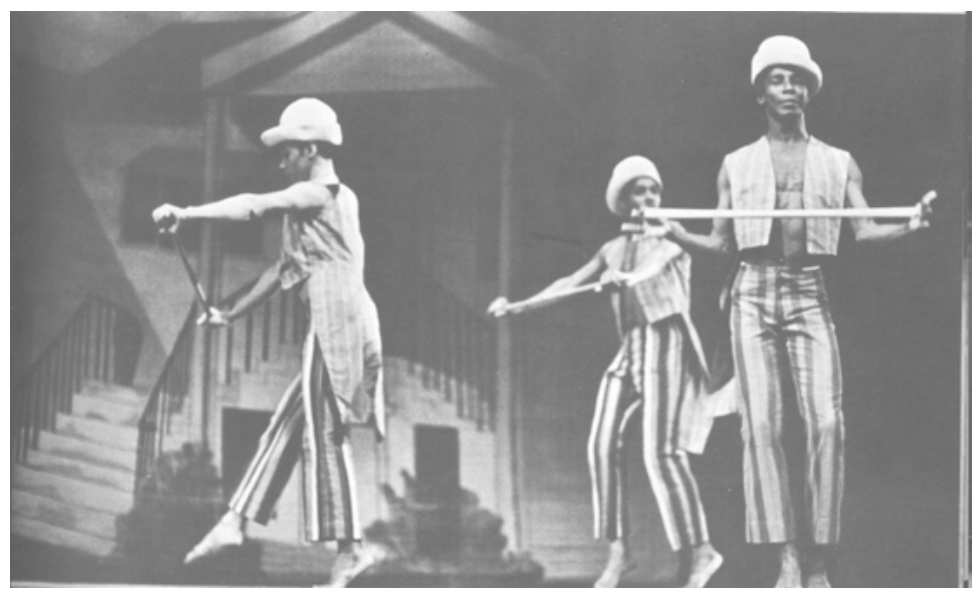

Bert Rose, Audley Butler, and Rex Nettleford in Rex Nettleford's Plantation Revelry, circa 1963. Photograph by Maria La Yacona (rpt. in: Nettleford 1969: 37).

Following the above chart, Plantation Revelry appears to present a reconciliatory image of plantation society as the cradle of the Creole nation. Interestingly enough, it reverses the plantation pattern in one intriguing feature. Rather than having the black servants be courted by their white masters - as was more often the case - it is here black men courting the 'high colored' ladies with their dance. Reminiscent of vaudeville dances, the elegant courtship with the white hats soon leads the male dancers into the more vigorous calinda, an acrobatic stick-fight of West Central African origin found throughout the Caribbean islands (Warner Lewis 2003: 199-218). 
As easily as European and African forms blend into the flow of the choreography, Plantation Revelry suggests such easy blending also in terms of the new social reality. And where better than in Jamaican Jonkonnu has this blending of two traditions been achieved? With the entrance of the Haitian set girls, the mixing of the aesthetic and the political becomes most evident, as the masquerade's tradition owes to Europe as much as Africa. Historically, the set girls were after all the first to cross the cultural divide, as the early account given by Alexander Barclay (1828) demonstrates:

The young girls of a plantation, or occasionally of two neighbouring plantations leagued, from what is called 'a sett.' They dress exactly in uniform, with gowns of some neat pattern of printed cotton, and take the name of Blue Girls, Yellow Girls, etc. according to the dress and ribbon they have chosen. They have always with them in their excursions, a fiddle, a drum, and a tambourine, frequently boys playing fifes, a distinguishing flag which is waved on a pole, and generally some fantastical figure, or toy, such as a castle or tower, surrounded with mirrors. A matron attends who possesses some degree of authority, and is called Queen of the Sett, and they have always one or two Joncanoe-men, smart youths, fantastically dressed, and masked so as not to be known. Thus equipped, and generally accompanied by some friends, they proceed to the neighbouring plantation villages, and always visit the master's or manager's house, into which they enter without ceremony, and where they are joined by the white people in a dance (11-12).

Compellingly, this almost reads like a description of the finale of Nettleford's choreography, which likely owed to the existing historical accounts of Plantation Jonkonnu for its plot line.

As has been described before, Jonkonnu survived despite colonial opposition and became probably the major Creole performance mode to represent the promise of a playfully integrated society: loyal to Queen Victoria, who had freed the slaves, and open to include everybody. And yet, Jonkonnu continued to keep a critical eye on hegemonic power and oppression (Hill 1992: 252). While Jonkonnu had declined after Emancipation, it returned full force during the 1950s. Supported by a Gleaner sponsored campaign, an island-wide Jonkonnu competition was held and further promoted in 1976 under the patronage of the JCDC for the CARIFESTA '76 presentation. Heralded as the embodied testimony of slave resistance, Jonkonnu received major public attention and stepped to the forefront of the emerging national consciousness, when Jamaicans of the post-independence era were increasingly com- 
ing to terms with their cultural identity. As Jamaican national consciousness turned towards Africa in the 1960s and 70s, Jonkonnu came to represent the African Creole spirit of cultural survival and tradition. And unsurprisingly so, for as Judith Bettelheim's study points out: "Jonkonnu has always reflected the changing socio-political climate of Jamaica" (Nunley/Bettelheim 1988: 44).

It is therefore hardly astonishing that the NDTC, too, should incorporate elements from that indigenous source in their dance theatre. In fact, Jonkonnu's cunning re-appropriation of the colonial insignia of power offers a perfect illustration of Bhabha's concept of colonial mimicry, when historically, as Hill points out, "[m]ilitary apparel replaced animal skins, models of ships and great houses were carried on the head instead of horns," precisely for the performers "to transfer some of that power to themselves" (Hill 1992: 236). Clearly then, the introduction of the Jonkonnu's Set Girls, Actor-Boy, the House- and Horsehead towards the end of Nettleford's Plantation Revelry evokes kinaesthetic memory, which owes to that performative tradition. The choice of the Horsehead is furthermore important, because the mask traditionally belonged to rural Jonkonnu rather than the city based fancy dress pattern with its Set Girls, Kings and Queens. As Bettelheim remarks: "Cowhead and Horsehead are rural, but because of their untamed power they also are revered. They scare, but they also amuse. They invoke both fear and courage" (Nunley/Bettelheim 1988: 53).

Finally then, Jonkonnu's integrated opposition of rural Horseheads and fancy Set Girls has by now come to symbolize a typically Jamaican societal ambivalence, which oscillates between grassroots 'fierceness' and a somewhat more town-based cunning refinement. Coming together in Jonkonnu, both traditions have in their own strategic performances been resisting British hegemony for so long. And yet, in Nettleford's Plantation Revelry, I would like to suggest, such integrated resistance is performed not only as the birth-place of the Creole nation, but also as the somewhat utopian vision towards eventually overcoming Jamaica's racial/class-based divide. 


\section{The Folk Repertoire}

To be/come its vision, the Company had now therefore to move from nouveau rich or nouveau real and cellophane and cosmo cosmopolitan ... to Accompong. Back, that is, to the hills of its island's history and the shared history of our whole huge half-sunk archipelago; forward, that is, to jerk and jeng and harst, cassava bammy, rivermaid and cooing dove and engine driving; shango from imitative eleison and necrophyllic languish, to rib cage contract/ripple, sufferer and cave and kumina (Brathwaite 1985: 50).

The preceding chapters have shown how Jamaican national consciousness increasingly turned towards grassroots culture. By proudly asserting Jamaica's African heritage, dance theatre made it possible for Jamaicans to reconsider the impact and significance of their country's folk heritage and certainly the NDTC played an important role in the legitimizing process towards this social change. Through dance theatre, Jamaican folklore entered "the collective experience of the people" as significant part of their own heritage to be proud rather than ashamed of. In fact, as this consciousness slowly spread into the larger spectrum of Jamaican society, the NDTC's dance choreography became more daring and started to go even deeper into and explore more of the country's religious rites for the company's evolving movement vocabulary. Revival, Kumina, Dinki Mini and other traditional folk forms were investigated and yielded an indispensable source of inspiration. To keep in mind, while this artistic investigation owes traces to the ritual's source, it consciously separated the religious and artistic spheres. As Nettleford has expressed his concern in choreographing from a ritual base:

[...] my choreographic approach is determined largely by my concern with rooting my work in the collective experience of the people I think I know that is by distilling the essences and attempting to arrive at the universality in a particular experience. The process often results in concealing the connection between a movement design born out of Jamaican folk forms and its distilled representation in my so-called 'serious' works (1969: 35).

Kinaesthetic memory thus forms the somewhat clandestine base from which Nettleford's choreographic reinterpretation develops in discovery of new artistic paths for Jamaican dance theatre expression. A first effort to explore this approach was Nettleford's 1963 folk choreography Pocomania, which he and the NDTC revived again for the company's 
$41^{\text {st }}$ season in 2003. Portraying sequences from a "poco" ceremony, this choreography presents Nettleford's technique of abstracting the essence of the ritualistic movement. In order to create a piece of dance theatre, Nettleford's choreography thus appropriates the folk form in an aesthetic rather than ritualistic manner, yet manages to maintain its psycho-cultural iconicity and meaning. 12

\section{Pocomania}

Pocomania, which is today more correctly spelt Pukkumina, forms part of the Jamaican Revival complex. According to Edward Seaga's research of the religion in the 1950s and 60s - which formed the basis of the NDTC's choreography - Pukkumina originated during Jamaica's Great Revival in 1860/61 and was both African and Christian inspired. As has been mentioned, the non-conformist Baptist and Moravian churches had traditionally been more inclusive than other missionary Christians and formed therefore the backbone of the Revival movement. Revival thus embraced Central African Myal possession as the unitary force between temporal and spiritual world (see Seaga 1969). Revivalism may be conceived of as an African polytheism that embraces the Christian Trinity, Angels and Saints, Prophets and Apostles, however, combining these with the African spirit pantheon of ancestral dead and diabolic host.

Pukkumina worships the so called ground or ancestor spirits, in which respect it needs to be differentiated from Zion, which focuses on the heavenly spirits. ${ }^{13}$ Spirit possession is the center of ritual worship. Located at Blake's Pen and St. Elizabeth Pukkumina is dominated by women, although the leader ("Shepherd") is traditionally male. He is the central figure, yet the Mother, Shepherd Boy, Armour Bearer and Governess are also of ritual importance (Smith, P. 1981: 2). The Pukkumina ground can be recognized by a tall pole with a flag and is usually part of the Shepherd's yard premises with the "seal" as its most sacred center of ritual activity. Other shrine-like areas provide for other ritual objects, such as water, stones and banners. Pukkumina member-

12 Interestingly enough, Brathwaite in a footnote to the above quoted epigraph suggests to consider the NDTC repertoire in terms of the impact of the vocabulary's psychocultural iconicity, i.e. precisley those poetic icons of Jamaican identity, which will be further examined here.

13 Different from Pukkumina worship of the ground spirits, Zion practitioners communicate with the Holy Spirit (Ryman 1980: 14). 
ship is structured as a "band" in which each member is assigned with a distinct role and function. There are three groups to be distinguished:

- Leaders

- Post-Holders

- Floor Members

Among the leaders are the Shepherd, Mother, Shepherd Boy and Governess. Post-Holders are the Rivermaid, Bell-ringer, Dove, Cutter, Hunter and Messenger. Floor Members are not assigned to a distinct function nor are they endowed with the spirit. ${ }^{14}$

While Revival or Poco meetings were of low prestige among people of the middle class during the 1940s and 60s, they became a highly influential source for the Jamaican modern dance movement of the time. With his 1963 choreography Pocomania, Rex Nettleford reintroduced the rite to the Jamaican stage in the wake of Ivy Baxter's pioneering effort. As he has stated in an article on the choreography in 1969, his focus was on "ritual and the ecstasy of individual participation in the cleansing powers of the spirit possession and of worship through dance" rather than in strictly speaking anthropological research (21). However, as a born 'country-boy,' Nettleford had been exposed to Revival ceremonies, as well as receiving his share of European classicism. He recalls this culturally diverse heritage:

As a peasant boy of six or seven living in what was then regarded as one of the 'darkest' and most folksy parts of Jamaica, I remember singing big chunks of Handel's "Messiah", Haydn's "Creation" and of course that old favourite "The Lost Chord". My grandmother and several country aunties loved the anthems and even if they sang them badly, they were exposed to some of the best liturgical music of our European culture. These same people would participate in pocomania, and I have had my dose of "groaning and shouting" as well as healing in the balmyard and the obeahman (1968: 131).

Certainly, Nettleford's familiarity with the ceremonial proceedings must have greatly informed Pocomania's choreographing process, when

14 These descriptions are indebted to Seaga's historical research, which formed the base for the NDTC's stage choreography. Since religious practices are fluid in their development in time, part of the individual symbols in recent Revival churches have changed, while the larger meaning and movement sequences still remain the same. This observation is based on my own attendance of a Revival meeting at Apostle Sinai Church of God, Spanish Town 24th August 2003. 
he sought to further translate Revival movements for dance theatre presentation.

However, while musicologist and cultural minister of the time Edward Seaga assisted Nettleford and the company in their effort to learn the movements from the Revival members, the dancers would also add artistically to the source. The program brochure of the premiere outlined the choreographed proceedings as such:

In this dance a 'poco' festival is portrayed covering the highlights of three days and nights. First there is the blessing of the upliftment table which in actual festivals is usually decked out with fruits of all descriptions, carbonated drinks and breads of all shapes and sizes. The 'bands' process in, each with a Shepherd (leader). As they approach the table they greet each other and pace the area around the table pledging obeisance. The greeting over, the Shepherds direct the lighting of the candles ("Light de light oh"), each candle costing the worshipper lighting it a small sum. Choruses are sung and the table is broken. The proceedings simmer down while the worshippers and onlookers partake of the fruits, drinks and bread on the table.

The second day is called SUNDIAL and can be considered a highpoint of the Pocomania proceedings. For then the sacrifice of a goat takes place and the worshippers begin to 'labour' for their journey through the spirit world. In this dance the Bellringer and Rivermaid are dominant features. The Bellringer imitates the sound of a bell, the Rivermaid is drawn to the pool (stage right). The Indian Spirit is introduced at the end and betrays the existence of a population of East Indians, who came to Jamaica as indentured servants to replace erstwhile slave labour after Emancipation.

The third day is usually quieter than the other two. But there can be more labouring. In the dance a short closing prayer begins to bring the ceremonies to an end (Nettleford 1969: 22).

Following the above outline, Nettleford's theatrical adaptation of Pocomania bears strong resemblance to Revival's African-Christian syncretism. Thus, costumes were modeled on episcopelianesque and Roman Catholic style, whereas the movement testified to the Neo-African source, even though there was no staged goat sacrifice held in the theatre space. ${ }^{15}$

Pocomania's Neo-Africanism is particularly evident in the following set of movements: 1 . the grounded rhythm of the shuffling feet, which

15 The following comparative analysis relies on video-tape as well as liveperformance protocols of Pocomania as it was performed during the NDTC's 41st dance season in 2003. 
embodies an African-derived spirituality that the Christian costume can veil, yet not deny; 2 . the vibratory or spinning movements - which are created by the rippling of the body at an ever increasing speed, as well as by jumping with feet together to both sides as the arms moved from shoulder height bent to straighten up in ready appraisal of the spirit; and 3. the grounded inching of the foot at the typical "one, two, one, two" repetitiveness. All of these elements are typically found in Revival dancing as they build up to spirit possession in the ritual setting. Particularly, the accompanying "windscreen-wiper like movement" of the upper body, appears as ready vehicle for communication with the spirit force and might easily lead even the stage dancer to possession, if the movements are not carefully enough choreographed and controlled (Nettleford 1969: 23). Important in that context is also the inhaling and exhaling of breath, which is referred to as "trumping" and produces a particular guttural sound. ${ }^{16}$

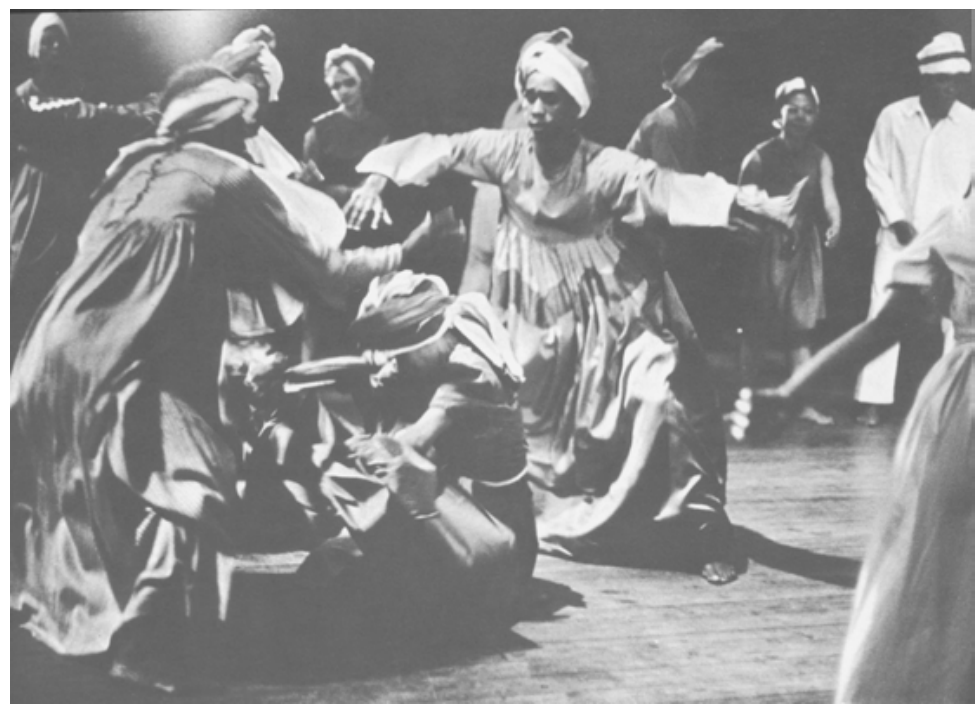

The National Dance Theatre Company of Jamaica in Rex Nettleford's

Pocomania, circa 1963. Photograph by Maria La Yacona (rpt. in: Nettleford 1969: 11).

16 "Trumping" has come to replace the former term of "groaning" in more recent ethnographic scholarship. 
What the dance choreography thus manages to convincingly portray, even in theatrical adaptation of the ceremony, is the movement's embodied meaning of Africanist religious survival. Pocomania as a study in the movement possibilities of Jamaican dance theatre experimented with Revival movement which, as Nettleford points out, not only went into dance theatre, but also into the popular dancing such as, for example, the engine jogging of the Indian Engine Spirit, which later on went into Ska. ${ }^{17}$ As Wynter has defined the symbolic impact of Revival in the larger sociological realm:

Revivalists through spiritual 'labour' and 'work' deny the brute facts of everyday existence by their transcendence in super-reality. They establish in dance 'a putative society'. In which they are the elect, the elite. Dance turns world upside-down, liberating participants. Challenge and response syndrome leads to fact that dance as a vital and meaningful reality found mainly among dispossessed (1970: 47).

Revival rhythmical and movement patterns thus form part of Jamaica's psychocultural kinetic consciousness, which even in the stage-transferred version of Pocomania - as well as in Ska and Dancehall culture thereafter - will evoke distinct identificatory patterns. Obviously, Nettleford's Pocomania does not convey the same sort of directly enacted liberation that Wynter describes, yet the choreography still manages to portray many of Revival's core features in a semiotized way. At least symbolically, these cultural icons continue to speak of Revival's empowering force. And as such, the stage performance ultimately paved the ground for better middle class understanding and acceptance of this formerly ridiculed practice.

Pocomania as the NDTC's earliest folk choreography is therefore probably less important in terms of its rather authentic preservation of Revival movements than the actual revolutionary potential of Pocomania's theatre acclaim. When many middle class Jamaicans of the 1960s did not take Revival seriously, then Pocomania certainly helped to enhance a larger appreciation of this cultural expression (Seaga 1969: 5). As is shown in Wynter's following comment on the prevalent antiAfrican stance of the middle class at the time:

17 Similarly, Kingsley Stewart has remarked on the prevalence of the "seal" still maintained as a notion in contemporary dancehall culture. Compare Kingsley Stewart, "Dancehall," lecture presented 14 July 2003 at Jamaica School of Dance, Summer Workshop 2003, Kingston. 
Africa exists [...] without interpretation and meaning. And without its framework of meaning it repels the more Christian element who see it only as one more example of the 'sexual licence' and immoral lack of restraint of the 'lower classes'. Meaningless it reinforces their attitude of rejection and contempt which is, since this is a part of their cultural being, self-rejection and self-contempt. This attitude extends to the dances which have become 'parochialized' a means of interpretation of a religion whose wider meaning is lost. Whilst the religion is constantly experienced and expressed through the dance, its universal elements and significance are obscured (1970: 46).

Nettleford's first folk-based choreography thus presented an affirmative bond to Revivalism and put forward a positive claim of cultural heritage and identity.

From the dance aesthetic angle Pocomania appears furthermore important, because it was Nettleford's first attempt at distilling Jamaican folk dance vocabulary into a dance theatre technique, which appears to resemble to some extent that of method acting. To illustrate this approach, Nettleford's choreography works with the performer's kinaesthetic recollection of apprehended Revival movements to the effect that bodily evocation of such memory will lend cultural authenticity to theatricalized Pocomania, even though there is no actual spirit possession performed on stage. As Derek Walcott has remarked in a review of the 1960s West Indian folk-ballet:

Real bongos, shangos or pocomania dances are possessed by the faith of their cultists, who are not performing when they dance, but are enacting their belief. The choreographer, therefore, prefers to simulate such possession as closely as possible, a technique that draws the dancer closer to acting, and acting emphasizes dramatic development (1966: 5).

Such simulation, I will argue, is certainly enhanced by the dancer's embodied memory of these cultural practices, which many NDTC dancers have been exposed to from their early childhood onwards. Evocation of such bodily remembrance, hence, develops into a dance technique which lends authenticity to the movement, yet prevents actual spirit possession on stage. Such technical abstraction appears important in order not to violate the integrity of the religious practice itself, when transferring it into a stage symbol; since theatre, after all, is neither a church nor a sacred space, i.e. at least in the NDTC's context.

In another review, which antedates the premiere of Pocomania by three years, Walcott had already critically addressed this issue of an 
almost anthropological folk essentialism in other Caribbean dance theatre companies of the time (1960: 10). Apparently, Walcott found many of these performances lacking in "creative authority," yet enjoyable in "what is current stock throughout the Antilles, a prettying of 'the folk,' which is satisfying to the middle class, and amusing to the peasant" (1960: 10). In his opinion, performing folk culture for folk culture's sake could hardly survive as an art of its own, since it would need further artistic development and technique. Walcott's question appears therefore rather rhetorical, when he demands:

We are now at the stage where we are recognizing our roots, but who wants to make a career of watching roots? And can one anyhow, since they are best underground, spreading a basis for society? To cut short the comparison for good: if you pull up a young plant too early, and wave it around in spontaneous delight at your agri-, horti- or folk-culture, it stands a poor chance of growing up (1960: 10).

The difficult task for the Caribbean choreographer then, was to investigate folk culture's rich dance religious vocabulary, not to merely imitate, but rather to transform it in order to develop an indigenous dance theatre idiom. It is therefore important to contextualize the NDTC's ongoing crystallization of these field-based movements, which the company translated into a modern dance expression, precisely as to overcome Walcott's critiqued "phase of quasi-folk" (Walcott 1960: 10).

Nettleford has thus argued that he most of all sought to "capture the meaning of the psychology of subculture cultism and the fundamentals of worship" to examine Revival's deeper significance for his art (1969: 22). Approaching the cult from a choreographer's perspective rather than that of the practitioner or anthropologist, he assessed the danced ceremony first of all for its possibilities of "sheer movement" in order to transcend the "psychological and sociological antecedents of the rite and preserve in Jamaican dance theatre the treasures which must go to build up the dance as an art" (1969: 23). Against a "doctrinaire" claim for authenticity, Nettleford insists that ritual and dance theatre share a concern for people's thoughts and feelings so that Revival movement can "indeed be woven into the fabric of the country's artistic expression without threat to the deeper social and psychological meanings of the cults themselves" (1969: 23). Abstracting the "essences of existence so that they can be of continuing meaning to the people they serve" thus becomes the "very challenge offered by the cult" and 
posed to the choreographer (Nettleford 1969: 24). Certainly, embodied kinaesthetic understanding as well as dedicated research of these movements is indispensable to enlarge these folk religious movements dramatically, as the NDTC's 2003 revival of Pocomania has clearly evidenced.

Pocomania's 2003 remounting rather faithfully maintained the original choreography so that actually Nettleford's seminal work presented quite a challenge to a new generation of NDTC dancers, who - forty years after - had to carefully train not to 'catch the spirit' during performance. Observing the NDTC's rehearsal process outside the NDTC's Little Theatre Studio, I noticed the extreme difficulty of this technical approach, as a new generation of dancers apprehended the movement vocabulary from older company members and video-tape. While the tape helped in terms of the larger arrangement and composition, the basic movements were better conveyed through the assistance by the older generation of NDTC members, who had been dancing Pocomania back in the 1960s. As NDTC choreographer Christopher Walker - in charge of re-mounting the work and also dancing the Shepherd role commented, the dancers' phenomenological response to the Revival movement was decisive:

[...] you have to be thinking something, there must be something consistent. So that's where I approached the remounting of it from. What were you thinking? How did it make you feel? This movement? I know, you can't remember what the movement is, but, you know, and they [older generation NDTC members] remembered a lot of it. And they would come in. They'd sit outside, details that they wouldn't remember, but seeing the rehearsal, it would jog their memory and they said: 'Oh, you know this is supposed to mean so and so...' And so that information helped a great deal and so I made notes on that, based on what I was hearing. Joyce Campbell saying, 'No, when I did that I did it so and so...' or 'I remember feeling so and so, because this person reacted to me in this way...,' which means, even though the person, who was doing that other part was not around, we kind of have the information. ${ }^{18}$

Indeed, it was interesting to observe how Nettleford's own input, as well as that of Joyce Campbell, Pansy Hassan, Bridget Spaulding and others helped to reshape the exact style and expressiveness of the movement. Nettleford explained that mostly due to the constraints of

18 Interview Christopher Walker 11 Aug. 2003. 
time, field trips are not so much involved in the NDTC's actual rehearsing process any longer. Yet, as Christopher Walker also affirmed, much of that vocabulary is now taught at the Jamaica School of Dance. Moreover, Revival churches are of course renowned throughout Jamaica so that many NDTC members will have some knowledge and experience of the religion. As Christopher Walker remembered in reference to Revival meetings from his own childhood:

I grew up in the country - St. Ann, that's where my town is - and I used to see them all the time. And when they had street meetings, I would see them carrying on and, you know, I'd watch from a distance. But I'd watch, cause there was always fear of the 'wrap-head' - that's what we used to call them 'wrap-head church.' There was always fear of it and that's because we never understood what it was, and that's because my mother was Catholic. I never understood that. But there was also intrigue. So I'd still go and watch. If my mother hears this interview, she'd gag, but I'd still go watch, because there was intrigue and I was just excited by the rhythm. And sometimes there was no drum at all, just the chanting and the humming and the grunting, and the movement of the body was just so subtle! So much more subtle than we do it right now, which for obvious reasons wouldn't work on stage, because it wouldn't carry across the proscenium. Very, very subtle. So I had been mocking that style of movement for a long time, which is a good thing, because, when I finally studied Revival at Edna Manley and went on field trips, the information was already there. Because, I was mimicking them from when I was little. But even though I was doing it in a mockery fashion, the information was there. ${ }^{19}$

NDTC dancers of all generations will thus usually be able to build on such kinaesthetic memories. This inherited knowledge bears a clear advantage of cultural upbringing so to speak, as it facilitates the learning process of the folk vocabulary and will easily distinguish an NDTC member's performance from non-Jamaican/Caribbean performers, who are trying to execute the same steps, yet will not necessarily manage to achieve a similar grace of perfection and identification. ${ }^{20}$

19 Interview Christopher Walker 11 Aug. 2003.

20 This observation derives from my attendance of the E.M.C.'s Summer Workshop 2003, where North American trained dance students were showing more difficulties in conveying the correct style of the traditional folk forms than students from Jamaica and other Caribbean islands, not to mention my own graceless efforts. 


\section{Kumina}

Kumina, also choreographed by Rex Nettleford, but with ten years of experience later, premiered in 1971 and has since then been continuously performed as "one of the 'immortals'" of the NDTC repertoire, as Gleaner critic Justin Whyle approvingly expressed in the 1990s (1995: 9A). Similar to Pocomania, this choreography is an abstraction based on Jamaican Kumina and extracts the essential movement and rhythmic vocabulary of that folk tradition in order to translate its formal characteristics and iconicity into dance theatre. As part of the early choreographing process, NDTC dancers were first taken to the field, where they would observe, participate and research Kumina, before they actually started to work with the gathered kinaesthetic and musical material for stage adaptation..$^{21}$

Along with the effort of the Jamaican Cultural Development Commission (JCDC) to preserve Jamaica's vibrant African folk retention, many of the early NDTC members also became researchers into the origins and meanings of their country's cultural heritage. ${ }^{22}$ Working for the Social Development Commission at the time, NDTC founding member Joyce Campbell, the 'Kingston bread girl,' recalls:

I traveled around in some of those years with Easton Lee [...] in those early years I remember, when I found out about things like the Etu, I took JIS and went out there and filmed it [...] I can also remember the first time I saw Kumina in St. Thomas. It had rained earlier in the evening, I remember distinctly, I can see it. So the earth was muddy and I saw those feet inching the toes in the mud, and that's the basic - sometimes you don't see it now - but every time I go back to it, that's the basic, they inch along like that with the feet. They curl their toes and inch along. While they are going, there is this lateral movement [she stands up and demonstrates] in here going and the shoulders and - I was fascinated! And that was my first thing of Kumina. ${ }^{23}$

Jamaican Kumina ritual is considered the most distinctly African group of rites in present Jamaica. Introduced by African contract workers in the late $1^{\text {th }}$ century, Kumina is a Kongo retention which focuses on

21 Part of the NDTC's early field work was documented on film and can be accessed at the NDTC archive.

22 Rex Nettleford, Marjorie Whylie, NDTC musical director, and former NDTC dancers Joyce Campbell, Sheila Barnett and Cheryl Ryman have conducted seminal research, to which my own is obviously greatly indebted.

23 Interview with Joyce Campbell 15 Aug. 2003. 
possession, ancestor worship, song and dance (Bilby/Leib 1986: 22-23). According to Kenneth Bilby, Kumina cosmology is based on the belief that the invisible spirit world is as real as the visible world. Kumina ceremonies serve as a means of communication with the ancestral spirits via music, movement, and language. Associated primarily with wakes, entombments, or memorial services, Kumina is also practised at births, thanksgivings and invocations and is traditionally located in the parish of St. Thomas.

Kumina dancing consists of two strands: 1. 'bailo,' which is the more secular, and 2. 'country,' considered as the more African and serious dance, which builds up to spirit possession. Initiated Kumina practitioners recognize their gods and ancestor spirits in the distinct dance style. Responding to the songs and drum rhythms, the possessed dancer will execute the spirit's according steps, while each instrument connects to a certain part/centre of the body. As Marjorie Whylie, for example, has explained, the Kumina shakas will communicate to the head center, transmitting the ritual's spiritual energy, which ultimately introduces possession. ${ }^{24}$ While the bailo dances may display a variety of possible movements, the following basic ground pattern has been identified:

The basic dance posture constitutes an almost erect back and propelling actions of the hips as the feet inch along the ground. The dancers move in a circular pattern around the musicians and centre pole, either singly or with a partner. The arms, shoulders, rib cage, and hips are employed, offering the dancers ample opportunity for variations and interpretations of the counterbeats or poly-rhythms. Spins, dips, and 'breaks' on the last beat are common dance variations. ${ }^{25}$

Cheryl Ryman has further specified a set of distinct Kumina movements, since she regards the dance as the ritual's most constitutive part. Ryman asserts:

24 Marjorie Whylie, "Traditional Music and its Relationship to the Dance," lecture presented at Edna Manley College School of Dance, Summer Workshop 15 July 2003. Richard Schechner refers to "trance acting" as a total theatre experience in which the performer surrenders to "allpowerful forces" (spirit, demon, god). As a neurobiological reaction, "[T]rance is the outcome of the simultaneous stimulation of both hemispheres (frontal lobes) of the brain" and as such considered a transcultural performance practice (Schechner 2002: 164-165).

See Jamaica Journal Vol. 10.1 (1976): 7. 
The distinguishing feature of this dance form is in the second or fourth position flat-footed inching and shuffling of the feet, accompanied by a side to side or forward thrusting of the hip. For this motion, the trunk is either held upright or tipped slightly back. The undulation of the ribcage may be employed either instead of the obvious hip motion or on top of it. The dance, even in a bailo context, conveys a great deal of quiet intensity and is accentuated by a subtle drop on the right leg, whether it is placed behind or beside the other leg in the fourth or second position stance, respectively. The highly typical wild, flat-back spins, followed by a break in direct response to a music cue, is yet another feature of African retention in Kumina and Jamaican dance in general. ${ }^{26}$

During a Kumina ceremony dance and music thus form an inseparable unit as dancers and musicians take their cues from each other.

Essential to Kumina drumming are the Kbandu (battery of drums, "female") and the Playing Cast (lead drum, "male"). While the former plays the rhythm with emphasis on the first and third beats, the latter plays the more complicated and specific basic rhythms to incite the spirit. Olive Lewin has described the interaction between drumming and dancing as such:

The rhythm [of the Kbandu drums] is reproduced by the feet, while the florid and improvisatory patterns of the playing cyas [cast] drum impel movement of other parts of the body - head, shoulders, arms, hips. It also conveys to the dancers whether to proceed in the circular line singly or facing, as partner, one who is immediately in front or behind, or to spin and break before one more proceeding in single file, anti-clockwise (2000: 235).

Other percussive instruments include the Scrapers (grater), Shakas (rattles) and Catta Sticks. Accompanied by incantation, rum is spilled on the players' hands and instruments. Libations of white rum may also be offered to the ancestors, when spilled in all four directions. The ritual proceedings welcome the ancestral spirits to "return to this corporal world through the possession of the living" and "in return they provide the living with solutions to their problems, offering advice and vital knowledge not otherwise available to them." 27

Ryman argues that Kumina ceremonies should be considered as a form of communication rather than worship of the ancestor spirits, who

26 Ryman, "Kumina - Stability and Change" 111.

27 Ryman, "Kumina - Stability and Change" 81-82. 
are called nkuyu or kuyu. Rituals of language, music and dance channel the communication process. Yet, only as a "dance-music unit" will possession by the $n k u y u$ occur. ${ }^{28}$ Kumina possession differentiates between two types. "Mounting possession," in which the spirit controls the dancer from within and "mimetic possession," in which the spirit guides the dancer from the outside. The latter will be observed more often and can be recognized in the dancer's gestures, miming and other features of communication with the ancestor. In mounting possession, on the other hand, the dancer is directly taken over by the spirit and enticed with supernatural powers. In this case the spirit force may enable the dancer to showcase the eating of glass, burning coals or similar supernatural displays (Allen 1982: 11-12). ${ }^{29}$ Passed on from generation to generation, this performance of the ancestor spirit's power becomes particularly important to the Kumina group, because it provides each

28 Ryman, "Kumina - Stability and Change" 90-91.

29 Apparently, Allen observed "mounting possession" during a field trip, which he described as follows: "[...] She was in what they call the 'myal', that controversial stage when the dancers are supposed to be possessed by the spirits. Then an elderly lady ' got out'. She grabbed a firestick out of a nearby fire and began to wield it about, sending some spectators into a quick retreat. Others who had seen many Kumina ceremonies, held their ground, certain that the woman would not harm them. But it seemed dangerous to me when she barged out of the line of dancers, rushed to a nearby kitchen and returned with a machete. She wielded the machete just as she had done with the fire. I was in no mind to receive any machete cuts in the bushes of St. Thomas and stayed wide of her. Even the stout-hearted ones like Brissett seemed nervous and uncomfortable. Then she rushed again out of the shed and proceeded to 'chop to bits' a 'bad spirit' which was lurking nearby in what looked like a butchery. On her return, apparently satisfied that she had defeated an evil spirit, she walked onto the blazing embers from which she had plucked the firestick and danced, while chanting something inaudible to me" (1982: 11-12). The 'inaudible' chant, Allen overheard, was likely to be given in Kikongo as this description appears to depict the country part of the Kumina ceremony. While Allen's report is full of the typical sensationalist vocabulary of the appalled onlooker, I consider it still important in this context, for it presents a point of view that is not only shared by some tourists and foreigners, but also those Jamaicans, who disprove of the rite as a morally harmful superstition. Thus, some of the Jamaican E.M.C. summer school participants refrained from joining the scheduled Kumina field trip in fear that it could negatively affect them. Interestingly enough though, as this report also clearly demonstrates, Kumina performance certainly speaks of a defiant power and demonstrates as such an effective cultural practice of revolt. 
member with a sense of heritage, continuity and power directly linked to the African homeland. ${ }^{30}$ As Lewin has pointed out, certain talents may be handed down from a deceased ancestor to a living member of the Kumina cult. Thus, for example, in the case of Queenie Kennedy, who inherited her distinct dance style from the spirit of Mother Margaret, another Kumina queen (Lewin 2000: 280-281).

In his study "Kumina - The Spirit of African Survival in Jamaica," Edward Kamau Brathwaite places the ritual into the context of what he calls "contact evidence of a living African presence and the consciousness of its place in the continuum: the persisting continental connection between New World and Old Africa" (1978: 46). Regarding Kumina less as a "syncretized religion," but rather as an "African/Maroon lifeform that has used the resources of Creole Christianity when/wherever necessary," Brathwaite stresses Kumina's socio-political function in terms of cultural survival (1978: 46). While the colonialist system sought to destroy the cultural link to Africa, Kumina had to be hidden from public view. However, since African religions do not separate the secular from the sacred, Kumina was not limited to a Christian 'onehour-church-service,' but rather permeated the whole of community life. By tearing down the binary construction of two different spheres for life and death, Kumina practice manages to transcend dualistic notions of separation. Whether it be body and soul, heaven and earth or home and diaspora, communicating with the ancestors in the ritual accomplishes a state of self-forgetfulness and reconciliation (Brathwaite 1978: 46).

Music and dance in particular enhance this spiritual awareness, for the rhythmic patterns and kinetic moves generate the communication which builds up to possession by the ancestor spirit. In this respect, Kumina not only serves as a cultural link for the community, but also creates the notion of wholeness and identity within the cosmological system. Active participation in the dance and music can therefore be regarded as yet another cultural strategy that helped to overcome the psychological trauma of the Middle Passage. Kumina dance and drumming thus helped to defeat the loss and forced separation from the African homeland as entranced dancers reconnected with the ancestral spirit force. Additionally, Brathwaite stresses Kumina's particular relevance, for the Kongo-based ritual stresses the African link more than Jamaica's other religious practices do. In contrast to Revivalism,

30 Ryman, “Kumina - Stability and Change” 117-118. 
for example, Kumina's importance relies on this autochthonous claim, which counteracts the homogenization of cultural practice under a somewhat enforced Anglo-Christian tradition of colonial provenance (Brathwaite 1978: 46). Brathwaite, however, takes an ambivalent stance towards the appropriation of Kumina by the Jamaican festival and dance movement, because he sees the danger of commercializing those more authentic forms. For example, he questions whether people will still acknowledge the ritual's complexity of meaning, once that it is transferred to the stage. Festival exposure, he is afraid, might lose the impact of the religious context and fail to promote deeper understanding and appreciation of the practice and its practitioners.

Yet, in his theatrical adaptation of Kumina, choreographer Rex Nettleford took care to sufficiently abstract the Kumina dance vocabulary so as to adjust it to the space and time parameters of the theatre stage. ${ }^{31}$ As has been mentioned before, the company strives for what Nettleford calls "conscious transition:" i.e. the development of a distinct Jamaican approach that emerges from experimentation with ballet and modern dance as it incorporates Jamaican folk forms. The exploration of all of these movement techniques thus serves as a significant vehicle in a process towards an original Jamaican dance theatre style that is by no means to be mistaken as a one to one reproduction of ritual. As Rex Nettleford defends his approach against cultural purists:

Folk dancing is for participating and not as theatre dancing is, for viewing. [...] Nowhere are these [folk forms] translated wholesale on the stage. Rather, they are distilled and their essence extracted, treated, and projected. When Beryl McBurnie, the Trinidadian high priestess of dance, presents rituals of Shango, Rada Plavadoo, she presents them as an artist not as a dweller in the hills of Belmont and Laventille. The Nation Dances of Cariacou must be translated into the language of dance-theatre for presentation. Otherwise they are best left where they thrive and have their being, if authenticity is what we want (1968: 128-129).

Transferring Kumina ritual into dance theatre choreography, Nettleford thus maintained the dance's basic foot movement, yet accelerated the speed of progression, which is usually much slower in pace.

31 For the following analysis compare, "Kumina," The National Dance Theatre Company of Jamaica, performance video produced by CPTC/Creative Production and Training Center, Kingston. 


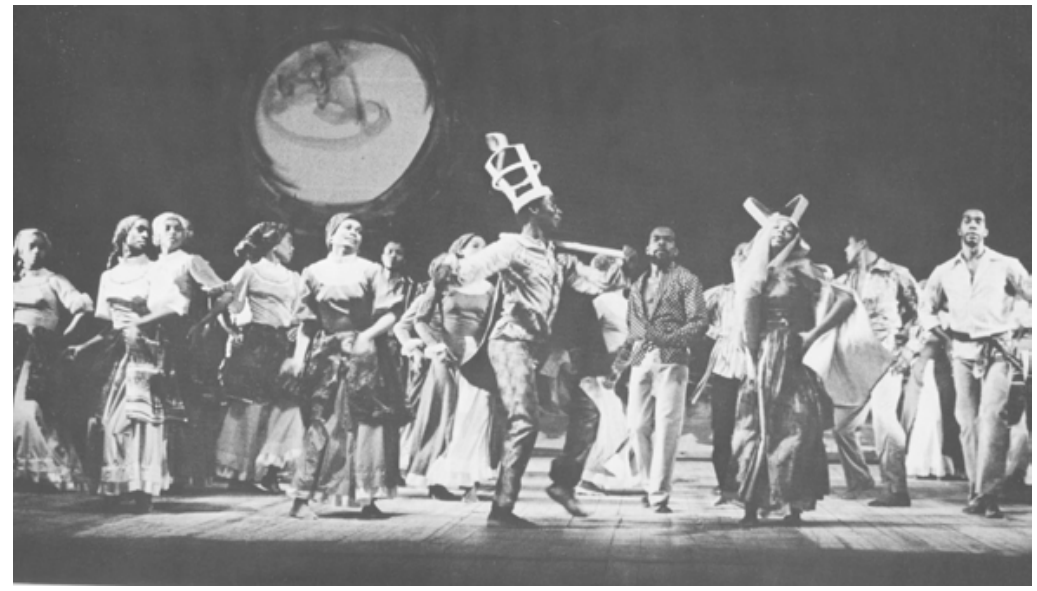

The National Dance Theatre Company of Jamaica in Rex Nettleford's Kumina, 1971. Photograph by Maria LaYacona (rpt. in: NDTC 30 th Anniversary Program).

Moreover, the NDTC's Kumina inserts several modern dance movements, which Nettleford superimposed on the basic Kumina shuffle. Leg extensions and port-de-bras, for example, are definitely not to be found in the ritual, yet for the stage performance, they add to the choreography's aesthetic appeal. Such explorations are taken further by the inclusion of the Warrick (stickfight) from Jamaican Jonkonnu, which Nettleford introduced in order to break the spirit inviting intensity of the dance. ${ }^{32}$ Group formations as opposed to the ritualistic circle as well as the cross-leg jumps of the male dancers were likewise choreographed to prevent dancers from entering the state of spirit possession. ${ }^{33}$ Maintained from the ritual, however, is the spilling of white rum to symbolically appease the ancestor spirits.

32 Marjorie Whylie commented on this strategy during the 2003 Summer School Workshop. Compare Marjorie Whylie, "Traditional Music and its Relationship to the Dance," lecture presented at Edna Manley College School of Dance, Summer Workshop 15 July 2003. The "Warrick" has been identified as a stick-fighting dance that derived from the British mumming tradition, however, as has been mentioned before, stickfighting is also a popular West Central African-derived tradition (Ryman 1980: 14; Warner-Lewis 2003: 199-226).

33 Music ethnographer Markus Coester also noted that the spirit inviting drum key was taken out of the Kumina drumming. 
Again, as Nettleford has argued for Pocomania, he does not intend to reproduce the ritual itself, but seeks to "capture the meaning of the psychology of subculture cultism and the fundamentals of worship" in his choreography (1969: 22). In comparison to that earlier work though, it is interesting to notice the advanced degree of abstraction here. While Pocomania was still closely relying on the field research, Kumina reinvents the ritual through the choreographer's prism into an artwork of its own right. ${ }^{34}$ And yet, despite the increases in tempo and the "chastizing" of pelvic movements to standards of middle class "acceptability," Monica Lawrence's analysis, for example, asserts that the theatre performance still generates a truthful experience of Kumina by capturing the ritual's essential elements. ${ }^{35}$ Largely due to the authenticity of the basic foot movement as well as the Kumina drumming, she furthermore claims that the choreography ultimately altered the social discourse on the rite, which for a long time had been culturally denigrated and neglected. ${ }^{36}$

To redress Brathwaite's voiced concern for commercialization of the folk forms, one might therefore want to finally take a closer look at Kumina's reception at home and particularly abroad, where this alleged danger has in fact been superseded by the communicative power of the piece. $^{37}$ As the following review of the NDTC's Toronto tour in 1982 documents, theatricalized Kumina still conveys much of its spiritual force, kinaesthetically re-connecting the audience at least to the African Jamaican folk heritage at home, if not necessarily to the ancestral African gods. As Maud Fuller commented :

34 For a more technique-based analysis of the Kumina dance vocabulary compare Carty 1988: 22-31.

35 Monica Lawrence, M.Phil. project presentation, given on January 30th 2003 at the Cultural Studies Group meeting, U.W.I., Mona Campus, Kingston.

36 On behalf of the field to stage adaptation process, Jean Johnson Jones has similarly argued: "Undoubtedly, removal from their former contexts alters their meaning; but the movements of the staged dances maintain a cultural validity which can act as a window through which more understanding can be gained of the people who perform them" (1999: 100-101).

37 As Sheila Barnett recalls though, Brathwaite was not even critical of the NDTC's Kumina, which he elsewhere has referred to as an "icon of Jamaica and the Caribbean region" (Barnett, "Notes on Contemporary Dance-Theatre in Jamaica 1930-1979," unpublished script, n.d.). 
After KUMINA had been reprised for the fourth time on opening night, the audience, having whipped itself into a state of near-frenzy, took up the strains of 'only the righteous' followed by oodles of 'boodoodum' to imitate the drumming. I saw no less than five very 'proper' ladies jutting their hips and shuffling their feet as they filed out of the auditorium with a bounce and buoyancy that had long ceased to be part of their notion of propriety. I must say - their hearts were very willing but alas! for their flesh. But such is the seductiveness of a work like KUMINA; it lures you into believing that 'you can do it too, Punchinello little fellow' (1982: n.p.).

As this example nicely demonstrates, Kumina's kinaesthetic energy stirs long lost memories of cultural belonging and identity, which also appears as the communicative strength of the dance in this particular case. The NDTC's Kumina consequently not only obtained recognition of Jamaican African identity with local audiences, but also provided the theatre spectator with an awareness of the ritual in the field that he or she most likely would not have been aware of otherwise. In this respect then, the dance's purpose is not merely entertainment, but it also contains educational tenets. As Mervyn Alleyne conclusively confirms:

Kumina music and dance have become accepted forms of the Jamaican national culture. Kumina drumming and the Kumina 'shuffle' dance movement performed to it have become standard elements of the Jamaican dance theatre, and the Seaforth Town performers themselves are invited to perform at national celebrations. In this sense there has been a theatrification of Kumina culture which so far has not led to a dissolution of its integrity in its local setting, but which, on the contrary, seems to contribute to a growing acceptance of Kumina as part of the national identity (2002: 209).

\section{Gerrehbenta}

Based on Jamaican wakes/dead-yard ceremonies, the NDTC's third choreography to be discussed in this context is Gerrehbenta (1983). The work owes its name to the traditional folk form of Gerreh and its instrument the Benta, which is popular in St. Mary and made of "bamboo with a string lifted from the membrane and played with a calabash to produce a singing note while sticks are beaten at the other end" (Brown 1995: 42-46). Yet, the name is misleading, for, in fact, the choreography opens with the entrance of familiar characters from Jonkonnu and is ac- 
companied by the typical drum and fife music of that tradition..$^{38}$ Center stage we see the impressive, quite awe-exerting mask of the rural Horsehead, who is soon surrounded by an inner and outer circle of female dancers in traditional costume and head-tie. ${ }^{39}$ At the same time, a character reminiscent of the Jonkonnu's Actor Boy as well as a Cowhead mask take their positions on the left and right downstage corner. Both of them carry massive bamboo poles, which they rhythmically stamp onto the ground.

Similar to the Jonkonnu street parade, the choreography begins with a danced walk that is processional in character and leads the women into an inner and outer circle, marching opposite direction. The circles here are derived from British Maypole and Ring Game dancing, which both have been adapted and creolized in many of the island's folk dances and children's games. Nettleford makes again use of the jig, which he had first introduced in Plantation Revelry as one of the major Jonkonnu steps to be used in dance theatre. Bettelheim characterizes the Jonkonnu jig as a "travelling hopping step" with turn out knees and one leg passing from front to back or vice versa so that support and free leg will alternate (Nunley/Bettelheim 1988: 64). Typical for Jokonnu dancing - in which each character also carries out a distinct solo performances and improvisations - are apart from the processions, also the isolations of different body parts (knees, shoulders, pelvis) and the bent over torso with the shoulder "shimmy" (rotation of the shoulders). All of which owe to an African dance aesthetic, even though the jig itself is of course originally a European-derived step (Ryman 1984b: 58).

After the opening sequence, this celebratory beginning switches into the more intense drum beats of the Gerreh and Etu dance. Both forms are Jamaican funerary rite dances performed to the accompanying traditional wake songs presented by Majorie Whylie and the NDTC singers during this section. The songs are: "Kanda Tone deh blow Maw-ga," "O Timothy a Tanga Man" and "Wonda who a Zuzu

38 For the following analysis compare Gerrehbenta, The National Dance Theatre Company of Jamaica, performance video, produced by CPTC/Creative Production and Training Center, Kingston.

39 In addition to what has already been said on behalf of the mask's origin, Cheryl Ryman's research also refers to similar horse masks worn by the Efik of eastern Nigeria. Among the Buru masqueraders, she comments, the Horsehead is regarded as one of the "most feared manifestations of an evil spirit in Jamaica" (see NDTC Newsletter July 1983; Ryman 1984b: 56). 
Fader." 40 Characteristic of Gerreh, which is practiced in Westmoreland and Hannover, is the use of ring games, dancing in circular pattern and a dance "in which performers are lifted as they balance standing on two horizontally held bamboo poles," as is here used by Nettleford to indicate the switch of sequence (Tanna 1987: 31). Ryman furthermore explains that Gerreh is performed during "the first two nights after the death of a person or until the deceased is buried [...]" (1980: 9). Patricia Bowen has described the dance movement as follows:

In guerre the dance steps usually carry the dancer forward and backward. There is the balance step and the shuffle as in Kumina. The balance may be exaggerated. The stress is on the supporting leg. The dancer moves forward to meet a partner, the pelvis making a figure of eight with right knee bent. Stopping immediately opposite partner, the couple continuing pelvic movements bends down, then retreat (1980: n.p.).

Etu, the other influential dance step here, also originated in Hanover and the surrounding regions. The dance, however, has been out of practice and was revived through the effort of the Jamaican Cultural Development Commission. Much of the religious intent of the dance

40 A recording of these wake songs and other traditional music compositions has been assembled on LP. Compare Heritage, record composed by Marjorie Whylie, Head of Folk Music Research Department Jamaica School of Music. Whylie's introduction to the recording of Jamaican Heritage music reads: "The music represents little known traditions and forms - little known that is, outside the communities where music and dance form an integral part of everyday life. In all the examples, the rhythmic impulse is very strong, even when there is no instrumental accompaniment. Voices are sometimes used in a percussive way, and handclapping and foot stomping support this norm. Instruments become, as a result of this, extensions of the body, and the interplay between rhythmic phrases and bodily response is a most interesting dialogue. The drum, as one would expect, is the predominant instrument, but most striking is the creativity and resourcefulness displayed in the use of available indigenous or discarded/recycled materials for instrument construction. The level of Africanisms still to be found in Jamaica may be surprising to some listeners, but suffice it to say that those elements in the music are but a part of the total neo-African experience and life-style of our country." Comparing the recording to the performance of the NDTC singers, one also notices a slight adaptation to a concert rather than ritual presentation as the NDTC's interpretation appears to have slowed down a little and naturally comes across as more 'classical' and 'refined' in singing and interpretation. 
has therefore been lost today. Still, historically, Etu ceremonies - like those of the Nago people of neighboring Westmoreland - bear witness to Yoruba origin and they were held for several occasions such as "dinner feast, wedding or forty night memorial (i.e. the $40^{\text {th }}$ night after a person's death)" (Ryman 1980: 9; 13). While a common dance style has not been recognized, some distinctions can still be made:

Generally the male dancers exhibit more strength and agility, than the women, who indulge in 'hippy' teasing movements. The dance posture is characteristically African, with bent knees, body slightly forward to erect, and flat-footed contact with the ground. Frequently, alternating feet brush the ground rapidly in response to the last beat of the drum. ${ }^{41}$

In Etu (Song: "Bambalala Yuwati" performed by NDTC singers) the drummers - who play a 6-8 compound duple rhythm on the typical drum set of "Achaka" (kerosene tin) and "Irre" (two-headed oval shaped drum) - and dancers work closely together. Particular of this dance is most of all the "Shawling Ritual," which is essential to the dance and is also an integral part of Nettleford's choreography. ${ }^{42}$ The shawling proceeds as such:

The Queen and/or another principal female member, throws a scarf or scarves around the neck of the dancer, who is then ceremoniously 'dipped back' from the waist, 'to give him strength', and finally the shawler raises the dancer's arm in salutation and congratulation. Sometimes, the shawl is tied around the waist or hat, and is used to 'crown' a particularly virtuoso performance. Although only two people (dancer and shawler) are normally found in the dance area a third person may enthusiastically join the performance for a while then sit. The group dances together, marking the end of the ceremony. ${ }^{43}$

Looking at the choreography in light of this description, obviously the placing of the shawls as well as the hip-teasing movements of the female dancer are discernible. Correspondences between these distinct funerary rites exist and even as they are blended, as well as transformed by the NDTC dancers' modern training, they still convey the cosmological link to Jamaican traditional dances. Derived from kinaesthetic memory, these dances communicate a life-asserting, positive en-

41 Jamaica Journal Vol. 10:1 (1976): 4.

42 For a more detailed description of the Etu drums compare Ryman 1980: 9.

43 Jamaica Journal 10:1 (1976): 4. 
ergy, which connects "body and soul(s), corporal and spiritual worlds" (Ryman 1984: 19).

Gerrehbenta thus celebrates the "procreative aspect of marking life in the midst of death," which is known as an integral part not only of nine-nights and wakes but in fact of most of Jamaica's traditional folk dances. ${ }^{44}$ As was already mentioned, Pigou has pointed out how African Jamaican epistemology conceives of death as "a prolonged event," which encompasses three different phases: "a) the separation of the body, spirit and duppy; b) a transitional phase before the spirit reaches the spirit world and c) a final phase when the spirit, assisted by the proper rites, reaches the spirit world" (1987: 25). Similarly Wynter has remarked that in Jamaican folk belief the "dead are not the negation of life, but part of the life force" to the effect that the "folkdance of the living is made more alive by the presence of the dead" (1970: 37). Originating under the hardships and suffering of slavery, funerary rite dances were commemorating death and loss, yet celebrating the spacetime continuum to the African homeland and ancestors at the same time. Such mourning therefore carries an empowering moment as the African-based cosmology unites the living and the dead through the practice of these dances. Celebratory in fashion they have stood and continue to stand for the desire to live on, to procreate and overcome. They embody remembrance in the face of loss, seeking reconciliation within the community in each individual dancing session. These traditional dances stress the social bonding among group members as much as they contribute to the affirmation of self.

This function of traditional dance becomes particularly evident during the final section of the choreography. In front of a scenic red backdrop, this sequence is dedicated to the Dinki Mini dance, the last of the folk forms influential for the choreographic process. ${ }^{45}$ Following a Dinki Mini song, one is lead even deeper into the vestiges of Jamaican history. For the traditional Dinki Mini songs, the so-called 'digging and grave yard songs' are associated with the death of Tacky, the leader of the 1760 slave rebellion in St. Mary. According to Jamaican oral history, Tacky's death occasioned one of the great Dinki Minis in time (Tanna 1987: 27-31). Structurally, Dinki Mini songs follow an African-based call

44 Compare Maureen Rowe, "Roots and Branches - The Precursors," taped lecture presentation (Kingston: Library of the Spoken Word, n.d.).

45 Ryman associates Dinki Mini directly with wake dances, observing that "the more obvious pelvic activity (fertility overtones) [...] serves to pit the power of life, through procreation, against death" (Ryman 1980: 14). 
and response pattern with the leader starting and the group responding as we have here from the NDTC singers. The highly popular mento music is produced by various instruments as maracas, grater, drums, guitar and sticks and has a "clear, strong fourth beat, in a bar of four beats" (Brown 1982: 45).

Similar to Gerreh of western Jamaica, Dinki Mini is primarily practiced in the eastern parts of the island. Performed from the second to eighth night of a nine-night wake, Dinki Mini cheerfully commemorates the deceased person. As a couple dance it is not only accompanied by lively mento music, but singing, ring games and Anansi stories may also be included. Climaxing the ninth night, the spirit is finally sent off to the other world (Ryman 1980: 8-9). Hazel Ramsay in an interview with Laura Tanna for Jamaica Journal has given a more detailed description of the dance. She explains.

[The] basic dance step [has] knees bent, moving the right foot over the left while the left foot shuffles forward. Then the right foot is placed behind the left while the left foot again shuffles forward. The hips move sideways, and even rotate while the arms are bent at the elbows, hand held palms up. Shoulders are erect and rotate backwards and forwards while the head is held straight and eyes look ahead. In a further movement, the partners may hold hands high, turn in to face each other and then face out, still holding hands. The couples then form a ring and dance counter clockwise (Tanna 1987: 29).

These characteristic movements can also be observed in the last section of Gerrehbenta, when the Horsehead is surrounded by couples of NDTC dancers, who engage in the flirtatious Dinki Mini dance. One more time the male and female groups of dancers enter and exit in diagonal procession, displaying the various shuffles, torso and shoulder isolations characteristic of the dance to afterward join in couples of man and woman or smaller groups of three. The last part is indeed a celebration, a party that in its ritualistic repetitiveness spreads over into the audience. While all of the company is encircling the Horsehead in commemorative appraisal, the scene slowly fades out on the NDTC Singers' refrain: "Take off you're clothes and jump in da rain a, ha [...]."

Especially the continuing presence of the Horsehead appears of particular significance here, since the mask frames Gerrehbenta's beginning and ending sections. Interestingly enough, in Mande country and parts of Mali ethnographers have found a similar horse mask, which performs analogous dance steps and is believed to represent "the summa- 
tion of the universe, incorporating intelligence, initiation, the spirit of life, and the wisdom of the creator," as well as "man's struggle and search for a life without end" (Nunley/Bettelheim 1988: 55). ${ }^{46}$ Supposing that the horse mask still conveys some of that symbolic value, its prominent role in Gerrehbenta introduces a rather intriguing semiotic shift. Reading the Horsehead as "enactment of man's struggle and search for a life without end," the masquerader's vigorous jumps allow to re-interpret the funeral scene: Set in front of the backdrop's designed burial ground, the red lit scenery behind the grave stone no longer represents gloom, but happiness. Death is not death, but life. And it is precisely this message that the three dancers in the beginning of the last section seem to address, when they step up front, turn towards the audience and start their celebratory dance.

By choosing such clear markers as the traditional nine-night music and songs, the shawling-ritual and the Horsehead, Gerrehbenta's lifeaffirming message is stressed. Originating from Jamaican grass roots culture, these cultural icons still carry an immense symbolic power, when transferred to the theatre stage. Easily identified by the local audience, they testify to the resistant resource of collective body memory. As Don Buckner has expressed on behalf of the impact of Jonkonnu:

Jonkonnu communicates with people, not in platitudes and big words but through music, dance, colour and drama which "tells our story". It seems to me that our strongest visual and psychological memories of what could be called an unquestionably Jamaican - Caribbean art form is embodied in Jonkonnu. It is saturated with images that stir memories in mind and muscle. I remember Mother Lundy, I remember people on stilts. I remember people being afraid, being fascinated by the procession and interplay. Fragments of memories come home to me very strongly (1993: 8).

Presenting a medley of four different folk forms, Gerrehbenta convincingly translates ritualistic movement into a powerful piece of dance theatre. Celebratory in nature, yet dealing with the universal topic of procreation and life in death, this NDTC choreography also derives from Jamaica's treasure of kinaesthetic memory. Publicly commemorating these traditions, dance theatre assumes a distinct role in nurturing

46 Similarly, Ryman points to the mask's mystical association "with the ruler or any person of importance" in Africa, as well as she highlights the prevalent horse and riding imagery connected to spirit possession (Ryman 1984b: 58). 
the larger community's self-understanding. As Brian Heap, arts' critic for the Jamaican Gleaner, has commented on the significance of Dinki Mini in the NDTC's 1998 Gerrehbenta performance:

There is a very distinctive 'cripple foot' step from the Jamaican dinki-mini which is now widely accepted indeed integral, feature of the Caribbean dance vocabulary. Hence it has become a part of NDTC's repertoire, which serves as a powerful metaphor not only for the struggle of Caribbean peoples against adversities, but also for the triumph of the Caribbean spirit. [...] inspired by indigenous death rituals which celebrate life, gerreh, ettu and dinki-mini, pit us once more against the ultimate adversity. And that cripple foot step, that triumphant shuffle, becomes the means of overcoming everything that life can throw at us. [...] the healing forces will always seek to overcome. Crippled spirit, cripple foot, one can heal the other, apparently - at least so it seems in $\operatorname{art}(5 c)$.

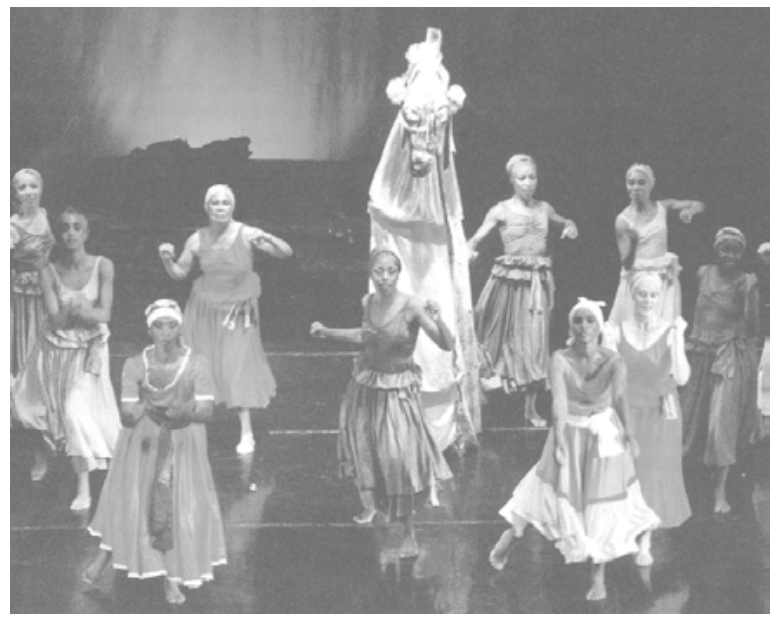

The National Dance Theatre Company of Jamaica in Rex Nettleford's Gerrehbenta, 1983. Photograph by Denis Valentine (rpt. Caribbean Beat Nov./Dec. 2002: 52).

In this sense then, Gerrehbenta (re)assembles kinaesthetic memory into a socio-political statement of empowerment. Against stereotypical notions of dance as having no meaning, being lascivious and whatever else colonialists such as Sir Edward Long have mistaken this practice for, it in fact testifies to quite the opposite: a very well thought through strategy of secrecy, camouflage and spirit that only the initiated fully 
understands. In terms of the African Jamaican identity claim, such dance theatre performance of traditional dances surely proves of undeniable importance.

\section{Bruckins}

Bruckins choreographed by Joyce Campbell and Barry Moncrieffe in 2002 presents yet another repertoire piece to showcase Jamaica's rich dance heritage, very much in line with the efforts of the JCDC's annual festival. The original folk dance is celebratory in nature, accompanied by speeches, parading, dancing and feasting. Etymologically "bruk" may refer to 1. not having money, 2. "the typical dance movement which gives the appearance that the body is broken at the waist" - in that sense also "to break free" - but can also 3. simply relate to forms of social gathering. ${ }^{47}$ According to oral history the first Bruckins took place in 1834 at Muirton's Works Yard. As the story has been told by Kenneth Bryan in 1984:

Now at this time there was some upheaval in St James and as was typical at that time, slaves heard on the grapevine about anything that was happening among slaves anywhere in the island. It is difficult to say just how the news travelled, but usually it was the house slaves who overheard conversations of their masters who spread the news. When the slaves in East Portland heard of what was happening in St. James they became unwilling to continue working and got together and started singing and dancing. They were jumping up and down using their machetes like swords and they made music with old pans, graters and bamboo. The owner allowed them to carry on dancing for a while, then he gave order to get back to work. But this was not easy for they assumed that others in the West Indies and in St. James were free. This, however, was not true. ${ }^{48}$

In fact, only four years later by the year 1838, freedom was really in effect and greeted by the famous Bruckins song "Jubalee" - "by far the most important of the songs:"

Jubalee, Jubalee dis is de year of Jubalee

Queen Victoria give me free, Queen Victoria

Give me free, dis is de year of Jubalee

47 "Bruckins Party," unpublished paper, African Caribbean Institute, Kingston.

48 "Bruckins Party" 3. 
Jubalee, Jubalee, Jubalee, Jubalee. ${ }^{49}$

Mention of Queen Victoria here, clearly signals the dance's acknowledgement and celebration of Emancipation. Other Bruckins' songs include: "Recreation," "True a Noble Chairman," "Walk in Deh," "Heel and Toe," "Mango Blassom," and "The Frack the Queen a go wear."50

As there are two sets, one red and the other blue, Hill and others have placed the emergence of Bruckins in the context of the Jonkonnu masquerade complex. After Emancipation, Hill argues, Bruckins evolved out of the decline of the public Jonkonnu festivity, which came under pressure from the local authorities, who made a constant effort to subdue the tradition. Also, because the 'brown' upper class did no longer identify as much with the masquerade tradition as they used to, Jonkonnu became largely a lower class cultural practice. Celebrating Emancipation day on August 1 ${ }^{\text {st }}$, former slaves commemorated their freedom day in due fashion and Bruckins added a new dance to that festivity, which in satire, rebellious spirit and social comment was very much in line with Jonkonnu tradition. Hill explains:

Moving from the public streets to the barrack yard and the village compound, the August 1 celebrants developed other types of events to mark their day of freedom. [...] to the black underclass, especially those who still worked the land, it was a day to recall, the day on which Missis Queen had set them free after more than a hundred years of enslavement. They formed ad hoc associations; they erected bamboo sheds with thatch-covered roofs in which they gave banquets, made speeches, sang songs of freedom, played their fifes and drums, and ended with lively dances that were called 'Bruckins' (1992: 253).

Also Joyce Campbell in her essay on "Jamaican Folk and Traditional Dances," suggests that the origin of Bruckins' Party is African and derived from the Jonkonnu Christmas processions. She asserts:

Bruckin' Party is a set dance - Blues and Reds performed in a sort of contest with each set trying to out-dance the other. Talks reveal that in the past the costumes were more colorful and were usually kept a secret until the dance was performed. A Bruckin' Party would start at night in one yard, then they would march on the streets to another yard where the Bruckins would end at daylight. The dancers represent Kings, Queens, Princes, Captains, Soldiers,

49 "Bruckins Party" 4.

50 "Bruckins Party" 4. 
Trainbearers, etc. in each set, complete with swords and crowns for the Kings. The men dance with sticks described as "razzling the swords" (1976: 8-9).

Accompanied by the "rattling" and the "bass" drum, music and singing are an integral part of the dancing. Most of the songs stem from oral tradition and are passed down from generation to generation. Some words are directly related to Emancipation and Queen Victoria ("August Morning come again/This is the year of Jubilee/Queen Victoria set us free").

Bruckins - as it has today been canonized by the JCDC's annual festival and as it is also performed in the NDTC's choreography - starts with the procession of the red and blue sets singing:

De Queen a com in [3x]

Oh yes, a beautiful sight.

Red Queen a come in [3]

Oh yes, a beautiful sight.

Blue Queen a com in [3x]

Oh yes, a beautiful sight. ${ }^{51}$

The dancers are dressed up in finery and execute very stately steps and dips, which originally derived from the European Pavanne. Each set has a King and a Queen and courtiers called grandson and granddaughter. Carrying swords in their hands and wearing crowns on their heads, the dancers, however, have adjusted the "upright stance of the Europeans" by tilting back on the diagonal and fully flexing the foot. ${ }^{52}$ Highly competitive rivalry reigns among both groups as each set seeks to outdo the other in performance by the end of the procession. Among the renowned movement sequences are: "Bruck, Siloh, Benup and Kneel-Down-Bow-Down." 53 Originally located in Ressington and Portland, Queen's Party and "Teameeting" were related forms also performed to celebrate the Anniversary of Emancipation from July 31 to August 1 (see Bowen 1980). In the staged adaptations, however, these do no longer appear. As becomes evident once more, the cultural significance of Bruckins and its masquerade competition of kingly sets

51 For a more detailed musical and song analysis compare Lewin 2000: 114115.

52 Compare Carty for a more detailed discussion of Bruckins dance vocabulary as technique (1988: 58-65).

53 "Bruckins Party" 6. 
appears to somewhat mirror that of the Jonkonnu masquerade complex. Here, too, formerly silenced and disenfranchised groups of the population appropriated stately power by disguising themselves with the insignia of hegemonic rule.

\section{Interlude III: Dance and Self-Discovery}

By artistically exploring material from Jamaica's kinaesthetic memory, the NDTC has laid the foundation of a distinct dance style that not only reflects the country's African heritage, but managed to display it on a nationally significant level. As Loren Kruger in her study on the national stage in England, France and America has pointed out, theatre oftentimes functions as "the appropriate site for nation building" as well as the "battleground of intersecting fields on which the legitimacy of national popular representation is publicly contested" (1992: 6). Considering Jamaica's social make-up at the time of independence the project of national reconciliation, as well as the question of precisely which values could be claimed as Jamaican after the fall of the British colonial hegemony, were certainly considered pressing issues. Already with Ivy Baxter's pre-Independence audiences, the process of re-identification with Jamaican grassroots culture had set in, when she first confronted her middle class audiences with their African ancestry. To those, who V.S. Naipaul had characterized as colonial "mimic men," the NDTC's Pocomania must have come home as quite a shock, yet also as a revelation. National dance theatre in Jamaica thus emerged as what Kruger's analysis has conceived of as a "site of struggle among competing attempts to legitimately define the appropriate relationship between theatre and society" (1992: 6).

Negotiating Caribbean identity via dance theatre proved particularly intriguing, because of its cultural ambivalence. While the early NDTC members were contested for their 'bare-foot' dance, they still conquered the national scene, i.e. traditionally the site of hegemony. As Kruger remarks, staged identification remains doubled and cannot easily be claimed by state power, since "the institution of theatrical nationhood appears as both a cultural monument to the legitimate but nonetheless exclusionary hegemony [...] and a site on which the excavation and perhaps toppling of that monument may be enacted" (1992: 6). Hence, national dance theatre in Jamaica operated subversively from within the Western theatre frame by appropriating modern dance as 
much as the proscenium stage, yet dancing quite African rhythms and beats. Thus, Ivy Baxter's Dance Group as well as Eddy Thomas' later Dance Workshop and ultimately the NDTC integrated those local performance modes into a theatrically effective dance 'mimicry,' which performed according to western standards on behalf of stage set and some of the training, yet expressed what was truly discovered on their own. The NDTC's conscious claim of folk culture and its performative traditions soon evolved through the backdoor, if you will, as the legitimizing force of national identification after independence.

When the theatre stage traditionally was a space of the upper middle classes and in the beginning British dominated, it changed into the space of the people with local performance traditions, comedians and the NDTC taking over in the early 1960s. The NDTC's creative appropriation of African Jamaican ritualistic dance movements for the theatre stage thus introduced a variant of ritual theatre, which Hill has defined as secular rather than religious in significance. In fact, he asserts that it was due to theatre and festival performances that eventually "the educated middle class joined forces with the less-educated underclass in the preservation and appreciation of an indigenous cultural form" (Hill 1992: 281). Folk-based choreography is therefore of continuing importance in the NDTC's repertoire, because it presents an identificatory as well as politically integrative societal forum.

Moreover, folk vocabulary still forms the base from which much of the NDTC's more experimental or abstract modern choreography evolves. Stylistic elements from the folk such as polyrhythms, rippling back and pelvic movements as well as the respectability of the bare feet on the concert stage have been the merits of the NDTC's conscious effort to (re)present that part of Jamaican history with pride and dignity. In this respect, Caribbean folk-based choreography has taken a powerful stance against the stereotypical notion of the alleged "culturelessness" of the African tradition which for too long had dominated not only the stage but also Jamaican public life. As Ryman has so pointedly expressed:

For the Maroon (Asante), the other "Africans" - Kumina (Kongo) and Etu (Yoruba) people, Revivalists, and the Rastafarian, their dance and all that informs its content and context, is the act and activity of creating a world that lends dignity, self-identity and a measure of control over one's life. To the extent that the mainstream society remains non-viable alternative to the strength of that offered by the African ethos in the traditional dances, they 
will survive as vibrant and dynamic agents and catalysts of African retentions and the Jamaican culture (1984: 21).

'Dancing Cultural Roots' in the Caribbean context thus outlines a performative paradigm that not only keeps kinaesthetic memory alive, but points the body towards a self-assertive expression of Jamaican heritage and future.

\section{In Celebration of Diversity - The NDTC's Caribbean Dance Vocabulary}

We ought to root our work in the collective experience of Jamaica and in the other West Indian territories - always trying to get to the essences, the universality of a particular experience. By doing this I think we will be able to communicate with audiences both at home and abroad. We will continue for a long time to have a variety of styles with an underlying thing - I cannot even describe it - a thing evolving which will put a stamp on us (Nettleford 1965: 21-22).

We have movements much like the Graham contraction and release in our own traditional dances. But there is at least one great difference. Graham looks inward into caves of the heart; our dance looks outward into sunbursts. 54

As has been shown in the previous chapter NDTC dance vocabulary prides itself on a strong folk dance tradition, which even in the more distinctly modern works of the company shapes the NDTC's unique style. ${ }^{55}$ Cheryl Ryman has codified the NDTC's "Core Vocabulary Structures" as consisting of ballet, modern and folk elements. Her list contains the following elements as the most prevalent: 1. contraction and release, 2. rippling back/body waves, 3. arched/hyper-extended back, 4. ribcage shifts, 5. hip-side thrust, 6. lunge, 7. spiral, 8. change of back, 9. flat back with side extension on the floor, 10. low crouched turn, 11. off-balance side extension and 12. catch step (see Ryman 1982).

54 Rex Nettleford in an interview with Jack Anderson (1980: n.p.).

55 Daniel Lewis defines the term "style" on behalf of the diversity within modern dance expressions as follows: "[...] style determines how a movement or step is executed; that is, what muscle action achieves the movement, what the timing of the movement is and what kind of quality of expression is given to the movement" (1984: 35). 
As her list indicates modern technique is juxtaposed with Africanbased folk forms which together form the basis of the NDTC's innovative blend of movement vocabulary. Nettleford, furthermore, has stressed:

The straightforward repertory of actual traditional dances is one thing. But the technical discoveries are strong in terms of the way Caribbean people move, whether in ritual, for recreation, or in reaction to everyday concerns; whether in jumping for joy, crawling with fear, writhing in pain, standing frozen in fear, or shimmying with anger. Very few of such locomotor responses are peculiarly "Black" or "Caribbean," but Caribbean people do express these emotions in body language that betrays a way of releasing energy and a vocabulary of "dance" that is distinctively different from that of other cultures (2002: 81).

Careful not to place a racial label on the NDTC's vocabulary, Nettleford avoids the politically laden concept of "black dance", yet insists on a culturally distinct style variation that emerges from Jamaica's unique historical background. ${ }^{56}$ In line with Victor Turner's anthropological concept of social drama the NDTC's cultural aesthetic thus appears to mirror the self-reflexivity of Jamaica's African Creole public performances (1990: 9-13; 1992).

According to Turner, social drama embodies the performers' "social ties, the power of their symbols, the effectiveness of their legal and moral controls" as well as "the sacredness and soundness of their religious traditions" (1990: 9-13). Dance and theatre thus present an "active or 'magic' mirror" of the society's social drama to the extent that it "influences not only the form but also the content of the stage drama" (1990: 9-13). Moreover, (dance)theatre serves as a "metacommentary,

56 "Black dance" historically referred to the legitimizing struggle for the acceptance of an Africanist aesthetic within US modern dance, which had been constructed as allegedly white. However, the controversy arises from the term's evocation of a racialized dance history that traditionally conceived of "white dance" as "light, ethereal, and refined," whereas "black performance" was connoted as "dark, brutal, exotic" (see DixonGottschild 2003; Fischer-Hornung/Goeller 2001; Myers 1988). Whether "black dance" is a useful category to describe a particular cultural impulse in Africanist dance, however, appears highly contested. In fact, as this study also seeks to demonstrate, it appears that most black performers today choreograph from highly complex sources, best described by the alternative paradigm of hybridity/creolization discourse. 
explicit or implicit, witting or unwitting, on the major social dramas of its social context (wars, revolutions, scandals, institutional changes)" (1990: 16-18). Applying Turner's model to the NDTC's stage adaptation of folk aesthetics and dance vocabulary, the latent impact of the folk forms' social drama so to speak is always present - even if only subtly so - and must be accounted for in order to achieve a culturally informed understanding of the complex meaning of Jamaica's unique dance heritage.

As has been shown in the previous chapters, Revival, Kumina, Etu and Dinki Mini steps, chants, music and rhythms embody kinaesthetic memory of a historically distinct background: the living testimony of African survival in Jamaica. This dimension of spiritually empowering presence informs not only the NDTC's folk choreography, but also each of the company's more abstract works. ${ }^{57}$ NDTC repertoire owes much of its originality and distinguishing style to this input of folk connoted dance movements. As dance scholar Susan Foster has pointed out, a performative aspect underlies each dance technique/school of dance training in so far as it develops/constructs the theatrical dancer as a particular "body-of-ideas," i.e. a map which creates a distinct "body topography" to evoke an idealized body image (1997: 238-239). Dance technique thus shapes the dancer's body according to the teacher's aesthetic/cultural sensibility. By focusing on the training of folk forms, the NDTC training has overtime established a "body topography," which stylistically distinguishes the company's original choreography from other modern dance works. As Foster also makes clear, technique "represents a given choreographer's or tradition's aesthetic vision of dance [...] to fashion an expressive self that, in its relation with the body performs the dance" (1997: 241). In this respect then, the NDTC's Caribbean movement vocabulary also articulates certain body parts in a rhythmical arrangement and fashion precisely to convey a unique expression of identity and self - thus presenting an inherently modernist concept. $^{58}$

The concept of "body topography," apart from its metaphorical implications, also applies quite literally to the NDTC's dance vocabulary.

57 For a detailed list of African Jamaican dance vocabulary compare Cheryl Ryman, "A-B-C of African Retentions in Jamaica: Dance," unpublished typescript (Kingston: African Caribbean Institute, 1978).

58 According to Foster modern dance historically "promoted the body's movement as material substance to be worked into art, [and] assumed an irrevocable connection to a self" (1997: 256). 
Commenting first on the expressiveness of life experience, Nettleford asserts the geographical impact as a second important source of the company's emerging style and technique:

Caribbean folk dances, particularly those still danced by an older generation, emphasize the body's center as if to celebrate life itself. These dances seem to recall a period when procreation and childbearing guaranteed men and women a sense of place and purpose. Building strength in the legs and feet is critical: strong feet and toes are needed for earth-centered movements, and sinewy calves will be resistant to the strains of marching and shuffling. Strong knees are requisite for attitudes of obeisance to the gods during ritual ceremonies, and strong thighs support a torso rippling horizontally while possessed of a particular spirit. The flexed foot is useful as symbol not only of hoe and pickax but also of resolution, strength, and earthiness. The arms, like other parts of the body, must be able to describe the curve of mountains, the flow of rivers, and the ebb and flow of oceans, just as in other traditions the movements of swans and the shapes of Gothic cathedrals, skyscrapers, and pine trees piercing the winter sky have found correspondences in dance attitudes (Nettleford 1985: 176-177).

In developing this Caribbean based dance vocabulary, modern dance offered itself for several reasons. Sondra Fraleigh, for example, in her phenomenological discussion of modern dance regards "freedom and individuality as the existential context of modern dance" (1987: xxiv). Throughout the form's historical development from an expressionist to a non-expressionist phase, modern dance has continuously elaborated on the notion of discovery.

Intrinsic to this approach is modern dance's "open (or free) aspect of method," which, Fraleigh claims, "resulted in many and widely varied styles" (1987: xxxii-xxxiii). Modern dance traditionally emphasized the spirit of inventiveness and change "through a questioning attitude and way of working, rather than assuming without question the already established models" (Fraleigh 1987: xxxiii). Fraleigh, furthermore, underlines the fact that dance in general, more than any other art form, "represents our expressive body-of-action and its aesthetic idealization". She insists that "dance draws upon both the personal and the universal body" with a tendency towards the latter. Dance thus testifies "to our bodily lived existence, our mutual grounding in nature, and our shared bodily acculturations" (1987: xvi). In this respect, modern dance simultaneously presents unique individuality and the universal human condition. As a result, Fraleigh considers it no accident that modern 
dance proved particularly "open to cross-cultural assimilation" and therefore occurs in various stylistic adaptations throughout the world (1987: 87).

While this is admittedly so, I would, however, stress that these creative transformations of modern dance vocabulary in the postcolonial Caribbean, amount in fact to much more than a mere assimilation. I rather suggest that what quite co-incidentally interconnects the two, are several striking parallels between modern and traditional dance forms. When modern dancers sought for a unification of the lived and staged experience of their assumed reality, African festival forms had never known a strict separation of these spheres to begin with. Within the African cosmos of dance, bodily presence is experienced as a lived totality of different epistemological levels. The dancing body thus encompasses the individual, ancestral spirits as well as a variety of deities. Phenomenologically speaking though, dance has always been described as an inherently spiritual act, which not only in religious folk ritual context, but even in secular formats may lead towards self-dissolution in terms of a liminal transition, i.e. the felt/experienced unity between a body-subject and body-object status. The more focused a dancer becomes in his/her movement, he/she will achieve what Fraleigh refers to as "present centeredness," i.e. a sense of unification of the danced action and presented image (1987: 41-42). The religious implication of Caribbean folk dancing thus parallels to some extent the notion of a mystical union prevalent in early German and U.S. based modern dance. Likely, this feature presents one common aspect of dance theatre's worldwide claim to universality.

Drawing on dance as "a fundamental (if not the fundamental) aesthetic vehicle for expressing personal and collective inner worlds" the Graham school of modern dance philosophically paralleled the function of dance to that of religion. Accordingly, religion and dance both offered "concrete form to the unseeable spirit of mankind, the hidden essence of human life" (Helpern 1994: 4). The dancer's body was conceived of as the prime instrument to convey inner expression. Starting from this fundamental position, modern dance developed ever new modes of training to deliver that particular self-embodying/revealing statement on stage. As Louis Horst has described modern dance's beginning efforts in the primitivist terms of his time:

The pioneers in modern dance and their successors recaptured the relation that the primitive has to his body - an intimacy with the muscle tensions of 
daily movements which had been lost to modern men. This is not at all the ballet dancer's awareness of line, of speed or balance, and dramatic portrayal of a role. It is, rather, an inner sensitivity to every one of the body's parts, to the power of its whole, and to the space in which it carves designs. The great quest was to find ways to attain this sensitivity, and manners in which to discipline it for communication (Horst/Russell 1977: 19).

Adhering to a Jungian concept of collective unconscious and primordial archetype, modern primitivism's quest for "ancestral footsteps," however, touched American Indian or African dance aesthetic - if at all - only on the surface. Rather, Graham's "inner landscapes" appeared to offer an interpretation of those 'primitive' forms in terms of a liberation from U.S. culture's repressive, guilt-ridden Judeo-Christian/Puritan upbringing. By seeking the "truth of movement" in somebody else's footsteps - whether Amerindian, Asian or African - Graham embodied in fact more of the West's long lost yearning for origin than that sought after notion of an ancestral, i.e. continuously lived cosmological connection. ${ }^{59}$ Alas, she, too, fell into the trap of a probably well meant, yet still somewhat patronizing Orientalism.

According to Horst, modern dance relied on primitivism primarily as a "background source" for dance study and creative inspiration. Graham-inspired modern dancers thus conceived of "primitive culture" in terms of an exoticist mysticism rather than truly acknowledging its highly complex dance vocabulary. Modern dance study of "earth primitive," for example, was described in quite derogatory terms. As the following excerpt demonstrates:

For an Earth Primitive study, movement can be experimented with which will suggest the mysterious powers that abide in the earth. Such a dance study invokes the mood and creates the texture of the primitive in his relation to the world beneath him. The dancer is alertly sensitive to the feel of the

59 Wole Soyinka comments on the racist implications and faulty designation in Jungian thought. Rather than to frame primitive thinking within the parameters of Darwinian evolution and Freudian psychoanalysis, Soyinka argues that one needs to acknowledge the Western lack of appropriate vocabulary. He claims: "What we call the mythic inner world is both the psychic sub-structure and temporal subsidence, the cumulative history and empirical observations of the community. It is nonetheless pri$\mathrm{mal}$ in that time, in its cyclic reality, is fundamental to it. The inner world is not static, being constantly enriched by the moral and historic experience of man" (1976: 35). 
earth under his feet. It is the genesis and grave of all living things - areas and oriented to the floor. They can be clumsy and animalistic. They can be brutal and threatening. They can project the lyricism of wonder, or the tenderness of the giver of life. They may have a drum-like percussiveness. But always they are simple and meagerly articulated; lean and taut (Horst/Russell 1977: 6263).

While this Western misconception engendered quite astonishing dance works of considerable artistic merit, one should never forget though that these North American choreographers actually told their audience more about the social strata which they came from, i.e. in the majority white Anglo-Saxon, than the cultures, which actually inspired their new modern movement discoveries.

Africanist cosmology and aesthetics, by contrast, do not separate between worlds as much as Western based traditions tend to do. The overall conceptualization is rather one of integration. As Green points out: "African dance is the integrated art of movement that is controlled by her music which is governed by her languages" (1996: 13). Therefore, African dance presents "a source of communication through which it is possible to demonstrate emotion, sentiment, beliefs and other reactions through movement," all of which appear to clearly assume the function of social drama in Victor Turner's sense. Among the decisive elements of the African dance vocabulary Green lists jumps, body segmentation and pelvic contractions, all of which can easily be found in the NDTC folk-based repertoire (1996: 15). So, as has been shown before, African-derived movements were indeed evoking already existing echoes in the bodily memory of the descendants of former slaves rather than expressing an auto-exoticist fantasy.

Notwithstanding the common lineage between traditional African and Caribbean dance forms, the new world dances of the African diaspora form an altogether different canon. As P. Sterling Stuckey points out, a "new history of dance" had inevitably emerged from the violent rupture of slavery (1995: 51). Jamaican dance theatre aesthetic may therefore structurally recall the group dances of Ghana and Nigeria, as both tend to perform preferably in "lines or circles, with the circle being more prominent in recreation dances and the line formation prominent in war dances" (Green 1996: 18-19). And yet, African and Caribbean dance forms share, genealogically speaking, the same ancestral perspective. Encompassing the omnipresent spirit force, which interconnects the living, unborn and dead, African and Caribbean dance forms 
function as "a way of life, a source of communication, and history reenacted through movement" (Green 1996: 26). African and Caribbean dance forms thus share the holistic approach towards a dance/life unit, which parallels a similar vein in modernist primitivism at least to some extent. Yet, examining this affinity more closely, one will find that each cultural tradition expresses its own particular (hi)story quite independently.

Shifting the analytic paradigm from "dancing bodies" to "bodies in movement," J. Lowell Lewis' anthropological analysis of embodied movement practices has furthermore remarked that "genres or types of human activity are more culturally diverse than human bodies (however construed) themselves are" (1995: 226). The argument puts forward "the question of how body movements are patterned, formed, and divided in different cultural worlds"(1995: 226). Lewis thus raises the issue of style and particular cultural aesthetic. As differently framed cultural spheres do not appear mutually exclusive, they often times share "deep iconic patterns or schemata that inform many social domains and therefore are central to the recognizable, distinctive, stylistic unities of given cultural systems" (1995: 227).

In the context of this study, Africa appears as the Caribbean's major aesthetic reference point for such shared iconicity. Therefore it will be useful to take a brief look at the African art historical background for a better understanding of the iconic transfer between the two cultural regions. With the aim of crystallizing an African-based aesthetic, Robert Farris Thompson in his seminal work African Art in Motion. Icon and Art (1974) was among the first scholars to investigate the integrative aspect of African arts. His analysis places dance as one element among many which taken together form what he refers to as "worlds of artistic happening" (Thompson 1974: xii). At stake is not merely a different emphasis, but rather a different conceptualization. "Danced art" thus intertwines different aspects from sculpture, crafts, music and dance by reinforcing their mutual impact on the aesthetic perception of the art work in time and space. Transcending the European genre confinement, African art can therefore hardly be grasped by such separation. In order to correctly address the complexity of such totalization, Thompson therefore suggests to "start with the shared norms of performance" before one actually begins to decode the meaning of any given element (dance, sculpture, music, chants, etc.) in singular (1974: xii). 
Looking, for example, at African sculpture, Thompson remarks that one will encounter a focus on forms of arrested movement rather than an excessive interest in anatomical accuracy. Parallels between sculpted body posture and choreographed dance movement can easily be identified, as in "the relation between the bent knees of the black dance and the identical expression of flexibility in the corpus of black sculpture." (Thompson 1974: 5). Among the "criteria of fine form" in African art, Thompson also lists "ephebism," i.e. the "bending quality" of a youthful vitality in sculptural stance and dancing, as well as the concept of "balance," which defines the peaceful interrelationship of human beings in almost ethical terms. Thompson defines African aesthetic as a "mediating force," which balances "identity through the merger with a larger social whole" (1974: 27). As opposed to Western representations of individualism, African dance focuses on the integrative power of the circle, the "generalization of humanity in the dancing ring" (Thompson 1974: 27). The typical call-and-response pattern, for example, mirrors this social unity in its formal aspect. Moreover, Thompson points out that plastic art and motion are intertwined to the extent that "phrasing the body transform[s] the person into art, make[s] his body a metaphor of ethics and aliveness, and, ultimately, relate him to the gods" (1974: xiv).

Kariamu Welsh-Asante describes such deep respect for the transcendent in terms of an inherent dimensionality within the African aesthetic. Following Thompson's basic outline Welsh-Asante distinguishes seven shared "senses" that stylistically link the new world's African diaspora to the continent. They include: 1. polyrhythms, 2. polycentrism ("It is this multiple existence of polysenses that is the African's signature in dance. The representation of the cosmos in the body is a goal."), 3. curvilinear ("The structure is always related to experience, message, theme and feeling."), 4. dimensional ("The dimensional aspiration speaks to the supernatural in space, the presence beyond the visual presence."), 5. epic memory, 6. repetition, 7. holism (2001: 144-151). Joseph M. Murphy (1994) has furthermore defined "working the spirit" as the central commonality of Caribbean religious practice. In his analysis of Haitian Vodou, Brazilian Candomblé, Cuban Santería, Jamaican Revival Zion and U.S. Black Churches, he stresses, for example, that "ceremonial spirituality" equals "community service" in the sense that the spirit is worked not only to praise but also to empower the practitioner (1994: 7). This notion of "service" and commitment to the community, I would like to recall, is also at the heart of the NDTC's 
voluntary engagement. As Rex Nettleford suggests, embodied spirituality may even serve as a means of "safe transit" into the rather disquieting environment of the $21^{\text {st }}$ century, when he claims:

[...] modern man's need for safe spiritual transit at end-of-century is leading to a search for modalities to reconnect much that have fallen apart. One may find some clues in the ever-present element of unity in African dance [...]. There is unity in the juxtaposition of the secular to the religious, of sacrifice to play, of ritual (in the sense of structured procedures), to improvisation, of the obligatory to the novel, of the naturalistic to the abstract, of tragedy to comedy and sadness to laughter, of this world to "other worlds," of man to woman (virile men dance the roles of women in masquerade without fear of their sexual credentials ever being dragged into suspicion), of ancestral/traditional to modern/contemporary. Adaptations abound (1996: xviii)

The Caribbean dance aesthetic is consequently based on the culturally diverse texture of its people and is as much modern as it is ancestral. Coming back to Fraleigh's idea of the expressed/experienced combination of individual input and shared universality in movement, Caribbean dance hence embodies a nucleus of diversity, which can indeed hold claim to universality. As Nettleford suggests:

For Dance, I feel, remains the most eloquently non-partisan of the theatre artforms. It stretches across the boundaries of race, customs and politics and religion, linking peoples of the world through a common idea rooted in the sheer power of movement. [...] The world then is our source in a very real sense and the dance can do as much as bring to Jamaica and the Caribbean something of the outside world as it certainly can take Jamaica and the Caribbean to the outside world (1968: 130).

How this cross-cultural communication of Caribbean identity has found its way through a postcolonial appropriation of modern dance will be analyzed in the following reading of the NDTC's modern Caribbean dance theatre repertoire. 


\section{Rex Nettleford's Aesthetic of Caribbean Dance Theatre}

\section{Ritual of the Sunrise}

There is a force of exultation, a celebration of luck, when a writer (read "an artist") finds himself (herself), witness to the early morning of culture that is defining itself, branch by branch, leaf by leaf, in the self-defining dawn, which is why, especially at end of the sea, it is good to make a ritual of the sunrise. The noun of the Antilles, ripples like brightening water, and the sound of leaves, palm fronds, and birds are the sounds of a fresh dialect, the native tongue... ${ }^{60}$

Presenting a signature choreography of Rex Nettleford's more abstract Caribbean dance theatre works, I propose a reading of Ritual of the Sunrise in this section which regards the choreography in the context of Fraleigh's notion of "discovery" in modern dance. As I have outlined her argument in the previous chapter, discovery is understood not only in terms of developing a vocabulary, but also in terms of introducing a stylistic prototype, which Sheila Barnett, former NDTC choreographer, has referred to as the Jamaican "Festival Style," i.e. a composition of creative modern variations on the folk-based dance material.

Ritual of the Sunrise divides into four sections: 1. "Sunset-Prologue lone voice walling hope," 2. "Discovery sequence- shaping of vocabulary," 3. "Self-defining sequence (dawn)" and 4. "Ritual-Jouvert, High Mass-Sunrise." 61 Introduced by a hymnal tone and the solemn voice of a choir singer (Veronica, Noiet de Temporal, Sal Negro), the scene opens on a tableau set of eight female dancers. Crouched onto the floor as if to evoke small packages, their bodies appear as mere shadow silhouettes. The spectator can only distinguish several dark spots - reminiscent of shells maybe - on the blue lit stage. Then, the dancers slowly rise to their knees and lift their arms in a reverential akimbo gesture. They take a brief break before the signal of a single drum beat incites them to instantly crouch back down to the floor, from where the group changes position into a flat back extension.

60 This quote by Derek Walcott reads as epigraph to the choreography. Compare "In Celebration of Diversity. The National Dance Theatre Company of Jamaica UK Tour 2001," NDTC Tour Program.

61 Compare "In Celebration of Diversity. The National Dance Theatre Company of Jamaica UK Tour 2001," NDTC Tour Program. The following analysis is based on live-performance and rehearsal as well as video-tape support. 
The following sequence leads the female dancers through a variation of several sculptured positions: from statuesque kneeling, to sitting and bottom turns, as well as standing upright with bends to both sides, turns and smaller units of retreat and advance in which, for example, the dancers move forward in unison with arms lifted and the torso subtly rippling back and forth in a devotional gesture of piety. Throughout the scene, a yellow light beam slowly increases in intensity so that it illuminates more of the dancers' white dresses. Also, the dancers keep moving in unison: two rows of three and a pair of two, which several times changes in arrangement from back to front. The scene ends with all of the dancers in flat back extension back on the floor.

Reflecting on the choreography's title and epigraph, the first sequence indeed creates the impression of early morning sun beams breaking through the clouds, if you will. Music, costume, lighting and movements in ensemble suggest iconic postures and gestures of worship, as well as the notion of constant flow as a subtle wave movement projects its kinaesthetic energy through the dancers' bodies into the theatre space.

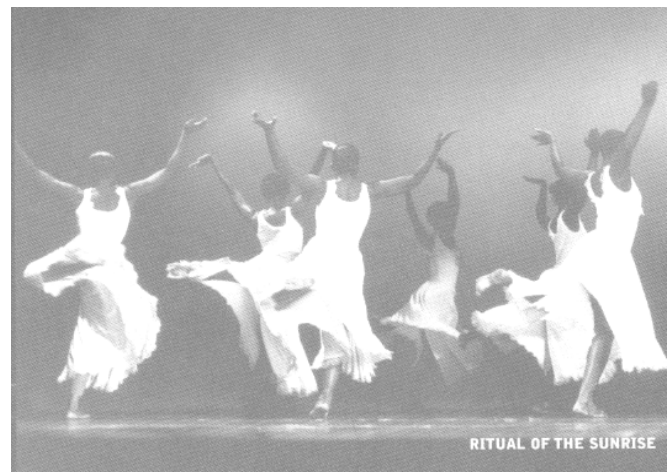

The National Dance Theatre Company of Jamaica in "Discovery Sequence" from Rex Nettleford's Ritual of the Sunrise (rpt. in: NDTC 40 th Anniversary Program).

In a first assessment, this floor-based composition certainly appeals to a correlation with the archaic impulse in modern dance. As Horst has described this idea:

The archaic period growing very gradually out of the primitive, gives birth to something new - aesthetic consciousness. The tribal artisan or dancer who pe- 
titioned the gods in primitive ritual becomes the artist breaking through the ritual, conscious of formal beauty for the first time. He is completely absorbed in the newly discovered aesthetic ideal, and this absorption makes for an intensity and awareness of detail, of color, line, texture and design. A creative passion supersedes his emotion as a mere worshipper. The craftsman who fashioned forms for service evolves into the artist who creates them because they are beautiful (Horst/Russell 1977: 69).

Horst's evolutionist model is of course highly problematic. However, leaving his modernist bias aside for the moment, one could still argue that the ritualistic "archaism" of Ritual of the Sunrise's opening sequence consists in the stylized abstraction of movement, color and music, which in totality create not only an archaic, but also ritualistic overtone, of which angelic, sea spume, purity, dress code of Vodou worshippers are but a few possible connotations to interpret. More importantly even the thematic correspondence: for archaism within modern dance, as Horst explains, is connected to the notion of giving birth and the direct expression of the creating human spirit.

Aesthetic consciousness as opposed to allegedly 'intuited' worship represents thus the transition from the ritualistic to the aesthetic phase in terms of the primitivist/evolutionary discourse. No longer a worshipper of gods, modern man thus becomes "the craftsman" to create in his own image. Adhering to similar formal principles yet deriving from an Africanist perspective of creation, Nettleford comments on such similarity between both forms:

The emphasis on weight in the negotiation and shaping of many a movement-pattern finds kindred association with the fall-recovery, tensionrelaxation complexes of some schools of American modern dance, as does the contraction-release complex, usually identified as a Martha Graham invention, but organic to all African dance, which predates American modern dance by a few centuries. Movement is moulded more often than attenuated. It is as though the material being worked on is clay rather than steel. Arms flow like rivers and torsos undulate like the outlines of rolling hills or the ebb-flow of the surrounding sea. These are technical foundations in the preparation of the body as the instrument of dance expression (2002: 88).

So while both approaches are modern in the sense that they assess movement in terms of developing a secular technique of artistic expression rather than to portray embodied ancestralism, the approach varies in that American modern exploits/appropriates a somewhat orientalist 
fantasy, whereas Caribbean modern develops an aesthetic, which is kinaesthetically recollected. In terms of "discovery" the opening sequence of Ritual of the Sunrise thus speaks of the Caribbean's aesthetic awakening in modern terms: "the early morning of culture that is defining itself" on the base of the Caribbean's unique cultural heritage as it is expressed in the Walcott epigraph.

Taken as inspirational source, Derek Walcott's poetics lend themselves to an interpretative reading of Ritual of the Sunrise, because as a Caribbean writer, he, too, is concerned with the discovery and definition of a self-expressive vocabulary. For Walcott, the Caribbean does not strictly speaking have a history in terms of an artistic canon or aesthetic, that is at least from the perspective of a Western dominated teleology of empire. Rather Walcott conceives of history as "the Medusa of the New World:" a complex entanglement of cultural amnesia and loss (1974: 4; 6-7). According to his literary philosophy, however, this should be neither considered a source for constant mourning nor for "jaded cynicism which sees nothing new under the sun" (1974: 3). On the contrary, Walcott's "truly tough aesthetic of the New World neither explains nor forgives history," but asks for "an elation which sees everything as renewed" and claims the freedom for "the re-creation of the entire order, from religion to the simplest domestic rituals" (1974: 5).

The loss of cultural memory is thus redeemed by the appreciation of the here and now in terms of creative "rebirth" and "cunning assimilation" (1974: 7). Much of that sensibility Walcott finds represented in the image of the sea. As he explained:

When somebody asks you where is your history or where is your culture, or what have you done, the question comes from a presumption of people who believe that history represents achievement [...] History is only an aspect of the kind of territory, one of the territories that they dominate. So if someone asks me, as a Caribbean person: 'Where is your history?' I would say: 'It is out there, in that cloud, that sky, the water moving.' And, if the questioner says: 'There's nothing there,' I would say: 'Well, that's what I think history is. There's nothing there.' The sea is history (1996: 24).

What the Caribbean artist thus shares with "modern man" in the West, is the same sort of "displaced, searching psyche" with a tendency to concentrate on the presentness of experience rather than opting for insecure transcendentals (Walcott 1974: 24). In that respect, the "sea of 
history" and the dance suffer from the same sort of a-historicity, for the dance, too, only exists in radical presence.

As Maxine Sheets-Johnstone has explained, dance is "truly ekstatic" in the sense that it defies fixation at any given moment (1980: 22). Dance only takes place in creation, which makes it so extremely difficult to trace. Similar to the image of the eternal sea then, dance evades ideological rigidity. Whether in terms of a cliché portrayal or objectified existence, one can never fully take hold of a dance's meaning/identity, for as a "form-in-the making" dance is already evanescing the moment one starts to contemplate. ${ }^{62}$ So in that sense, dance not only embodies a radical presentness, but a radical annunciation of freedom, too. However, in terms of the Caribbean sensibility this freedom should not be misnamed a bleak existentialism, for the outlook is rather optimistic. As Walcott concludes:

The Caribbean sensibility is not marinated in the past. It is not exhausted. It is new. But it is its complexity, not its historically explained simplicity, which is new. Its traces of melancholy are the chemical survivals of the blood which remain after the slave's and the indentured worker's convalescence. It will survive the malaria of nostalgia and the delirium of revenge just as it survived its self-contempt (1974: 18).

In analogy, the NDTC's Caribbean dance vocabulary also emerges from such "chemical survivals," which celebrate the discovery of being alive and creative despite the historical hardships.

Coming back to Ritual of the Sunrise, the new day dawn - evoked by the slowly brightening light beam throughout the opening sequence symbolizes precisely "the ritual of the sunrise," when the dancers rise from the blue lit darkness of an imaginary sea towards the symbolical sun. "Walling hope," as the sequence is entitled, the dancers' bodily recovery from the annihilating flood so to speak leads them straight into the sun beam of a next morning, tellingly entitled: "Discovery sequence - shaping of vocabulary." The transition between the two dance episodes is indicated by the entrance of the male dancers, who are also dressed in a somewhat more extravagant white costume (one leg bare, the other in white leotard and a frilled sash as surrogate shirt) and in-

62 Sheets-Johnstone defines: "Since movement is never complete at any one instant or point, never fully there, consciousness exists its body in movement as a form continuously projecting itself toward a spatial-temporal future; hence, as a form-in-the-making" (1980: 36). 
troduce more announced body ripples and Yanvalou steps, derived from Haitian vodou worship. ${ }^{63}$ As one of the Haitian ritual's most common dances Henry Frank characterizes Yanvalou as follows:

The Yanvalou is a dance of supplication in honor of Agwe, the deity of the sea and Damballah, the snake god of fertility. In the execution of this dance the worshippers try to mime the undulating movements of the snake and the waves of the sea by moving gracefully, forward and back, their shoulders and the upper part of the body. The participants are often dressed in white during ceremonies honoring Agwe and Damballah. There are two types of Yanvalou: Yanvalou Doba (back bending) where the dancers bend forward and the Yanvalou Debout (straigth) where the dancers perform upright. The latter is in honor of all the deities of the Rada rite (2002: 111).

Introducing the Yanvalou at this point interconnects the image of the sea with that of fertility and by opening that dimension of a spiritually informed movement pattern, the sequence seems to suggest ritualistic worship as the prime nutrient of Caribbean dance vocabulary. Drawing from that source, the scene metaphorically recalls the invocation of the ancestral spirit force as the guiding principle of Caribbean dance movement.

From this rather solemn beginning, which indeed may be characterized as a certain melancholy over a loss of origin, the third part "Selfdefining sequence (dawn)" playfully engages with the exotic image of the Caribbean tourist resort: the female dancers enter first in costumes adorned with ornamental flower bouquets, worn as corolla, and colorful skirts of layered fabrics in green, blue and pink variations. Next enter two of the male dancers in fancy bird costume, wearing a single feather, as well as glitter and gold. Such a splendid panorama easily suggests the island's tropical flora and fauna - the paradise, which people especially from colder climates would certainly expect to see from a Caribbean National Dance Theatre Company. Accompanied by

63 Burroughs describes the adaptation of the ritual dance movements by non-Haitian dance theatre practitioners as follows: "It is commonly held among non-Haitians that the rhythmic structure of Yanvalou is $6 / 8$ time, and that the most basic elements of the dance occur with the execution of three steps. They are best described as step-together-step although when they are notated according to the rhythmic structure of Yanvalou, there are pauses between some of the steps. As these movements are executed by the feet a simultaneous undulation of the torso that seems to emanate from the pelvic region occurs" (1995: 9). 
the obligatory steelband and flute music, the glamorous display is enhanced by refined lighting which wins over its audience as it pays tribute to the well known Carnival and Jonkonnu tradition. Yet, as has been mentioned before, the simplistic exoticism of the scenery may be misleading. For example, in the beginning of this section three male dancers enter in a powerful twirl, which sets their red cloth costume ablaze. Slightly bedazzling in apparition, the movement adapts the ancestral power behind African masquerade forms. In Yoruba Egungun, for example, red cloth, represents protection against disease (Thompson 1974: 219). Similarly, the harmless appearing bird costumes of the two following dancers pay tribute to African animal masks, while being of course a very real element of Jamaican geography. Clearly though, with the time and local detachment in mind, those references to African ancestralism remain at best a subtle hint.

Collaborating with choreographer Nettleford on the costume design for his works, NDTC chief costume designer Arlene Richards usually attends rehearsals as she seeks to grasp the idea behind the dance, which she will then try to bring out in the costume. Commenting on that process for Ritual of the Sunrise, she explained:

Ritual of the Sunrise [...] that's all about the birthing of a culture, the maturing of a culture and so different aspects of the dance represent different stages of development. The very opening is the birth and the dawning and so forth. And usually that is in the spiritual sense, so I chose white to represent that. [...] but then, when a culture really begins to unfold, then all the varying colors, colors of personality of the people all those things begin to unfold. So I just use nature as inspiration [...] But first, I remember speaking to professor, and I'm saying to him, 'This is called Ritual of the Sunrise, but where is the sun?' And the sun influences so much and it's life and it's energy and it's the source, so I wanted something to represent the sun in there. So I did these things with all the rays when the guys come in with the gold [...] and then out of that come all the varying colors [...] and then came the birds, and he really was working on a theme with birds, because he had the peacocks in there. And so I just used exactly where he was going to just develop it further. ${ }^{64}$

So for Richards the red costume actually represents "bursting sunrays" rather than the ancestral mask which I found the costume alluding to. What this shows then, is that such costumes and masks have by now so fully adapted to the changed environment that today they bear witness

64 Interview Arlene Richards 23 Aug. 2003. 
to new forms of self-expression. However, what has become paradigmatic of the Caribbean carnival spirit and is expressed in the abstract medley of modern dance forms, Dinki Mini steps, Kumina turns and Yanvalou struts, can in terms of the Caribbean aesthetic - to quote Walcott once more - be defined as follows:

A race in exile and slavery loses its language quickly, since it is not in a position to communicate or to make itself understood, but has to understand orders. But it preserves, both for a communal identity and for defiance, its ancestral rhythms. Banishment may have increased rather than lessened the fierceness of some of those dances [...]What is there to celebrate, since even joy has its springs? The answer is that he is celebrating a man's right to be happy and free while he is alive; his right to become what he wants, to do what he wants, [...] He asserts that this is possible: in fact, that it is necessary. It is a tribal ritual now that, like all tribal cycles, especially those based on single crops, as ours once was on cane, buries and resurrects its kings and queens and then dances in votive frenzy (1965: 4).

As "ritual[s] of appearance" Jamaican dance theatre and Carnival thus share the same "sense of joy," since celebratory elation is at the heart of both art forms.

Celebration has of course generally been claimed as the "universal impulse" of dance throughout the world, since dance embodies identity as an "indivisible physical and spiritual whole" and thus cherishes the joys and sorrows of life (Fraleigh 1980: xvii). In the experiential totality of body/mind movement, dance may even transcend the confinements of present time and space. While this fundamental truth of dance practice applies to dancers all over the world, it has of course become particularly prominent in the Caribbean, where African cultural identity was largely maintained in social and religious dance festival forms. Caribbean dance celebrates cultural survival and freedom of expression, for which not only NDTC dancers, but also their lucky audiences have every reason to "Give Praise" - as announced in the lyrics of the song, which fittingly accompanies the choreography's final section "Ritual-Jouvert, High Mass-Sunrise."

Ritual of the Sunrise thus ends with a sequence of progressing line formations and circular patterns, which recall structural elements from Revival, Dinki Mini, and Kumina, while accompanied by David Rudder's 'High Mas' music score to underline the NDTC's Trinidad con- 
nection. ${ }^{65}$ With over twenty company members on stage, the reappearance of entering and exiting dancers creates a mosaic pattern which resembles the topography of ebb and flow of the Caribbean seaside as well as that of the islands' soft mountain curves. In fact, as the epigraph from one of Derek Walcott's poems suggests, the Caribbean's luscious geography appears a source of inspiration for voiced poetry as much as danced movement: not only the noun, but the body, too, "ripples like brightening water, and the sound of leaves, palm fronds, and birds." The traumatic image of the sea - historically representing the loss of the Middle Passage - may thus turn into a lastly redemptive one: waters to wipe clean the muddy sands, leaving behind an untrodden beach, blank for new beginnings.

\section{Cave's End}

Journey of a lifetime

A light at the end of the tunnel

Always...66

As has been shown, the Caribbean genesis is a prevalent motif of Nettleford's choreography, which informs many of his epic dance compositions. From Plantation Revelry to Ritual of the Sunrise and the more recent $40^{\text {th }}$ anniversary Cave's End, the Caribbean topos of an evolving Creole nation appears as the driving force of the choreographer's imagination. ${ }^{67}$ Paying tribute to Jamaican musical icon Jimmy Cliff and his vision of "dread," i.e. "hope in despair," the selections from Cliff's Journey of a Lifetime form the musical score and central theme of Cave's End. Similar to Ritual of the Sunrise, this choreography, too, evolves from the evolutionary image of a metaphorical journey from darkness towards light. While Ritual of the Sunrise was carried by an overall lyrical impulse, expressive of a particular aesthetic sensibility, Cave's End allows at least in some sequences for more of a socialrealist reading in terms of danced comment on contemporary Jamaican society forty years after independence.

Cave's End starts with a "Prologue," which introduces the Haitian Ibo step to the rhythm of South African traditional music (Ulwamkelo

65 Compare NDTC 40th Anniversary Program 2002.

66 Epigraph to Cave's End, NDTC 40th Anniversary Program 2002.

67 Another important work on the same vein is Nettleford's The Crossing, which is a dance theatre composition on the Middle Passage. 
Iweirokneli). ${ }^{68}$ The scene opens on a group of dancers, who stand in the upstage left corner, assembled in a tight cluster which is arranged according to sex (female dancers in front, men in the back) and height. As the music begins, the blue lit stage is illumined by a single light spot from the left side, which irradiates the dancers' body contour and thus rears the impression of a mosaic of differently shaped individuals. Dressed in rainbow-colored unitards all dancers start executing the same basic step: a ribcage shift with arms akimbo and a quick flat to demi-pointe rise of the foot with simultaneously bent knees switching to both sides in demi-plié. On top of this basic movement one dancer after the other raises an arm and finally spreads out the fingers of the raised hand as if to make a statement of 'hello, here I am.' To top the sequence off, all of the dancers roll their upper bodies half-circle backwards in a hyper-extension or alternatively the group in ensemble shifts in a body wave to the left.

Next, all of the dancers move forward in unison, isolating the torso and changing direction after every two steps so that eventually the group will have come full circle by turning to side, back, side and front. This formation is repeated two times. As the music switches from the percussive opening into a more melodic tune, the male dancers separate from the group as they perform balletic turns in two pairs, progressing forward from both sides of the group which itself remains in place. The multi-armed and legged body of the beginning thus disperses into singular bodies performing individually. As the music has switched from percussive into melodic tune, the movement, too, has adapted from the folk-based Ibo step and torso ripple to modern balletic idiom. This alternating pattern is maintained for the rest of the sequence, which, however, does not strictly adhere to that first introduced correspondence of music and movement. In fact, one can also find modern movements accompanied by percussive instrumentation later on. Yet, both styles form part of the Caribbean tradition and that is

68 Rex Nettleford, "Jamaican Dance Theatre - Celebrating the Caribbean Heritage," lecture presented at the Jamaica School of Dance, Summer Workshop, 10 July 2003. See also NDTC Fortieth Anniversary Program 2002, where Rex Nettleford lists South Africa "from the days of apartheid to contemporary life in freedom" to the "various 'connections' [which] are significant in the NDTC's nurturing and development since 1962." The following analysis is based on live-performance, rehearsal and video-tape support. 
what should be expressed here. As Nettleford has defined the Caribbean aesthetic elsewhere:

Europe's melody here seems to have found new challenges from Africa's rhythm, creating vibrations - unprecedented and, to some, awesome. Sometimes the drum tones are deep, steady and haunting. At times they take on a rapid, breathless, frantic sequence of seemingly unstructured polyrhythms. At other times it is that dry, sustained and high-pitched sound called 'ciye' by the Haitian voodoo drummers, as if coming from choruses of castrati deprived of their manhood in the wake of bondage. The operative words here are 'as if'. For the realities of the situation point to possibilities of a cultural fusion rich and cohesive in its diversity (2001: 210).

By choosing a South African musical composition - which precisely matches the above mentioned syncretism - Nettleford's "Prologue \& Invocation" section of Cave's End reinforces his persistently announced artistic vision in terms of forming Jamaica's National Dance Theatre Company over the decades. In fact, what is expressed in the blending of "Europe" and "Africa" is not only an aesthetic solely confined to the Caribbean, but one that shares echoes with postcolonial societies and their liberation struggles all over the world. The "Journey" in terms of an ongoing quest for self-definition therefore continues, of which the solo dance of the second part gives an ardent demonstration.

The transition is marked by a black out during which the audience listens to a traditional drum insert accompanied by the following voiceover as the stage light slowly goes up again: "Out of the darkness came forth light/all life begins in darkness/and we're all moving towards the light/so stop with me on this journey of a lifetime." Led by two dancers in expressionist modern dance vocabulary, the sequence introduces the dance's guiding principle, which ballet mistress Arlene Richards, has assessed for her performance of the part as such:

What the dance is really saying is that we are all on a journey. And it's a journey of a lifetime it really says. It speaks about this hope, but it is also speaking about moving into what I would call a level of consciousness, that you are moving towards the light. So you're coming out of darkness and you're moving towards the light. And you can apply this for all American societies where you move into the light and so for me, yes, it is a journey of moving towards this consciousness and that's how I approached the work. And you know it's funny that you say that, because it has now become even more important for me personally in life this kind of a statement where you move to- 
wards a consciousness and a consciousness not necessarily anything religious, but just in terms of how we as a person approach our relationships with people and whether art allows us an enlightened position you know, which is really a position of love and peace and harmony. And that is how I see that figure moving towards a greater end, where there is that kind of freedom of expression. ${ }^{69}$

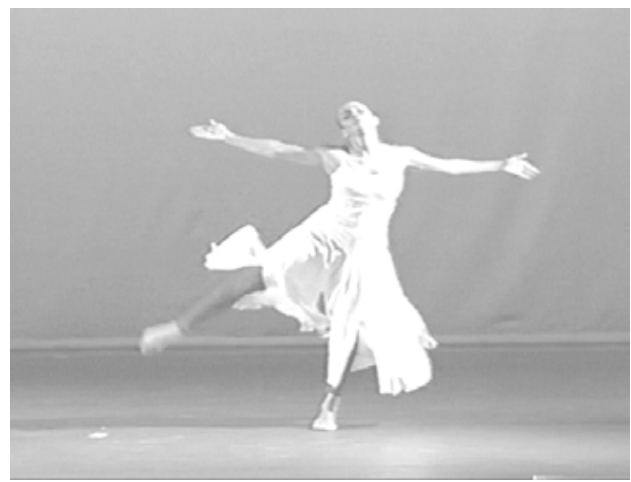

Arlene Richards in "The Journey" from Rex Nettleford's Cave's End, 2003. Video Still.

In performance the floor oriented solo - during which the dancer struggles her way upwards in relevé, turns and outreaching arm movements - conveys much of that rather personal statement of a move towards (self)consciousness. This rather abstract notion seems to be embodied also by the presence of three female dancers, who, for several times during that sequence, enter and exit upstage parallel as well as they cross diagonally. Forming a sort of background composition to the solo performance, they appear as the dancer's three muses, who in their dresses of softly tinged, rainbow-colored rays symbolically allude to the spiritually enlightening force; especially towards the end, when the blue lit backdrop changes color from orange into deep red. What is interesting to observe in Richards' modern dance interpretation here, is an earthbound elucidation, which actually never quite takes her off the floor. Despite the harmonic melody, one is thus never completely lulled into the airy lyricism, but strangely aware of the dancer's inner struggle and work. This "journey" - so the dance seems to say is not always an easy one, but very well worth the trouble.

69 Interview Arlene Richards 23 Aug. 2003. 
Accordingly, the "Street Vibes" episode presents - in a slightly selfironic mode of expression - typical macho postures danced in a rather vigorous jazz idiom: bouncy walks with rotating shoulder and arm work, kicks and jumps to display self-assertive manhood, likewise shared between the six gang members in street-wear and the two policemen in black uniform on stage. The "street-fight" thus carries a rather humorous tone, which appears quite in contrast to the violent reality of gunmen roaming Jamaican streets. While the police is usually conceived of as the enemy and in Rastafari terms part of the system of Babylon, the choreography presents them mockingly as a part of the people awfully in need to be re-integrated. Presenting a powerful crossfertilization of Caribbean and U.S. American street dance aesthetics, the sequence indulges in the cliche idealization of the "tough" and the "cool" image of male/macho-prowess, typical of those gang communities. What Nettleford refers to as "male indulgences" though has a rather negative flip-side, namely that it makes women the "burden bearers" - confining them to a social role they do not really want to represent.

Thus, the second episode - "Revival" - addresses women's quest for liberation in an abstraction of the Jamaican Revival folk idiom. Dressed in the already familiar costumes of the three spiritual muses of the "Journey" part, the dance builds on the prevalence of Revival rhythms in Cliff's music. Forming a continuum of the dance-music unit in Jamaican popular culture, not only dance choreography, but Jamaican popular music from Reggae, Ska to contemporary Dancehall, too, are all greatly influenced by the folk rhythms generally and Jamaica's Revival church in particular. "I am not here to be a burden bearer," as Cliff's lyrics proudly proclaim, therefore recalls the continuity of the sufferer in Jamaican society and his/her proud claim to better Jamaican living conditions. As has been shown before: Revival has played an enormously important part in embodying that tradition of resistance and survival, which the "Revival" sequence of Cave's End clearly pays tribute to.

Thus the dance subtly suggests the familiar Revival step, which, to remember, was first introduced to the Jamaican dance theatre stage by Pocomania. However, the reference to the forward/backward tilt as well as the off-balances and the typical head-wraps is quite abstract. And I would even go as far as to say, probably only apparent to an audience 'in the know.' While a foreigner might have difficulties to place this modern abstraction, Jamaicans will clearly be able to uncover the off- 
stage cultural reference. And those who have seen Pocomania forty years earlier, might even find direct reference to that earlier piece in Cave's End. For example, when the group of male dancers enters in file and they each swing a shawl-substitute, extending from their Revivallike head-wrap, the costume suggests the Revival Shepherd's cloak. ${ }^{70}$ And then there is also another even more explicit hint, in which the male dancers for a very brief moment take up the exact same position as was choreographed for the ending of Pocomania: the Shepherds standing together in off-balance.

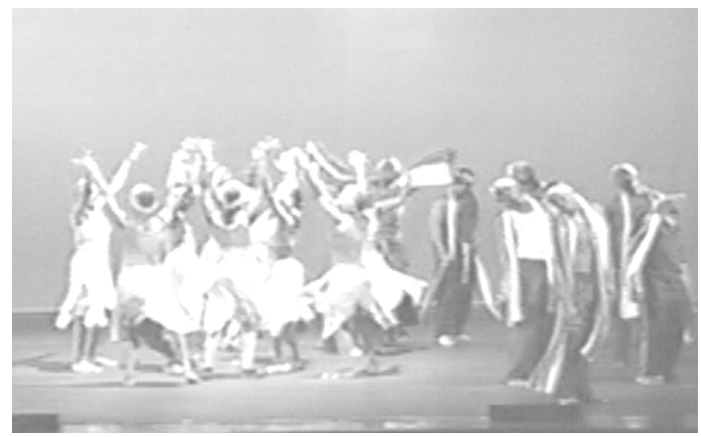

The National Dance Theatre Company of Jamaica in "Revival" from Rex Nettleford's Cave's End, 2003. Video Still.

Especially the comparison between this very early work of Nettleford's choreography to Cave's End, which is a rather contemporary composition, demonstrates the refinement of abstraction, which the field movement has undergone over a time span of forty years. As I have argued before, I would not think that as a non-Jamaican, one will easily detect the Revival background here. The NDTC's folk imprint thus creates a certain eclecticism of the company's Caribbean dance theatre. As Arlene Richards has explained:

We have our own material. And I think that it is very important that we use our own material and that is what distinguishes us from another group and another country. And so in any country, I believe, that your modern dance is gonna be eclectic. It's going to be some of this and some of that and is going to be a nice blend and fusion. And so that is what I do in my work because I

70 Rex Nettleford, "Jamaican Dance Theatre," lecture EMC summer workshop 2003. 
think that is what is going to distinguish it from anything else that you've ever seen, if you take it and, oh boy, where is that coming from? It's the folk material [...] for example, in my work it's very slow, it's very, very slow. In a ritual it would not be done at that kind of pace you know, so I change it just a little bit and incorporate it in the work. Cause I think that it is important that we do that. And I also think it is important that we maintain the essence of our folk material and we have sufficient folk material in an almost pure artistic sense. ${ }^{71}$

The folk forms' empowering message thus remains a constant in Jamaican dance theatre, a sometimes more outspoken, sometimes extremely subtle, yet always continuously present force to be counted on as it has carried a people on their life-journey.

Correspondingly, "Looking forward," the fifth section of Cave's End, explores the underlying message of Jamaican Dinki Mini. Recalling that Dinki Mini derives from Jamaican nine-night funeral rites, the dance perfectly matches Cliff's message of "hope in despair," introduced by the song of this section. Commenting on the impact of the rhythm and movement for this sequence, Nettleford states:

The dance here progresses into what the lyrics say - one has to be forwardlooking and the dinki-mini rhythm utilized by Cliff is here ideal. The body becomes free, the mood is even joyous and hopeful in the middle of what could be despair. It is danced in different groups to emphasize the importance of the collective endeavour on the journey. ${ }^{72}$

Introduced by lead dancers Arlene Richards and Abeldo GonzalesFonseca the section starts on a balletic tone, yet soon switches into the 'healing cripple foot' step of Jamaican Dinki Mini, which was already introduced in the chapter on Gerrehbenta. As with the Revival section before, this allusion to the folk repertoire is furthermore evoked by a group of three dancers, two men with a woman in the center. Performing the basic Dinki Mini traveling step, they move diagonally forward in a playful attitude, turning and swinging their arms in an audience inviting gesture. The Dinki Mini's celebratory mood is thus taken into the choreography as an expression of elation and happiness. Alternating with more balletic turns and extensions, the couple is juxtaposed by group formations of dancers, varying of seize. Thus, we first have a

71 Interview Arlene Richards 23 Aug. 2003.

72 Nettleford, "Scenario Cave's End." 
group of four dancers with two men in the back and two women in front, which is followed by another group of six female dancers already in costume for the final section of the dance.

"Change," as the finale is entitled, introduces another set of original costumes, which consist of white 'disco' unitards, reminiscent of 1970s fashion with a rainbow-colored ray of glitter on the torso-top. As the lights go on, all of the company is on stage, lined up in file behind each other and marching forward with accompanying shoulder rotation, arm swing and an African-based head isolation. Arriving at the front of the stage, the whole group switches into Yanvalou steps. The following sequence then alternates between the male and female group of dancers, as each group performs a variation of Jamaican modern variations in unison, i.e. modern blended with folk abstractions, until the lights fade back to the blue lit beginning and the dancers exit again from where they came: upstage left. Having completed the journey, so to speak, this last part embodies the dynamic of change in life. As Nettleford describes:

The journey having been made - "towards the light", the entire stage becomes the destination - well lit, celebratory and redemptive - albeit with a full understanding that change is the dynamic of all life and living. Everything changes for life to go on, completing as it were the cycle which began with formlessness and progressing to form, place and purpose - waterfoetus-child-adult! An understanding of this "life-in-motion" is itself a liberating force. The contained energy of the performance of this is intended to depict the tension that exists between the cause for exultation and the wisdom of restraint without cynicism or lack of will. ${ }^{73}$

Performed for the NDTC's fortieth anniversary Cave's End thus presents the company's coming-of-age process, since each of the choreography's parts documents a particular stage of developing vocabulary as well as aesthetic consciousness. Playing on Jimmy Cliff's traditional rhythms and hymnal tunes, the blending of Europe's melody upon Africa's rhythm could not have been more fittingly presented. Cave's End ultimately announces the state of the nation forty years after independence: a global entity adapting to cultural changes from Europe to Africa via the Caribbean, Canada and the United States.

73 Nettleford, "Scenario Cave's End." 


\section{Eduardo Rivero: The NDTC's Cuban Connection}

\section{Sulkari}

In an exchange collaboration with Cuba's National Modern Dance Company, NDTC dancers since the late 1980s have also been trained in the Cuban technique of contemporary dance, as it was first developed by Ramiro Guerra. Similar to the NDTC's own training, Cuban contemporary dance also emerged from the early teachings of German expressionist dance, which allowed for experimentation with daily life movement as well as choreographic freedom of self-expression. Yet, as was already briefly introduced, Ramiro Guerra also explored African Cuban folklore, which he incorporated in his technique on top of the North American modern schools and the discovery of isolations which helped to merge both forms (Mousouris 2002: 56-72). Paralleling Jamaica's cultural decolonization process, the Cuban modern dance movement also accompanied a period of cultural re-definition: Cuba's cultural revolution of 1959. At that time Ramiro Guerra installed Cuban modern dance as a small department of the Cuban National Theatre, where the first national efforts to investigate the country's rich musical and dance folklore were undertaken. ${ }^{74}$ Coming out of that tradition, Eduardo Rivero, who since 1988 is director of his own Compania Teatro de la Danza del Caribe in Santiago, emerged as one of Cuba's most distinguished modern dance choreographers. And it is his work as choreographer and dancer that became most influential on the NDTC.

A student of Ramiro Guerra and former member of Cuba's National Modern Dance Company, Eduardo Rivero had started choreographing his own works by the 1970s, exploring further the African Cuban heritage of his country. In his artistic development Rivero became more and more interested in the process of abstracting movement from African Cuban ritual, very much in line with the efforts that were undertaken by Rex Nettleford and the NDTC. Emblematic of Rivero's dance technique is his choreography Sulkari (1981), which blends elements from ballet, Graham-based modern and Cuban folk dance vocabulary. ${ }^{75}$ Particular to Sulkari is furthermore, the direct impact of African sculp-

74 Interview with Eduardo Rivero 13 Aug. 2003.

75 For a more detailed description of Eduardo Rivero's dance technique compare Gene Cumberbatch-Lynch, An Analysis of the Rivero Modern Dance Technique (State University of New York, College at Brockport: Unpublished MFA Thesis, 2001). 
tural patterns, which informed much of the movement abstraction of the piece.

In 1979/80 Eduardo Rivero passed Sulkari to the NDTC and thus introduced the Cuban Modern Technique to the NDTC repertoire. According to Carson Cumberbatch, who was cast as one of the three male leads in the first NDTC production, the Cuban technique shares several of its fundamental exercises with NDTC vocabulary. Starting with barre exercises and adapted ballet positions, a Rivero class will usually continue with center work, Graham floor exercises and progressions of axial movements from African Cuban folk material and other sources (Cumberbatch-Lynch 2001: 22). While most of Rivero's floor exercise is Graham influenced, it has increasingly incorporated Caribbean dance aspects. Over time Rivero's training thus built a distinct mode of energy release to create far more flexible rib cage moves and a less stable hip than in conventional Graham technique. Cumberbatch explains:

Mr Rivero to translate his vocabulary of dance to a Cuban style and technique, studied the Cuban folklore, i.e. the way the Cubans walk, stand and move, to develop the Rivero/Cuban technique. This is based on movements of hip and spine, shoulders and neck to develop the rippling of the back. The ripples begin at the base of the spine, travels through the entire spine, right up to the back of the head... The rippling back or body waves which is so typically Caribbean, captures the flow of the sea, rivers and the undulating mountains, along with the ripples of the arms (1986: 31).

In this respect, then, Rivero's development of a Cuban technique or style variation of modern dance is indeed comparable to the NDTC's training and vocabulary. As Cumberbatch also notices, this consistency of Graham technical influence makes for the actually rather stylistic than technical variation between the two companies. He lists the following commonalties between Cuban and Jamaican modern technique/style:

1. hyper-extended back

2. contraction-release of upper torso (which is an original African dance feature even though it became so prominent for Graham technique)

3. ribcage shift in second position parallel demi plié or straight

4. spiral/cross sit, followed by fall to floor

5. rippling back/body waves in flat back position in demi-plié 
6. spirals (three-dimensional curve, moving around central axis) around upper part of body

7. change of back

8. lunge (transference of weight from one leg to other)

9. side thrust of hip

10. slide to ground

11. off-balance leg extension on floor

12. stepping from one knee from a closed to an open position (1986: 31).

Breathing, kneeling in devotional reverence, the hyper-extended hands (praise), lifts and flexed foot, and the rippling back are also shared components of both schools of training. However, due to the structural and organizational differences of the institutionalization of modern dance in Cuba and Jamaica, there are also notable differences. For example, there is a stronger ballet retention in Rivero's work, likely dating back to his first dance training with Alicia Alonso and the National Ballet of Cuba (Cumberbatch-Lynch 2001: 3). Moreover, his unique stylization of African sculptural patterns into dance movement differs to quite an extent from Nettleford's livelier, more relaxed and energetic dance compositions.

The video-taped version of the NDTC's 30th anniversary performance of Rivero's Sulkari, begins with three female dancers entering the stage diagonally from upstage left to backstage front, accompanied by Rivero's arrangement of traditional Afro-Cuban drumming and the NDTC singer's solemnly melodic humming. As the three female dancers step forward with the typical bent knees and hyper-extended back of Rivero's dance vocabulary, they exert the signature ripple of his technique, which starts in the back through the spine and extends from there into the shoulder girdle and arms. Arriving front stage, they turn around to step back center stage, where each dancer subsequently performs a technically highly proficient solo. These solos demonstrate the versatility of Rivero's unique modern dance style, which introduces superbly toned shoulder ripples, reverential knee turns, and pliés with flexed hands and bent joints. In combination with the purist brown ballet suit, the strong-featured eye make-up and the powerful 'Afro'-style hairdo and white shell-necklace, the composition evokes an overall sculptural, almost carved image of Yoruba inspired archaic postures.

According to this pattern, the male dancers enter in the next sequence, each carrying a wooden stick which is rhythmically stamped onto the ground. Bare chested in bikini-pants with only a shell girdle 
resting on their hips, their toned bodies are, similar to the women's bodies, on display. As they lift the stick or bear it like a yoke on their shoulders, it symbolically changes from occupational tool to heavy burden and aggressive weapon. Despite the stylized abstraction of the danced movements, it would actually be quite hard not to think of the typical warrior/hunter/provider triad here, when these gorgeous male bodies exert their beautiful, acrobatic leaps. Not enough though, the stick, becomes even more heavily loaded in symbolic meaning, when pointed upwards from between the dancers' legs. Now, clearly it carries some sort of phallic connotation, considering that through all this macho prowess, the female dancers sit in the back and watch.

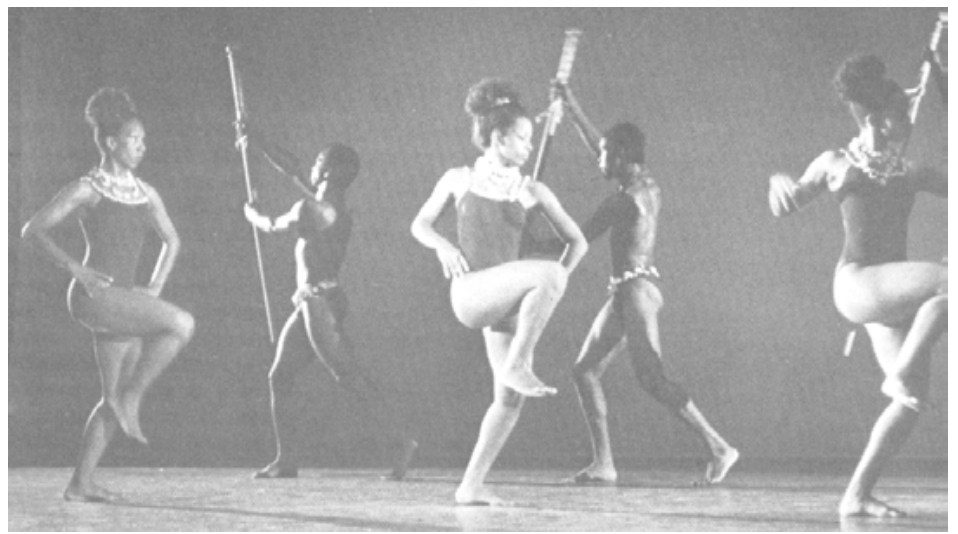

The National Dance Theatre Company of Jamaica in Eduardo Rivero's Sulkari, 1980. Photograph by Maria La Yacona (rpt. in: Nettleford 1985: 148).

In accordance with Nettleford's African Scenario, one could easily read this scene as another approach towards the Caribbean's African heritage from the Cuban perspective. As such it is a powerful choreography, particularly because of its technical versatility. Yet, while Sulkari carries ritualistic overtones, which are evoked by the African Cuban traditional drum score and folk singing, the oppositional arrangement of three female and three male dancers almost enforces a reading in gender terms. ${ }^{76}$ Rivero's modernist stylization of African Cuban folk material emphasizes the toned muscularity of his dancers, which in its

76 Such a reading is further supported by the dramaturgical note in the NDTC's 30th Anniversary Program, where the dance is described as: "A dance of exaltation in fecundity and fertility, so that through the manwoman relationship the life of man will continue [...]." 
heroic gender portrayal may at times appear somewhat problematic, or dated if you will. Thus, his stylized gender portrayal creates an image of the black male dancer, which evokes a modernist Darwinian type of the masculine. Ramsay Burt has critiqued this same representation of essentialized masculinity also in the work of Martha Graham, José Limón and Alvin Ailey, and the Graham foundation is likely responsible for that same notion in Rivero's work, too (1995: 132-134).

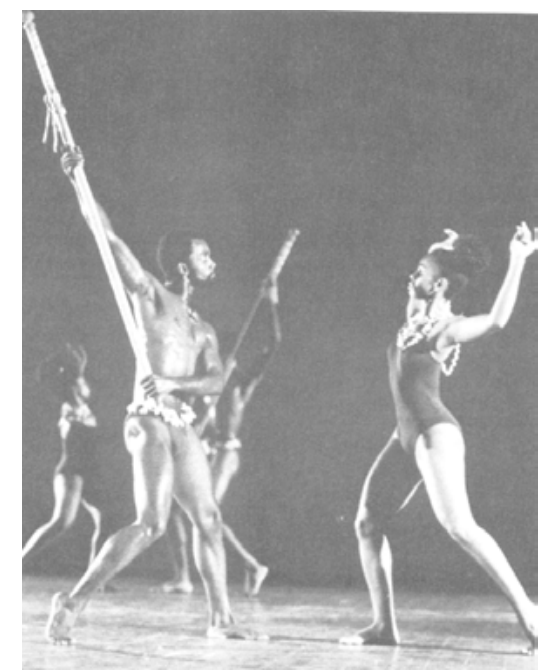

Gene Carson and Denise Robinson in Eduardo Rivero's Sulkari, 1980.

Photograph by Maria LaYacona (rpt. in: Nettleford 1985: 121).

Rivero's aestheticized display of male prowess appears unsettling, because it enhances an image of macho hyper-sensuality, which is in pictorial accordance with a prevalent racial stereotype. As Burt points out, "non-white masculinities appear from a dominant, white point of view to be in touch with 'essential', 'natural' masculinity" (1995: 128-129). Perceived as such, they pose a representationally unsettling counterimage to the white male spectator, who might feel threatened, yet at the same time awkwardly fascinated by the portrayed hyper-sexuality of the racially construed Other. However, to defend Rivero's work, one has of course to admit that, when I, for example, was watching Sulkari as the special performance of Rivero's Compania Teatro de la Danza del Caribe at Kingston's Little Theatre in the summer of 2003, there were neither that many white men nor white women present to feel optionally appalled or enticed; except for the casual handful of tourists who 
usually will find their way down to the theatre from the nearby New Kingston hotel area. And one can assume that the same is true for the company's performances in Cuba, which makes their performance situation a different one compared to that of the Alvin Ailey Company in the United States, for example, which performs to a somewhat half white, half black audience.

Yet, being of course a white woman myself, what I found personally disturbing - and this statement I am afraid I can only make as a very subjective one - was precisely that knowledge I share with Ramsay Burt and other academic critics from our Lacanian film class theory. Suddenly, several questions formed in the back of my head, while contemplating Rivero's work: Had I been made so very aware of stereotypical minstrelsy that by now, whenever I see a black performer with bulging eyes it will remind me of $\mathrm{O}^{\prime}$ Neill's Emperor Jones? Curious, if other people would share my concern, I was however to be surprised by the general enthusiasm and applause the performance received. Stepping out into the lobby during the break, I overheard comments like "Wonderful!" and consequently no longer dared to voice my critique, as the same sort of racial discourse intimidated me, as a white European, to 'once again' voice a critique that could come across as patronizing. Another question: Was I over sensitized? But what actually did Sulkari then (re)present?

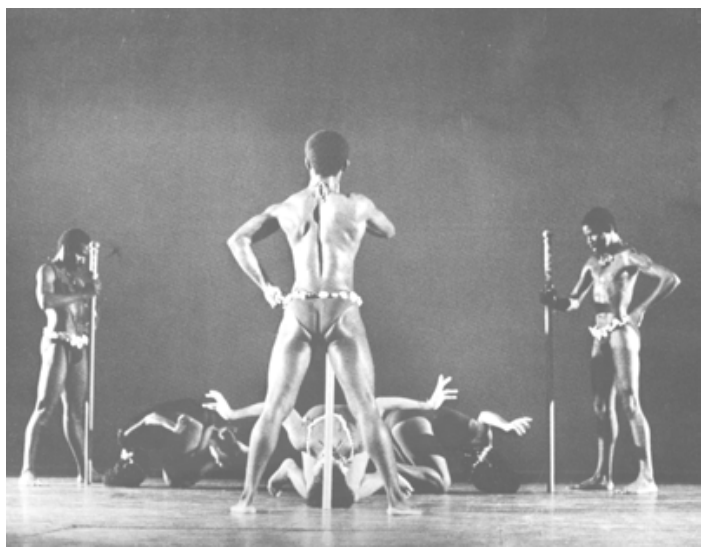

The National Dance Theatre Company of Jamaica in Eduardo Rivero's Sulkari, 1980. Photograph by Maria La Yacona (rpt. NDTC 40th Anniversary Program). 
Especially the last section of the dance, when the male and female dancers engage in a sequence of pas de deux configurations, erotic spectacle seems to overshadow the ritualistic impact. Considering, for example, the following episode, when the female dancers first slide down the stick, which is firmly upheld by the men, and then kneel submissively down in front of their partners, do these danced actions not suggest a sexualized reading of the scene? Triumphantly lifted on the males' shoulders, these women dancers become trophies rather than goddesses, it may seem. However, unlike the example of feeble looking ballerinas, these 'exotic' women remain quite self-assertive and strong in their fierce gaze at the audience. Puffing their cheeks in a stylized imitation of possession, they do indeed convey extraordinary, yes perhaps even frightening power. As Martha E. Savigliano has pointed out on behalf of the "political economy of passion" and its relation to a colonizing desire:

Passion and Desire do not move in plain opposition to each other. They circle one another in an ambivalent, unbalanced dualism in terms of power. Desire is invested with legitimacy, the authority enjoyed by those in power. Passion's power lies in its illegitimate nature precisely because it is imputed to nature, to the primitive, to the irrational. Hence, Passion's power resides in 'empowerment,' in seeking to partake (part-take) of some crumbs of the power held in legitimate hands. Passion's power is akin to a terrorist maneuver that asks for containment. It is wild, inhuman, beyond conquerable nature - that is supernatural - and must be subjected to the workings of the civilizing/humanizing Desire (1995: 10).

So to suggest a hesitant conclusion from my reading here, maybe what I was first misled to read as a stereotypical, almost derogatory sexual dependency/victimization scene in Sulkari's partnering of male and female dancers is in effect a rather empowering stance.

What appears as ambivalence in Sulkari is thus its juxtaposition of gender neutral African based ritual to the exotic/erotic modernist archaism: for neither are Rivero's dancers African sculptures per se nor are they actors in the role of men and women in a 'primitive' village scene. Rather, Rivero's modern dance technique translates an abstract idea of that cultural power. As he has commented:

The bended knee is the same as in African sculpture. The strength in the face, in the eyes and the lips and cheeks are very strong expressions of African culture and what we called the phenomenon of possession. In Cuba this is very 
strong in the Afro-Cuban culture of Yoruba rituals. Observation made in respect of these rituals reveal a living sculpture, with strength in the face, and the expression of these people. That is a great strength for when you see a Yoruba sculpture or carving you are seeing a Yoruba possessed person. And that strength that you see in the culture and that you see in a possessed person, that is inside Sulkari. Sulkari is an art form that goes on stage, the dancer cannot be unconscious, i.e. be possessed, and come out of themselves on stage. The dancer must have the same strength of the sculpture and the possessed person, but very controlled, extremely controlled. And that is the strength of Sulkari. That is why in my class we used so much the breathing, and all these elements, which we find in African dance and African retentions in Cuba (in: Cumberbatch-Lynch 2001: 25).

Rivero's abstraction of possessional dances thus seeks to symbolically convey the quintessential expressiveness of African Cuban ritual. As Susan Vogel has also remarked, on behalf of the aesthetic foundation of African sculpture: unlike 'naive' mimesis, African sculpture rarely imitates people or animals for what they are in themselves, but rather it conveys abstract "ideas about reality" (1986: 12). Hardly naturalistic therefore it should rather be interpreted as "the result of a highly intellectual and abstract process of translating ideas, concepts, and values into physical form" (Vogel 1986: 12). In this respect, the dancers' bulging eyes and puffed cheeks are not intended to convey the derogatory minstrel stereotype, but rather the power of possession. However, even if such an aesthetic may speak differently to a Caribbean audience than to one abroad, i.e. me in this case, the problem of the stereotype remains as "white definitions of gender and 'Otherness' intervene" (Burt 1995: 130). Transferring this ambivalent stance to Sulkari, the interrelation of the stylization of ritualistic ecstasy and power on the one hand with a clearly gendered erotic connotation on the other are somewhat both present: in-between traditions there can never be just one reading it appears.

\section{Congo Layé}

Arsenio Rafael Andrade's Congo Layé, the second NDTC choreography to be briefly mentioned in this context, also employs the signature elements of the African Cuban technique, yet to a stylistically rather different effect. Intended as a "Eulogy to my ancestors, to my blood, to my motherland Africa," choreographer Andrade announces quite clearly the agenda under which he wants his choreography to be read. A former member of Eduardo Rivero's company in Santiago and a graduate 
of the National School of Dance in Havanna, Arsenio Andrade moved to Jamaica, where he joined the NDTC as principal dancer and also teaches dance classes at the Jamaica School of Dance. In comparison to Sulkari's rather statuesque composition, Congo Layé by contrast presents the same technical elements in a far more energetic accentuation and ensemble based composition. Accompanied by music from Conjunto Ballet and Folklorico Afrocubano, the pace and rhythm set are already much faster and as the ensemble of female dancers appears on stage, they lift their arms in an aggressive posture as if pointing a spear towards the audience. They, too, puff their cheeks, however, as their warrior make-up signifies, the expression seems less ambivalent than in Sulkari, since the whole narrative of the dance is an already familiar and yes, probably also a meanwhile somewhat topical one.

Congo Layé once more explores the African heritage in Caribbean dance by interpreting the African Cuban movement vocabulary in terms of a defiant warrior stance. Embodied in acrobatic jumps, turns and lifts such technically spectacular arrangement hardly fails to win an audience and probably, in this respect, it is an assertive gesture every Caribbean choreographer needs to make at one point in the career. Power and tempo mark the female as well as the male group of dancers who engage in confrontational and competitive juxtaposition. In this respect, Congo Layé demonstrates that the Cuban technique may potentially form the base of various dance interpretations. While Sulkari is rather contemplative and solemn in expression, the same technical foundation in Congo Layé becomes an energetic vehicle to conjure the defiance within African dance practice in the Caribbean. Thus, indeed, the Caribbean's rich folk heritage re-invents modern dance to stylistically quite unique interpretations and appropriations, depending on the choreographer's imagination. 


\section{The Caribbean Modern Interpretations of Clive Thompson}

\section{Of Sympathy and Love}

Born in Jamaica and an early acolyte of Ivy Baxter, Clive Thompson pursued most of his career as a dancer in the United States. A mainstay with first Martha Graham Company during the 1960s and then Alvin Ailey American Dance Theatre in the 1970s, his work as a choreographer naturally owes to these strong technical foundations. As Thompson explains, it was in particular Graham's approach of character, which had a lasting impact. He recalls:

Martha works from the moment. [...] She works on that in her imagination, speculating on the reasons why, and this is a wonderful approach to dance and theatre, because you get involved in character. The characters unfold and become real individuals. From the moment the curtain goes up you're telling, reliving the story right till the curtain comes down. It all unfolds with you, by you, on the stage. As opposed to telling stories just by wonderful virtuoso movement, I enjoy virtuoso movement, but movement for me, is not enough. I think this is my Graham background. I think the artist must be able to add meaning to the movement. In Graham, there is nothing wasted. No gesture added and then thrown away. There's a cause, and you're always aware that you're communicating to that audience (in: Mclain Stoop 1978: 82).

This approach of character is particularly evident in Thompson's recent Of Sympathy and Love, which he choreographed for the NDTC's $41^{\text {st }}$ dance season in 2003. A duet for two male dancers on the biblical Lazarus theme, the dance divides into two solos and a brief pas de deux at the end. As Thompson reflects on the choreographing process:

This idea, the idea of Lazarus, the Lazarus theme has been in my head for long, long time. It's one of my concepts that I've been going over and over. And one of my concepts was that I didn't see Jesus, I just saw a white light and I heard the voice saying that sentence. And I see, I was seeing Lazarus back out of that cave at one time with cloth hanging from him, because I didn't want it to be cloth, but to represent decomposed flesh and the face covered. ${ }^{77}$

Starting from that original idea, the choreography begins with a blue lit stage floor and the empty space, which is first entered by the music:

77 Interview with Clive Thompson 21 Aug. 2003. 
single piano keys set the solemn, almost sacred mood into which the first solo dancer in the character of Jesus enters. ${ }^{78}$

"Jesus wept" from John 11:35 has been interpreted as a sign of Jesus' humanity (May/Metzger 1973: 1304-1305). And it is this human aspect of the Christ figure that Thompson's choreography of the solo seems to also focus on: entering from the side wings of the stage, the dancer directs the focus of his movement in a vulnerably open relevé with arms upheld and an upward look as if in appeal to his God/Savior. Then, he turns towards the audience in that same posture, whereby he establishes himself as the link between both spheres. On his knees, the dancer apparently measures his psychical burden in a bodily arm gesture, which in staccato retardation drops from a relevé to shoulder height. In Graham oriented movement vocabulary, the solo introduces its character through a series of gestures, which - supported by the purist white costume - evoke an expression of lament and endurance. Repeatedly, the dancer, for example, covers his head protectively under crossed arms, while simultaneously bending the torso horizontally over. Technically refined balances and turns, furthermore, create an image of balanced beauty and grace - Christ's humble humility, his human pain and forbearance of suffering.

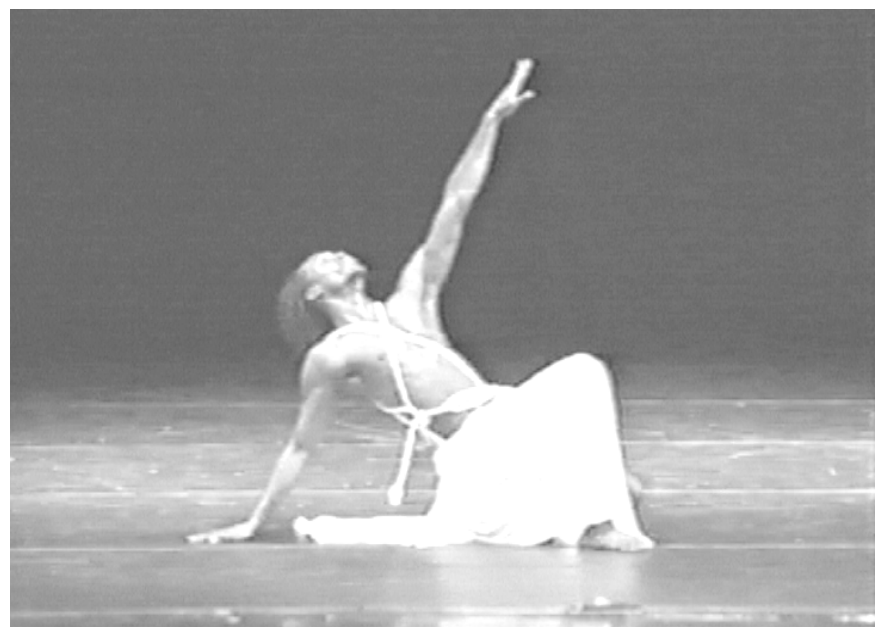

Mark Phinn in Clive Thompson's Of Sympathy and Love, 2003. Video Still.

78 Albert A. Johnstone has described how "ludic symbolism" via a narrative correlation of props, movements, lighting, etc. generates the "dancercharacter relation" in dance theatre (1984: 171-172). 
Choreographer Thompson is highly demanding of his dancers, because, as he has said, mere expertise in technique is not quite enough. So what Thompson demands of himself, he also expects to see from his dancers, whom he challenges to find in their dance not only technique but more importantly a means of communication. As he has described the elation, which derives from this transcending moment of technique into expression: "It's wonderful to know that you've transcended yourself, become a character, and shown, as in a mirror, a part of humanity for the audience to see the reflection of mankind."79 Reassessing the "Jesus Wept" solo from this perspective, the dancer's expertise consists precisely in achieving such transition, when the audience can indeed partake through the movement gesture in the emotional expressiveness of the dance.

The second solo, "Lazarus Come Forth" from John 11:43, was inspired by Thompson's discovery of the Native American musical arrangement. In this case, the finding of the music re-shaped the original outline of the dance. As Thompson recalls:

The concept than changed and there were two solos. The first solo of Jesus, "Jesus Wept." The second section are rituals performed on the sacred ground, the burial ground, the holly ground [...] it's not unlike what happens here in the Caribbean or what happens in Africa, or Brazil or there in Germany, in various parts of the world as spiritual manifestation of the people. Not just black people, all people, all [...] mankind, where the spiritual manifestation just takes different forms. And when I heard this music, I said: 'Ah!' And it solidified. ${ }^{80}$

The transition from the "Jesus Wept" part of the dance is introduced by a loudspeaker transmitted voice-over: "Lazarus Come Forth," after which an upstage light beam goes up immediately on the hand of the second male dancer, accompanied by the sound of a vigorously pulsating heart beat. Stretched out on a bench and clad in flesh-colored rags, the focus is solely directed to the dancer's hand, which moves along his lifeless body as if an independent entity almost. This is a captivating scene to follow as the hand touches the chest right above from where the heart is located and sucks the upper body into an almost violent contract release, similar to that of an electric shock reaction. Yet, 'Lazarus' is still not back to his senses as the hand further inches along to the

79 Interview with Clive Thompson 21 Aug. 2003.

80 Interview with Clive Thompson 21 Aug. 2003. 
back of the head, lifts it to the chest, sets it back down, moves to the knee, contracts and releases again, rests down and lets the body relax briefly, before the whole body contracts in a tense upward move to instantly crush back down.

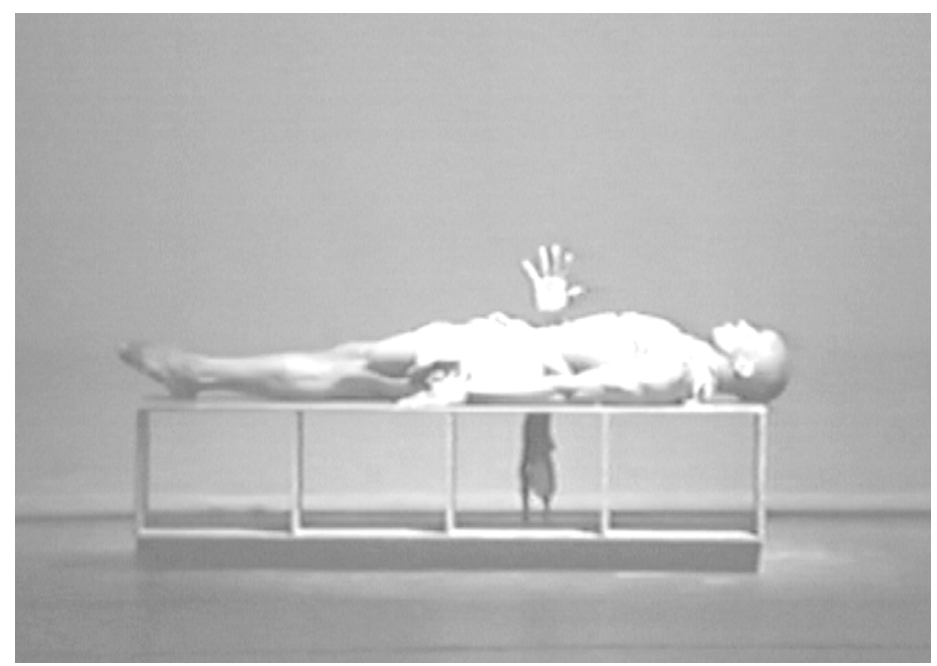

Marlon Simms in Clive Thompson's Of Sympathy and Love, 2003.

Video Still.

From there, the dancer engages in riskier positions, as, for example, turning on the bench, lying on the stomach, extending the leg, etc. to eventually leave the bench behind. And then, he moves ever so free to explore the whole space of the stage, to extend and balance, to jump and turn, almost as if he had never danced before. Thompson comments on the development of this scene:

When I had Marlon there the first time, I knew I wanted to go into the cave, I didn't want the bench, but we rehearsed with that and the bench, it's a prop from a previous work, it worked, because you don't see the bench. It just suspends. The blue you really don't see, I realized today. It doesn't need a lot of décor, because the movement is so strong. Especially, when I see the hand, now the light comes in too slow, when he says: 'Lazarus, come forward...' The light has to come up then, because it goes right into a heartbeat. And the heartbeat is the opening. [...] I love the moment, when you just see his hand appear. And it doesn't look as if it was joined to him at all. Only afterwards. [...] I used the image also of spirit moving through his body, but the power 
was in his hand, because it's the hand touching these things and bringing the energy. The spirit was just moving through the hand. ${ }^{81}$

Thus, apart from bringing the energy to the dance, the "moving spirit" also surprisingly appears as the link that connects this inherently modern dance work to a Caribbean sensibility, as it speaks of the redemptive impulse that is so prevalent in the religious syncretism of Jamaican Revival as well as the other folk retentions.

As has been restated throughout this analysis, the liberation aspect of Christianity has been a constant motor of African Jamaican resistance, which is also at the heart of the Lazarus theme. Thus, towards the end, both dancers join in a brief pas de deux, where the dancer of Lazarus is lifted on the Jesus dancer's thigh - a lean on, supportive position - after which the dancer of Jesus leads Lazarus for a few steps. Finally, they each take second position relevé, arms lifted and facing backs opposite each other. While Lazarus looks upward to the back, Jesus looks straight into the audience, again establishing that bond between the godly presence and human sphere that was already introduced in the beginning. A deeply religious work, Of Sympathy and Love technically owes to Thompson's Graham foundation, yet at the same time Thompson and his two dancers make it distinctly their own expressive creation. Enhanced by the Native American soundtrack - its ancestral voices and wind blows - Of Sympathy and Love not only speaks of the gospel's story-line (which in my reading comes across far more explicit than it was actually experienced during performance), but also of that spiritual infusion of breath energy which is so much part of the Caribbean ancestralism. As such Thompson's choreography successfully defies national and cultural boundaries and yet expresses his own unique imagination.

\section{Interlude IV: Dance and Cultural Diversity}

While the North American modern dance school technically shaped Thompson's physique as a dancer, the Caribbean impulse did, however, remain the base of his individual dance interpretations. Thus, Thompson's presence in the "Fix Me Jesus" section of Ailey's signature piece Revelations, carries a Caribbean stance unlike that of dancers who

81 Interview with Clive Thompson 21 Aug. 2003. 
had performed the part before. Asked for the Caribbean input in his work as dancer and choreographer, Thompson remarked:

I have a very conscious way in Alvin Ailey's Revelations, Rex will always say that he has never seen "Wading in the Water" or "Fix Me Jesus" performed the way Sara Yarborough and I did it. We are both Caribbean people, she being from Haiti and I'm being from Jamaica. And especially, even with Judy during the white section, when I come down dancing and I'm dancing with Mari Kajiwara, who's Japanese, she's coming very straight up and down, and I'm, it's very subtle, but you see the movement of the pelvis as the hips are going. It's a Caribbean thing. It's not necessarily black as in African, but it's Caribbean and it's definitely Jamaican. So you see the folk forms that we have, that one grows up in, which surround you. It's not necessarily conscious - it's just there, you get it, if you look, you go either to, or you hear a Revival meeting, my parents did a lot. Or you go and you see the people dancing and singing, and I didn't know what it meant, but I was there and got caught in the drums and the tambourines and the singing and you look at that thing and see that. All those things are there and in you. When you become more conscious now, then you realize, what you were doing: 'Oh, that's a Dinki Mini and that is a something, but you already know it. Cause it's been there. ${ }^{82}$

Based on the work of two of the prime American modern dance companies, Thompson's work certainly appears more indebted to that tradition than Rex Nettleford's more folk-oriented work, even though Thompson's Folk Tales of the 2003 season also investigated that latter idiom in an entertainingly self-ironic manner. Hence, as has been shown throughout the previous analyses, both traditions easily blend into each other with quite fascinating stylistic results. Moreover, since the NDTC's repertoire has successfully blended the North American schools of modern dance with their own explorations of Caribbean folk material, as well as the Cuban Technique, the common cultural sensibility of the African diaspora's dance expression undeniably shines through.

To conclude, modern dance pioneers such as the women already mentioned as well as the later generation of men in the Caribbean and the U.S. have mutually enriched their dance vocabulary by adding that Africanist perspective, which the very early modern dance had lacked, or at least not publicly claimed. As with McBurnie's early beginnings in

82 Interview with Clive Thompson 21 Aug. 2003. 
Trinidad, the Cuban example of Ramiro Guerra and later Eduardo Rivero, as well as the NDTC's work in Jamaica, the Caribbean shares a 'black history' of dance very much in line with Alvin Ailey's American Dance Theatre. ${ }^{83}$ Not only did the Caribbean pioneers have the same vision of modern dance to announce their own cultural experience of diaspora, but also were they Renaissance women and men with a clear humanistic dedication to the social and educational outreach of dance theatre into their larger communities. As Clive Thompson has summarized this universal outlook within modern dance:

I tend not to think of our audience as the man who just pays a few dollars to come in and enjoy. I think of it as humanity, and we're all part of the whole human thing. You should be taken away a bit, but not necessarily into fairyland. You must be able to see some of reality, some of man's struggle, some of our history, some of our joy in the theatre, at times (in: Mclain 1978: 83).

Therefore, as has been demonstrated by the example of the NDTC's creolized dance technique, such crossing humanity is indeed achieved in their celebratory dance of cultural diversity - undeniably Africanist in gesture, but also an expression of our shared humanity in the world.

\section{Next Generation's Re-Inventions: Jamaican Dance Theatre Goes Global}

A new generation of students has emerged whose environments oscillate between the local and the global; whose enjoyment of cultural practices find the modernist concepts of popular and high art a straight jacket irrelevant to their lives; and whose experiences and identities transcend those mononationalisms. For these students, the narrowness of the canon of western theatre art dance is being challenged; not to overturn it, but to gain a more balanced perspective on the practices of dance and codified movement systems in human society (Buckland 1999: 3).

This study of Jamaican dance theatre has thus far focused on the historical development of Jamaica's National Dance Theatre Company

83 Compare Thomas F. DeFrantz' insightful study of Alvin Ailey's America Dance Theatre Dancing Revelations. Alvin Ailey's Embodiment of African American Culture (Oxford: Oxford UP, 2004) and Jack Mitchell, Alvin Ailey American Dance Theatre: Jack Mitchell Photographs (Kansas City: Andrews and McMeel, 1993). 
within the frame of postcolonial nation-building, emerging vocabulary and identity formation. However, a new generation of Jamaican choreographers has meanwhile matured, whose dance theatre works clearly demonstrate a new development. Starting with NDTC ballet mistress Arlene Richards, these young choreographers - with exception of Arsenio Andrade, who joined the NDTC and the Jamaica School of Dance staff from his home country Cuba - have been trained in the NDTC vocabulary and are so to speak original 'products' of that school. Interestingly enough, despite the NDTC's strong folk dance background, their recent choreographic work appears increasingly oriented towards modern/contemporary dance expression. While this generation will still integrate Jamaican folk vocabulary to a considerable extent, it appears no longer the primary concern of experimentation. Rather, today Jamaican folk dance heritage presents to them but one - alas, in terms of 'rootedness' very important - of the many dance vocabularies out there. In a way, this survey of selected choreography shall finally outline rather than conclude that with this generation of promising young dance choreographers - the children of the 'new Jamaica' - Caribbean dance theatre continues to re-invent itself, precisely to fit the artists' contemporary needs of diverse identity expression.

\section{Arlene Richards - Cocoon, Renewal of the Spirit}

Starting dance lessons in high school, Arlene Richards won a scholarship to attend dance classes at the Jamaica School of Dance in Kingston. Many of her teachers there were members of the NDTC at the time. Richards took classes with Tony Wilson as well as Patsy Ricketts before she joined the NDTC in 1978. ${ }^{84}$ When she received her dance training at Edna Manley College, she recalls that her teachers put a strong emphasis on folk forms. Dancing Pocomania and Kumina with the NDTC later on, she thus came to assess Nettleford's choreography as an art form rather independent from the religious ritual practice, which helped her as a practicing Christian to overcome a certain reservation towards the ritualistic dances of another religious denomination. ${ }^{85}$ However, Richards' own choreography does not abstract on the ritualistic background of Jamaican folk dance vocabulary, but rather employs these forms in entirely new configurations. For example, her choreography Cocoon

84 For biographical data compare NDTC 30th Anniversary Program.

85 Interview with Arlene Richards 23 Aug. 2003. 
deals with extraterrestrials, whereas Side by Side has explored the emotional entanglement of two sisters. While both works will also incorporate NDTC vocabulary, it may be easily overlooked, for Richards transfers that vocabulary to her more topical, contemporary themes. Similarly, her more recent Renewal of the Spirit also relies heavily on theatrical narrative and modern dance vocabulary, which in terms of declared 'Jamaicanness' does not articulate itself quite as strongly as the NDTC's earlier works. And yet, I will argue that Richards choreographs Jamaican dance drama in the best sense: for her story-telling compositions create colorful stage imagery, characters and conflict, comparatively seldom seen in dance theatre today, but very much in line with the tradition of Jamaican ritual and masquerade.

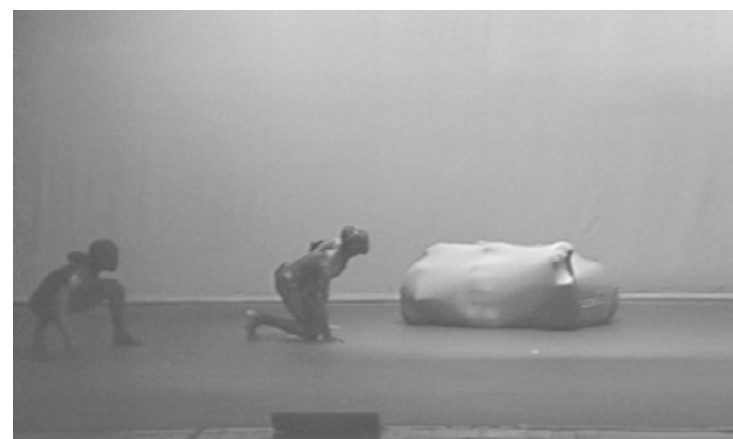

The National Dance Theatre Company of Jamaica in Arlene Richards' Cocoon, 2003. Video Still.

Cocoon, for example, presents the discovery/encounter between the inmates of an extraterrestrial 'spaceship' - created by the seven female dancers covered under a satin balloon - and two supposedly 'human' male representatives. Introduced by the futuristic electronics of the canned music, the opening scene is dominated by that estranging image of the cocoon as it mirrors the 'alie/n/ation' of the dance characters on stage. Certainly, the image of the cocoon on top of the synaesthetic sensation of the music presents a stunning stage metaphor to play with: a birthing shell, a ship of transport, transcendental force, bounded yet without boundary between time and space, etc. The satin prop works wonderfully here, for it allows the dancers to explore and actively engage with the flexibility of the fabric during that scene. By pressing her face against the satin, for example, a dancer creates the astonishing imprint of a ghostly mask; or, also, by briefly standing bent over butt out, 
another dancer points to the life-force within the cocoon as simultaneously a radiating light beam illuminates the satin's silvery surface from the top. Finally, in a repeated move from the beginning, all of the dancers lean back outward again so as to flatten down the balloon's volume, 'shedding that outer skin' with arms, elbows and fists fighting against the malleable tissue, swirling in a circle flow-wave from dancer to dancer, before one after the other actually breaks out of the prison/ capsule/cocoon.

In fetus-position or gliding along backwards, the dancers singly roll out from under the satin and either assume what appears as a wriggling beetle perspective, or, even more curious, they perform a tedious, dragging crawl by moving forward from contract fetus to stretch release, reminiscent of a snail or other amphibian species. Tinged in softcolored blue light, Richards has choreographed the scene as surrealistic underwater-world, reminiscent of a dry-swimming symphony of uninvestigated movement possibility on back, knees and side-stretch, subtly accompanied by the electronic sound dribble of drum and pan-flute acoustics. Interrupted by the intruding noise of unintelligible whispers, the dancers suddenly stand up - as if 'possessed' - and execute a sequence of robotic walks and angular moves as if directed via remotecontrol or that voice from off-stage. From the organic amphibian crawl then, the audience is instantly confronted with highly mechanized marionettes in line formation and pairs, lunging to both sides, exerting jumps and handstands of disoriented obeisance.

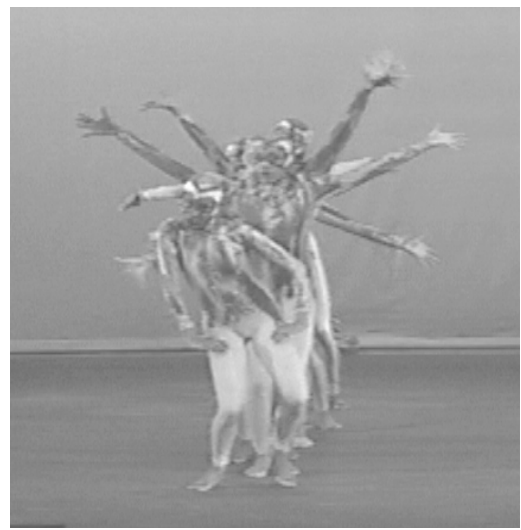

The National Dance Theatre Company of Jamaica in Arlene Richards' Cocoon, 2003. Video Still. 
And while the futuristic aspect of the choreography, costume and music could not have appeared farther remote from ancestral African rites thus far, the episode that follows appears strangely reminiscent of familiar Revival ritual. In fact, as one of the 'robot'-dancers falls 'sick' on the ground, the group - not unlike the historical descriptions of Jamaica's powerful myal-men - starts to exert a healing ritual supposedly designed to bring back the dancer's spirit. First encircling the entranced/lifeless body with conjuring gestures, the group dancers finally lift her up above their heads to acclerando music. At that moment, a glaring red light fills the scenic backdrop and increases the emotionally tense atmosphere of the sequence. Produced by the unsettling sound effect of the unintelligible voice, the dancers respond somewhat unwillingly to that elusive force in space. So while this sequence does not deal with the specifics of Jamaican ritual by any means, the underlying theme of supernatural power, deadening threat and remorseful healing remains strikingly similar.

Moreover, the scenic imagery is to great extent evoked by Richards' congenial costume design. Since she has been quoted earlier, yet to briefly repeat, her costumes seek to underline the message of the individual work. In Cocoon this approach proves particularly convincing, because of Richards' assured apprehension of the materiality of her props as well as the color design. While the women are dressed in white-bluish water-colored diving-type suits, the two men wear pink, flesh/ribcage-colored unitards and matching bathing-caps. Depending on the light, the women's costume may create iridescent effects of manifold blue variations. Lighting and costume thus become integral elements of the overall composition to successfully create Cocoon's impression of 'other-worldliness.' The choreography's narrative hence evolves not only from the dance, but such binary opposition of color, costume and lighting, too, which in totality convey the dramatic tension of the scene.

Following the brief exposition of character and conflict, the next sequence then stages the encounter between the two worlds as a romantic pas de deux of the two men and two women soloists. Dream-like in atmosphere the choreography here consists of technically versatile lifts and balances to underline the eroticism of the love theme, followed by a group formation finale of the ensemble. While the romance lyricism of the scene appears a bit kitschy perhaps, it proves at the same time to be luring enough in its utopian promise and quite enjoyable to watch: 'If only 'alie/n/ation' was ever overcome that easily -' Yet before one 
steeps into such sentimentality, the finale's again humorous tone of squatted 'kangaroo bounce' and 'flamingo head' isolations is already taken up again. Alien creatures indeed these dancers may become, if they venture freely into unfamiliar movement territory. Unfortunately, such imaginative paradise is quickly lost, as again the unintelligible voice intrudes and another space-ship pops up right onto the red illumined backdrop. To the distorted sounds of an e-guitar the friendly visitors are being called back home, finally ascending the violently flickering space-ship projection.

Cocoon surprises, because of Richards' quite candid use of popculture elements. Her colorful costumes, trick-scenery and electronic sound devices draw freely on the abundant fund of film, news-release, TV and stage theatricality. Engaging playfully with that diverse material, she creates dance theatre that is easily accessible to audiences from all walks of life. In almost less then twenty minutes, Richards' Cocoon thus manages to take her audience through a dense tour de force of fantastically allusive dance-imagery: from outer-space right down to the beginnings of evolution through African Caribbean ritual and romantic courtship. As a matter-of-fact, Cocoon re-enacts no less than the whole mystery and drama of life, where - whether it be a sacrifice to ancestral God or revengeful Cyber-Spirit - the ultimate secrets remain untold. As Richards' epigraph to Cocoon tellingly suggests: "The Universe - all that is - vast, varied, yet to be explored. What if ...? Would you ...?"86

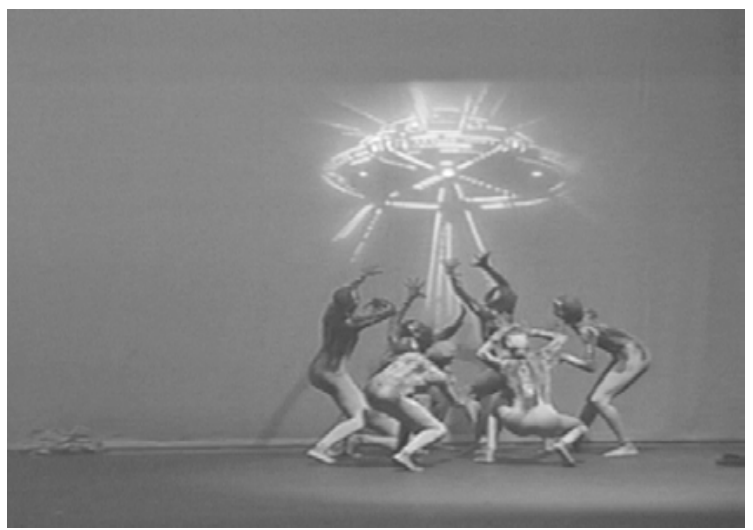

The National Dance Theatre Company of Jamaica in Arlene Richards' Cocoon, 2003. Video Still.

86 Compare NDTC 40th Anniversary program. 
By entering the psychology of alterity from the extraterrestrial vantage point, one might even go as far as to find her treatment slightly selfironic. Certainly, the landing of 'extraterrestrial' beings is not that new to the Caribbean. After all, the region has survived several attacks throughout its turbulent history. And if the visitors have not come from Mars quite yet, than certainly from strange European and North American crusades. Personally, I only need to recall the gigantic ships harboring on the Jamaican sea-shore off Ocho Rios to picture a somewhat different, but no less surreal scene. Richards' creative power, hence, appears to operate from a cunningly internalized cultural sensibility, which is after all truly Jamaican. And last but not least, her marvelous stagecraft and affinity for theatrical means surely owe a lot to folk traditional aspects - as, for example, Jamaican Jonkonnu - without explicitly having to portray them as such.

The other work I will briefly discuss in this context is Renewal of the Spirit, which Richards choreographed for the NDTC's $41^{\text {st }}$ season in 2003. As the Gleaner has pointedly summarized, "Renewal of the Spirit is a dramatic dance which deals with a man who loses his faith and a woman who subsequently finds hers" (2003: C4). Given away that much, the choreography would not appear all too exciting, if it was not for the beautifully arranged costumes and original ensemble dances. Referring back to the same critic's review, the costumes were praised for their authenticity as portraying the "surplices and cassocks worn by priests and garments worn by nuns" (2003: C4). And it is in fact mainly due to this naturalist realism of the costumes that a certain reading is provoked, despite of the rather neutral modern dance vocabulary. Therefore, I, for example, found it quite hard not to think of the choreographed 'priests' and 'nuns' in terms of the all too familiar dramaturgy of tacky German TV series, according to which a priest will also 1. fall in love, 2. from grace and 3. straight down to the 'devil,' which in a nutshell breaks down the underlying suspense of Richards' dance drama.

In a series of melodramatic 'dance events,' Renewal of the Spirit thus presents two excelling solos by the protagonist lovers - the priest and the beautiful woman, he falls in love with - as well as their highly romantic pas de deux of astonishing lifts and passionate modern expressions. Sinners in the hands of a vengefully loving God though, the priest is struck down by lightning from the heavens, while his lover will return to the compassionate arms of the church. Beautifully represented by the following ensemble performances, Richards' choreogra- 
phy next presents her audience with group formations dominated by the spiraling ebb and flow of mourning priests and nuns as during the funeral scene. Finally, Renewal of the Spirit concludes with an ancient, yet no less surprising theatrical effect: the deceased priest's 'duppy' reappears as a truly frightening deus ex machina in form of a masterfully crafted puppet effigy.

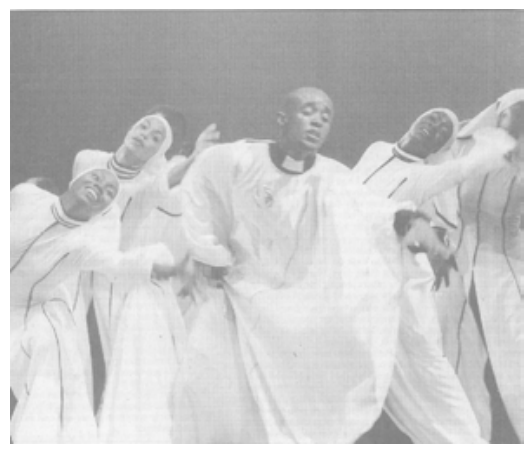

The National Dance Theatre Company of Jamaica in Arlene Richards' Renewal of the Spirit, 2003. Photograph by Wiston Sill (rpt. in: The Gleaner 30 July 2003: C4).

Admittedly, such tense melodrama presented itself quite unexpectedly. Not being used to dramaturgical correspondence between TV and dance theatre conventions, I hastily placed Renewal of the Spirit into the pop cultural entertainment/diversion box. Maybe one could name it 'dance theatre soap,' if that genre existed. Yet, as Renewal of the Spirit was performed almost every night during my stay with the NDTC's $41^{\text {st }}$ season in 2003, I was fortunately given many a chance to revise that preliminary conclusion. As it turns out, to read the dance solely in terms of the topical seduction theme does justice neither to the choreography's excelling soloists nor to the finely choreographed and costumed ensemble performances. To begin with, I believe that at first the concept of dancing nuns and priests in conservative Catholic costume irritated, not because of cultural estrangement, but rather owing to an over-familiarity at least on my part. For one, I was reminded all too well of what actually wearing these 'costumes' feels like from childhood mass service, not to want to imagine to try and dance in them. Thus referring back to my own experience, made me wonder all the more, why would you choose to portray such an issue as a 'scandalized' priest in Jamaican dance theatre? Considering Catholic celibacy 
somewhat ridiculous for my own cultural upbringing, I found it even more astounding in the Jamaican context.

And yet, when I learned more about Jamaican Revival Churches and even attended one of their services in Spanish Town, Catholicism does not even have to be the issue here. Regardless of the actual denomination portrayed, Richards' choreography started to make sense as the connection between dance, spirituality and faith moved to the foreground. Assessed from that Jamaican cultural background then, the choreography's religious message of spiritual deliverance did not appear that limited a viewpoint at all. As Richards has furthermore explained to me:

I think the dance speaks to your spirit and your religion and what you believe in and how you remain faithful to it or not. [...] As to - if I committed myself and I had chosen this path, how do I stay faithful to it and if I don't, if there are consequences. What happens, if I don't? And that is really what the work is teaching about, it is not, you know, targeting anybody at all. And we have always used dance to do that. ${ }^{87}$

So what slowly occurred to me after this interview, as well as the increasing study of Jamaican folk forms, was the noticeable prevalence of that (Neo)African spiritual dimension, which really infiltrates so many levels of the Jamaican cultural sensibility. Not only in the folklegendary 'duppy' and religious rituals, but also in the popular dance, music and apparently even Anglican churches, the concept of the 'spirit' permeates Jamaican identity perception. 88

When I now consider Richards' choreography in retrospect, then Renewal of the Spirit is precisely remarkable for that articulation. Regardless of whether one finds the plot significant or not, there are definite elements which despite the overall modern dance vocabulary will speak of that Jamaican kinaesthetic trace. Not only in the body ripple or the resurrection of the deceased priest's spirit/duppy as an effigy puppet, but also in the funeral scene before, which was actually inspired from contemporary Jamaican wake ceremonies and the elaborate décor of the dancehall. As Richards remarked:

87 Interview with Arlene Richards 23 Aug. 2003.

88 Compare Interview with Arlene Richards 23 Aug. 2003, where an audience member apparently had told Richards that he identified the performer as a danced portrait of his Anglican priest. 
[O]ur popular culture is greatly informed by our traditional folk forms. Greatly. Especially over the last five years, our dancehall culture, the movements are instated by what happens. I don't know, if it is, because so many people die. That sounds terrible, but there are so many wakes, they get accustomed to the movements and I've seen it more and more coming into the dancehall. [...] But I was influenced by that dancehall culture, too. The funeral, because there is that thing that you go to a dance funeral and you come out in your very finest. All your gold and glitter and everything comes out at the funeral. It's no longer this very solemn black thing, you know. I mean, this is a celebration. ${ }^{89}$

The degree of cultural cross-fertilization between folk forms and modern, popular and highbrow, life and stage, etc. appears thus as the hallmark of Richards' choreography. Despite the folk traditions' comparative 'invisibility,' I hope to have convincingly shown that it still contributes to her work's overall communicative power. Not only aesthetically, but also in terms of her artistic engagement. Richards wants her dance choreography to address issues that concern and affect her immediate surroundings. ${ }^{90}$

While this may not adhere to fashionable postmodern trends, I consider her work important precisely because of that. Thus, even where one would not be necessarily made aware of it, Richards' Jamaican sensibility is still present in a subtle way. In fact, Richards 'resistance' to mimic what she does not believe to be meaningful, expresses a renowned Jamaican attitude, which in tradition goes as far back as Jonkonnu, where dance theatre and costumes were also designed to purport distinct social statements. As Richards has commented on her own artistic approach:

A lot of companies are moving towards a postmodern kind of way of dancing. But that's not acceptable to us. I don't think we can present it as a Caribbean people that is so colorful, I don't think we could present it to anybody at all. I mean sometimes they go, 'Oh it's not sophisticated!' But we can't present it to anybody. So it's not acceptable, because if you go and do it like that, then everybody has the same dance, you know. But life is interesting, because then we're hearing: 'Oh you shouldn't be taking on so much of...' Whatever it is, you know. Because then, there are also people still thinking that we are 'Caribbean' and we should still have the grass skirts, or little loin cloth, or something. So that's why it's important that we have to know who we really are

89 Interview with Arlene Richards 23 Aug. 2003.

90 Interview with Arlene Richards 23 Aug. 2003. 
and hold on to that. And work with what we really have in a very positive and confident way. ${ }^{91}$

Far from naive, therefore, Richards purposefully creates dance theatre for a broad range of audiences. Easily accessible, her work is emotionally moving rather than intellectually challenging perhaps, yet as such it adds to the overall appeal and diversity of the NDTC's genuineness. And if people will see different things in her marvelous scenery and dance design, then that has also been intended, since Richards' danced 'statement' is very far from doctrine. As she will ultimately claim: “[i]t's there for you to interpret it." 92

\section{Arsenio Andrade - Epilogo}

Arsenio Andrade's choreography Epilogo is a dance/performance tribute to Malcolm X. Composed for three male dancers, the choreography begins, when the curtain rises on a blue lit backdrop. The three dancers stand in a triangle freeze arrangement with two of them downstage corners and one of them upstage center. Dressed in black satin pants and tank tops, they have their backs turned toward the audience and face the backstage wall. As excerpts from Ossie Davis' "Euology for Malcom $X^{\prime \prime}$ are delivered over loudspeaker from off-stage, the upstage dancer makes his first move, while the other two remain still. ${ }^{93}$ Accompanying the solemn lyrics of: "Here - at this final hour, in this quiet place - we have come to bid farewell to one of our brightest hopes...," the solo dancer first reaches up relevé, then turns around into a lunge to the right, one arm extended upward, the other pointing down, rising briefly on demi-pointe, falling into a bottom turn and finally continuing the sequence by stepping towards downstage center between the two others. Framed by their backs, the soloist reaches up again, both arms

91 Interview with Arlene Richards 23 Aug. 2003.

92 Interview with Arlene Richards 23 Aug. 2003.

93 Ossie Davis delivered this speech at the funeral of Malcolm X on Feb. 27th 1965 at the Faith Temple Church of God in Harlem, New York. For the original speech given compare www.americanrhetoric.com (04.03.20005). Davis' speech was also reworked for Spike Lee's 1992 movie Malcolm X. Also the choreography's final song "Revolution" by the Rap/HipHop band Arrested Development, which Epilogo introduces during the third part, was originally composed for that film. Whether the film, however, was in fact an inspiration for the choreography has not been verified. 
lifted, before he steps back into a half-frontal standing freeze. Meanwhile the lyrics have continued:

[...] extinguished now, and gone from us forever. For this world is where he worked, where he struggled and fought - where his tribe was and his people now are - it is, therefore, most fitting that we meet like this to share these last moments with him. ${ }^{94}$

This introductory adagio solo is taken up in flow by the second dancer, on the upstage left. Turning inwards, he faces front, swinging both arms in a half circle outward, extending the left leg into an arabesque pointing his arms to the side stage wings. As the lyrics proceed:

For we have ever been gracious to those who have loved us, who have fought for us and defended our honor even to the death. When they asked us what we find to honor in this stormy, controversial, bold young captain - we will smile. And we shall answer and say to them: Did you ever talk to Brother Malcolm? Did he ever touch you? Did you ever have him smile at you? Did you ever really listen to him? 95

Simultaneously, the dancer continues pirouetting first position and then adding another arabesque, this time oriented opposite direction than the one before. At last, he addresses his partner, the third dancer, with an inviting gesture for him to take up and resume. While the speech carries on:

Did he ever do a mean thing? Was he ever himself associated with violence or any public disturbance? For if you did, you would have known him. And if you knew him, you would know why we must follow him: Malcolm was our manhood, our living black manhood! That was his meaning to his people. And, in honoring him, we honor the best in ourselves. ${ }^{96}$

This last accompanying solo consists mainly of defiantly controlled athletic postures such as hyper-arched back bending, lunges and a crouched knee-fall - slightly reminiscent of ancient Greek discusthrowers - as well as a final stand with back turned towards the audi-

94 For Andrade' personalized adaptation of the speech compare video-tape version of Epilogo, NDTC 41st dance season 2003.

95 Compare video-tape version of Epilogo, NDTC 41st dance season 2003.

96 Compare video-tape version of Epilogo, NDTC 41st dance season 2003. 
ence, both arms crossed behind the head and fists pointed to the center of the shoulder girdle.

Eventually, the first scene ends with all three dancers back on their beginning triangle position. While the speech concludes - "And you will know him then for what he was and is - our prince - our black shining prince! - who didn't hesitate to die, because he loved us so" the dancers, who are now facing the audience, slowly pull up their right arms inwards into an upheld clenched fist, before they finally rearrange the triangle in orientation so that, on the very last beat, they face again the upstage left exit by reaching out and pointing off-stage with upheld heads.

Through juxtaposition of performed lyrics and danced movement, this introductory scene starts on a highly elegiac, yet distinctly powerful tone as the speech's rhetoric elegance is matched by the dancers' grace of movement. Since the single solo sequences demand exact control and concentration, the soloists furthermore translate Malcom X's praised personality traits into their dance, as both demand extraordinary discipline, self-forgetfulness and dedication to the cause. Reaching up and pointing direction thus appear as the prevalent movement motifs and may be read as suggestive emblem of Malcolm X's iconic significance as a cultural leader of the African American Black Power movement. Also, the dance not only reinforces the lyrical praise of Malcolm $\mathrm{X}$ as a revolutionary role model, but presents the idealized image of 'black manhood' directly on stage via the tightly built bodies, perfectly synchronized focus, balance and pointed directedness of the dancers. Quite purposefully, Malcolm X's political slogans of 'black power' and 'black is beautiful' are thus transferred to the proud exhibition of the male dancers' eroticism and strength.

The second part dramaturgically moves from the elegiac commemoration directly into action. Choreographed from everyday movement, the very first sequence allows the dancers to walk around freely. Their walks rely heavily on bounce steps and dangling arms, the 'cool' posture/attitude of street gang members - when they step up front stage and directly address the audience in a defiant stance, shouting out one after the other:

A: People, understan'! This is for all my ancestors who were raped, killed and hung.

B: Because of their plight for freedom and dignity.

C: They died for me, the died for you. 
B: Yes, this is for them. You know that today in the year 2003, we're still fired up and we're still talking about revolution. ${ }^{97}$

With neither music nor voice-over accompanying this sequence, the 'action' solely rests on the dance performers, who appear as revolutionary agitators during this scene. At the end of the last line, they retreat back to the upstage left corner, where they take position in the same configuration as at the end of the first part.

The third and last section of the choreography then presents a blended medley of modern, jazz and hip hop dance vocabulary as competitive performance contest between the three dancers. As Thomas F. DeFrantz has pointed out on behalf of the cultural significance of hip hop dance forms, they are - apart from exhibiting "bold assertions of expertise, of resilient virtuosity," and "the power of the body" - primarily important, because they present "a mode of cultural identification and recognition that links African Americans in corporeal orature" (in: Lepecki 2004: 64; 76). DeFrantz defines corporeal orature on the basis of hip hop's claim to citationality, which transcends the merely visual impact of the dances' reception process. Hip hop and other related social dance forms, he argues, are therefore performed not only to be visually consumed, but to call for action. Regarded as "forms of orality and affective physicality," hip hop ultimately then presents a "form of battle." (2004: 67; 72).

Apparently, this notion of agitating empowerment and panAfricanist solidarity is also shared by Epilogo's final sequence. Since Andrade's choreography assembles different gestures, dance moves and vocabularies from an Africanist dance vernacular, Epilogo's danced message reaches from the Caribbean, to Africa and the Americas. Remembering Malcolm $X$ through dance, thus becomes an articulate strategy of announcing that political message through a shared aesthetics of the 'cool' and 'spiritual,' as conveyed by the communicative calland-response performance of the three dancers on stage. Accompanying the last choreography, furthermore, by the song lyrics of "Revolution," performed by the renowned U.S. Rap/Hip Hop formation Arrested Development, certainly adds to the performative subtext of this work, which even as a dance theatre stage performance owes most of its communicative powers to the street idiom's recalcitrance.

97 Compare video-tape version of Epilogo, NDTC 41st dance season 2003. 
So when Andrade's choreography actually chooses more from a North American Modern/Hip Hop dance idiom than a Caribbean folk traditional one, then this work ultimately defies national boundaries. By linking the Africanist aesthetic heritage to Malcolm X's pan-African liberation struggle, Epilogo pays tribute to 'Brother Malcolm' as the Caribbean's adopted son of liberating promise. And finally, one may notice that whereas Andrade's use of dance vocabulary may vary, the revolting message/call to the ancestral heritage - already introduced by Andrade's African Cuban Congo Layé - remains insistently the same.

\section{Marlon Simms: Millennial Beings, '100 Park Lanes' Redemption}

An alumnus of the UWI Dance Society, NDTC dancer Marlon Simms is not only an outstanding performer, but has also appeared as a promising young choreographer in two recent works. Millennial Beings (2001), Simms' choreographic debut with the NDTC, as well as '100 and Park Lanes' Redemption are both expressive of a modern rather than folk dance sensibility and yet they, too, speak of Jamaican issues. Thus, Millennial Beings which has been hailed as an "exercise in form" chooses modern dance as Simms' mode of self-expression, i.e. the dance vocabulary he can most identify with (Batson-Savage 2003: E1-2). A duet for two male dancers, Simms choreographed Millennial Beings for himself and company member Mark Phinn as a composition which bespeaks a rather personal approach to his work. As Simms has described his dance motivation in the same Gleaner Interview, "Each time I danced, I just felt better about myself." While this commitment to the art form clearly communicates in his elegant dance style, it also subtly informs his choreography, which even in a high degree of abstraction conveys much of the choreographer's unassuming intellect. Millennial Beings thus explores the notion of instability and change at the turn of the century in a densely choreographed sequence of bodily movement metaphors, of which evidently no one interpretation will suffice. Yet, starting my analysis from the relationship between the two dancers, this assessment will focus primarily on the dancers' parallel interaction to certain sound cues and voice-over inserts as they allow for a preliminary reading on the now following terms.

When the stage-curtain goes up on the blue lit stage, only the dark shadow silhouettes of the dancers' bodies are revealed. Standing still in second position right behind each other, they form a single resting unit 
as the music sets in. The chosen sound-track from The Art of Noise can be considered programmatic, for what follows is indeed a sampled mix of composed noise, cut-in voice trailers and suggestive sound-scapes. Right at the beginning, a voice-over sequence is tuned into, which reminiscent of political news propaganda - announces the following bits: "[...] to maintain law, stability in our country" / given instructions [...] for appropriate steps to be taken to maintain law and order." 98 Accompanied by the sound of increasing rumble, the front dancer makes the first move by lifting his left arm to rest in an angle from shoulder high onto his head. This move is instantly responded to by the back dancer, who as the 'inverse mirror' lifts his right arm in the same angular manner. This pattern is repeated for several beats during which the posture - of what the audience perceives as a single moving unit changes through different arm positions, leg extension and stretch, head turns, balance, plié, etc. Either in responding alternation or exact simultaneity, both dancers thus establish their interdependency during this very first sequence. Wearing the same costume, which consist mainly of body and face covering white strings on top of a leotard, they resemble archaic warriors through that particular body and face decor. Their very slow and controlled execution of movement, furthermore, evokes a statuesque impression of body outline, which - in response to the sound - invites the image of a functionally disciplined bodymachine.

After approximately one minute, the sequence changes with the separation of the unit, as one dancer steps to the sight into a semihead/shoulder stand, while the other changes into an arabesque with the face/torso oriented down to the floor. As the sound switches into a slowing down motor/propeller noise, both dancers get down to the floor, where they propel forward by center oriented bottom turns. Reaching the center, they get up again. Standing upright, one lifts his partner hip height and thus carrying him, he swings around in a carousel movement reminiscent of children simulating flight. While the decreasing propeller sound culminates in a detonation and the voiceinsert: "Well that wasn't much of noise...," the lifted dancer is slowly levered down. As if responding to that explosion and the cynical comment, the dancers next continue to carry out individualistic walks at an increased speed of mechanized small steps with hunched over contract

98 Compare video-taped performance NDTC Concert in Honor of the Delegates of to the 14th International Meeting of University Administrators, 8 Jan. 2003, Little Theatre, Kingston. 
torso and arms. Again, one dancer is lifted by lying onto the other's bent over back, facing the ceiling as if on a stretcher. Maybe wounded or as likely a corpse, who is then lifted again hip height and apparently lifeless. From that position the supporting dancer lowers his partner down to his hips and then turns around, thus presenting him to the audience in an almost accusing manner that possibly suggests 'why did this one have to die?'

Yet, the sequence presumes without much of a pause, as the dancers are already aggressively kicking forward again or fall to the ground in a 'beat down' fashion. The scene now reminds one increasingly of militaristic drill: sit-ups alternate with splits and push ups as well as the mutual weight lifts and testing counter-balances of the two dance partners. Momentarily defying gravity, they are yet conquered by it. Another voice insert comments: "Your agony must endure forever..." Primarily evoked by the violent aggressiveness of the sound, the two dancers convey an increasingly autistic image. Their disoriented movement sequences tread awkwardly on the same spot, to which they repeatedly return as they finally crawl onto the floor from stage right to off left, just like two soldiers in the rainy mud or jungle thickets. Millennial Beings ends to the sound of blowing winds and softening piano keys. 'After the storm' so to speak with the lights going down, both dancers return to the resting postures of the beginning, again controlled, settled and finally lying down onto the floor, opposite each other with facing feet and heads turned to the stage wings.

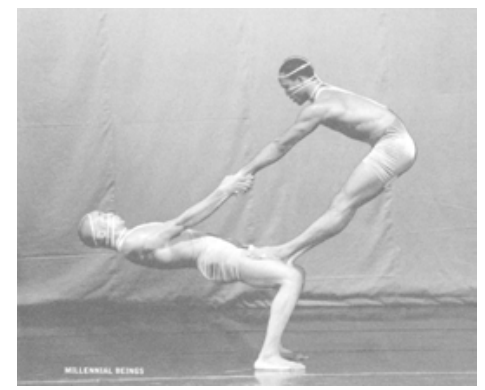

Marlon Simms and Mark Phinn in Marlon Simms' Millennial Beings, ca. 2001 (rpt. in: NDTC 40th Anniversary Programme).

Certainly, an abstract choreography like Millennial Beings lends itself to various interpretations, for example, in terms of the terror and wars, which have marked the turn of the century. Yet, Jamaica with one of 
the highest murder rates in the world, obviously has its own tragic history of ongoing violence to lament. The two defiant warrior protagonists of Simms' choreography may therefore also metaphorically represent the country's ongoing gunmen enmity, from which Jamaica's future generation harshly suffers. Millennial Beings thus tells yet another story of survival in a hostile environment and also of the 'agony' related to that. Especially, if one regards this work in relation to Simms' '100 and Park Lanes' Redemption - which he choreographed in dedication to the seven innocent victims, who died as a consequence of gunmen invading that Jamaican community - then, I am suggesting that Simms' choreography may even be read in yet another vein, i.e. as danced testimony. Thus, '100 and Park Lanes' Redemption performs the reconciliation with Jamaica's violence trauma in the sense that the seven women and the one male dancer on stage move through a sequence of gestured mourning. ${ }^{99}$ Embodying commemoration, Simms' modern dance interpretation of the incident purports a quiet activism against deadening silence. As was commented by the Gleaner on March 1st 2005 on behalf of the '100 and Park Lanes' shooting, these crimes give "an index of the times that murder on this scale may never find eye witness to tell the tale in a court of law." Yet, if that is the case, then dance theatre may present the appropriate site to address these socio-political issues and to dance against the violence trauma of a society, where in fact almost every Jamaican will likely know if not the victims personally then almost certainly someone related to them. ${ }^{100}$ The impact of modern dance in Simm's choreography therefore lies in its universal adaptability of vocabulary, since its free form allows the dancer to speak from his or her own socio-political perspective.

\section{Christopher Walker - Fragile}

NDTC dancer and choreographer Christopher Walker studied dance at the Jamaica School of Dance and the State University of New York Brockport in the U.S. and is currently teaching at Hobart and William Smith Colleges. As a choreographer he brings profound knowledge and understanding of Jamaican folk, African contemporary and U.S. modern dance idioms to the dance theatre stage, all of which he blends into a very engaging dance expression. Walker's original approach to

99 This observation is based on the performance given 'In Tuition' at the Little Theatre 2003.

100 Compare interview with Clive Thompson 21 Aug. 2003. 
Caribbean dance theatre is demonstrated in his recent choreography Fragile, which he choreographed for the NDTC's $41^{\text {st }}$ dance season in 2003. The dance begins to a cow horn signal and drums, as the curtain rises on a tableau of a single dancer leaping her way through couples and individual dancers in freeze positions. Dressed in richly coloured traditional African cloth and head wrap, the dancers' scenic arrangement suggests an African village. Yet, one dancer appears to be slightly 'out of frame,' since he is positioned on the apron of the stage and assumes more of an onlooker's perspective. Stepping out of the freeze, the couples embrace, while a woman soloist, who is tellingly dressed in the symbolic white robe of a spiritual leader, bends down under the imitative ripples of spirit possession.

The tableaux sequence invites the audience to invent their own memory images, evoked by the suggestive movements and relationships between the dancers on stage. Choreographed as a "dance for the griots, a dance for the storytellers," this scene points to the source of Walker's Caribbean dance theatre imagination. ${ }^{101}$ While I have elsewhere interpreted this scene in the context of the loss of the Middle Passage, one can also regard the same image in terms of a trace, i.e. the maintained link to African culture and performance modes (Sörgel 2004: 93-99). For example, Walker composed the dance choreography in terms of the particular emotional fragility evoked rather than as historical evidence. In that sense, the topos of the Middle Passage has become distilled by the choreographer's imagination to an extent that certain movements and pictorial keys will instantaneously speak to the African diaspora's collective unconscious. To recall Ricoeur at this point, fragility of memory and identity are curiously intertwined, especially in the danced act of communal remembrance.

As the next scene opens to the song lyrics of "No More Auction Block," such image-memory is taken yet one step further, when the dancers run in from the stage wings as if they were throwing themselves against an imaginary center wall. Defeated they fall down to the floor, from where they build another wall of upright trembling bodies. The dancers cross their arms against their chests in a protective gesture, make a lunge to the left and wheel their arms on the right in a powerful pull. Being pressed down, these bodies collapse onto the floor to yet pull up again, before they disperse into smaller group units on stage. Up-stage, for example, a couple looks as if to attempt recovery from the

101 Interview with Christopher Walker 11 Aug. 2003. 
floods, while in front another one is going through a series of progressing lifts in search for rescue. Movements and configurations overlap and alternate simultaneously so that the audience needs to choose focus. For example, one dancer pulls her knees close to her upper body, autistically rocking back and forth on her bottom. Literally stripped from the costume, the dancers portray human existence as reduced to movement and spirit, the very essentials of the dance. Symbolized in the rem(a)inder of the head wrap, the link to Africa prevails strong and while the same dancer crosses the stage in a last walk of this sequence, her head is held high and as Jamaicans say: "she walks good," even though her arms might dangle as if of a lifeless marionette.

Dancing the song of freedom, movement has the power to redeem in "Redemption Song," the next section of the dance; we encounter the group of dancers as they are suspended from the chain. Entering in file from up-stage right, the dancers carry out individualized movements as soon as they reach center stage. And it is in these that one will find the traces of Jamaican folk forms most evident: a powerful half-circle jump up in the air which is a characteristic feature of the Pitchy Patchy in Jamaican Jonkonnu, the crooked posture of Dinki Mini, the backwards tilt and grounded shuffle of the Kumina. These African derived retentions again testify to survival in their use of social comment and satire: once directed against the planter oppressor, they have now become a powerful symbol of cultural resistance and spiritual strength. They are part of the African continuum in the New World and present on the theatre stage as much as in the popular culture on the Jamaican streets.

The last section then starts with a brief prelude, when two dancers present a solo in silence. After that all the dancers step in chatting to each other and smiling, before they finally join in a colorful finale to the backdrop of the rising sun. Wearing red, yellow and green half skirts to reveal bikini-pants of the same color and with a pearl string that is supposed to symbolize the umbilical cord as a link back to the mother(land), the costume expresses part of what has become known as the Caribbean carnival aesthetic: for on top of certainly celebrating the pelvis as the center of life and African Caribbean dance, this repeated display of carnival spirit testifies one more time to Jonkonnu's fierce final laughs, where appearances point one way, yet message turns around the other. "Fragile," indeed, these young dancers and choreographers have thus tuned their bodies into a powerful instrument of self-assertion. Whether it be to the music of British pop culture 
icon Sting, U.S. rap formation Arrested Development, the postmodern Art of Noise, or that continuously driven force of the ancestral drums, "authenticity" lies lastly within themselves and their danced out inner knowledge of who they are and what they want to be. Watching the NDTC perform, the company's artistic freedom of expression and joy makes every audience member realize what it may take to come to one's own terms at last.

\section{Interlude V: Dance Beyond the Color Line}

Over the past forty years embodied freedom and self-discovery have been the continuous force driving Jamaica's National Dance Theatre Company. Dance as the living epic of the Jamaican people has created imaginative and insightful dance theatre that will not only speak to the people at home, but also to those abroad in a distinctly Jamaican art form. As this final analysis of recent NDTC works has shown, folkbased choreography continues to inform even the company's more experimental or abstract modern works. Whether in message or theme, subtle pelvic moves or shoulder ripples, Jamaica's kinaesthetic body memory forms the backbone of the NDTC's distinct dance style. Jamaican dance theatre, furthermore, not only reflects the country's African heritage, but also manages to display it on a nationally significant level.

At the same time though, Jamaican dance theatre's postcolonial nationalism has from the very beginning been conceived of as part of PanCaribbean solidarity and the shared experience of black Atlantic diaspora. Spirit and epic memory in the Caribbean context thus do not only testify to the survival of the African aesthetic in the New World, but outline a performative paradigm that keeps kinaesthetic memory alive and points the body towards a self-assertive expression of cultural heritage and future. In Against Race, Paul Gilroy has described the recent transformation of the political implications of diaspora in terms of a "strategic universalism," which in its postanthropological outlook opts for a "cosmopolitan utopia" of diasporic interculture (2000: 326-336). In this respect, diaspora experience as expressed in contemporary Jamaican dance theatre interconnects cultural diversity with a decidedly antiracist, postcolonial agenda. As Gilroy explains:

Diaspora allows for a complex conception of sameness and for versions of solidarity that do not need to repress the differences within a dispersed group 
in order to maximize the differences between one "essential" community and others. Diaspora's discomfort with carelessly overintegrated notions of culture and its rather fissured sense of particularity can also be made to fit with the best moods of politicized postmodernism. Identity conceived diasporically resists reification in petrified forms even if they are indubitably authentic. The tensions around origin and essence that the diaspora brings into view allow us to perceive that identity should not be fossilized in keeping with the holy spirit of ethnic absolutism. Identity, too, becomes a noun of process. Its openness provides a timely alternative to the clockwork solidarity based on outmoded notions of "race" and disputed ideas of national belonging (2000: 252).

Modern dance's malleability to culturally encoded variations thus proves as a particularly powerful mode of expressing precisely such articulations of sameness in full acknowledgement of co-existing differences. Through the dancing body's iconic signature, diaspora identity may thus operate transgressively even from within stereotypical notions. Jamaican dance theatre thereby transcends the binary opposition in a dance idiom and vocabulary that is simultaneously strangely anew and awkwardly familiar. In this respect, Jamaican dance theatre in fact emerges as the prime example of transnational as well as translational vernacular, which in Gilroy's terms may envision precisely the new millennium's utopia of a "planetary humanism" beyond the color line (2000: 333).

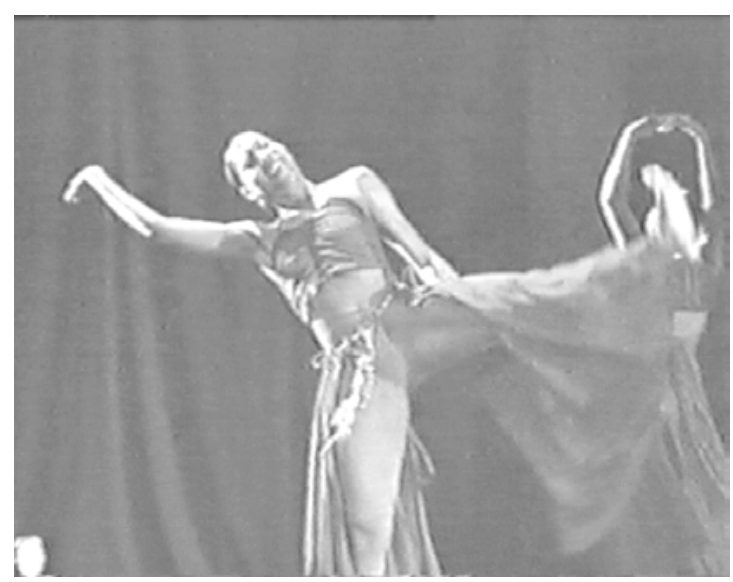

Natalie Chung in Christopher Walker's Fragile, 2003. Video Still. 